\title{
The Accountability of Cambodian NGOs in Climate Change Projects: The impacts on local communities
}

\section{By}

\section{Sothiary Toch}

\author{
A thesis \\ submitted to the Victoria University of Wellington \\ in partial fulfilment of the requirements for the degree of \\ Master in Development Studies
}

School of Geography Environment and Earth Science

Victoria University of Wellington

2015 



\begin{abstract}
The accountability of non-governmental organisations (NGOs) is important to development work. Judging the performance of an NGO in providing social services and whether it has fulfilled its responsibilities with a set of standards is increasingly important due to NGOs working more in social development. In Cambodia NGOs have also become actively involved in climate change actions at all levels and have become an important player among other actors to enforce climate policies. While the influential roles of NGOs in climate policy advocacy and negotiation have been recognised, the impact of their involvement in climate change actions at the local level has been less prominent. This poses a question as to how NGO accountability impacts on local communities with the projects that they are carrying out concerning climate change issues. This thesis explored Cambodian NGOs working in partnership on climate change issues and how issues concerning their accountability to local communities can be evaluated.
\end{abstract}

This study involved seventeen NGO representatives from different NGOs who work directly in climate change projects in Cambodia. A qualitative approach was employed using interviews with the participants and this primary data collection was supplemented by documentary evidence from secondary sources. The interviews captured the experience and knowledge of the processes of working in partnership on climate change projects by the research participants. The particpants shared with me some of the benefits and difficulties in working in partnership with other NGOs on climate change issues. From their reflections I was able to discern some key findings.

I found that NGO partnership in climate change projects in Cambodia enhances effectiveness and efficiency in project implementation. Partnership strengthens the downward accountability of NGOs in carrying out the projects because inputs and resources are redirected to the ground level of operations and not diverted away from the intended beneficiaries. The partnership movement is grass roots driven, and small local NGOs are able to receive funds and directly benefit local communities. Partnerships enable funding aid to reach the local people through the sub-grant provision scheme. Funding NGOs provide capacity development and technical support throughout the project cycle to their partners so that they can have sufficient 
capacity to carry out climate change work at the ground level. Partnering NGOs also work with NGO network members in climate change policy advocacy and communication by bringing local voices into the process of policy development. Cambodian NGO partnerships in climate change projects significantly contributes to climate change adaptation actions. I conclude with some recommendations for how this process can be improved.

Key words: NGO accountability, partnership, climate change projects and Cambodia. 


\section{ACKNOWLEDGMENT}

I would like to sincerely thank the many people who have provided guidance, input and support to produce this complete work. First of all, I would like to express my gratitude to my supervisor Professor John Overton who provided expert support and was a source of encouragement throughout my research. His guidance and motivation significantly contributed to the outcome of this work. I am also thankful to all the professors and lecturers who lectured me in the first year of my study programme.

I would also like to extend my appreciation to all the research pariticipants who shared their knowledge, experience and ideas. Without your contribution, this research would have not been completed. I especially thank Mr. Sambath Sim, Capacity Development Advisor of Cord Cambodia, who provided the list of climate change NGO networks for the interviews. I also want to thank Dr. Rachel Tallon who helped proof read my thesis.

Many thanks to the people and friends who inspired me throughout my two years of study. To my wife, Sreyhouch Kheam, she has been amazing. She encourages and mentally supports me to finish the study.

My deepest gratitude finally goes to New Zealand Government for providing funding for my two year study through the New Zealand Agency for International Development (NZAID). This support made life easier in Wellington. I also would like to thank to the Victoria International people who provided logistical coordination and support during my study in Wellington. They are supportive and helpful. 
TABLE OF CONTENTS

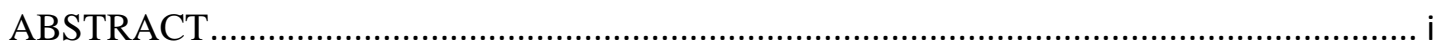

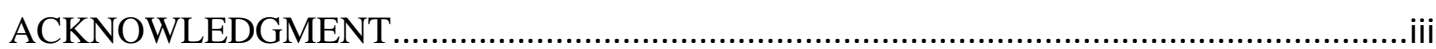

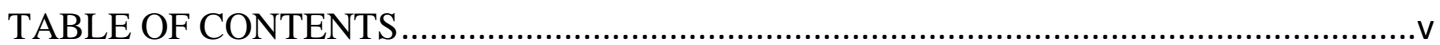

List of tables..................................................................................................................

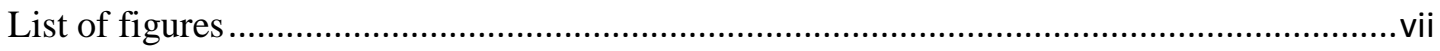

List of abbreviations .................................................................................................... vii

Chapter One: Introduction, Aims and Objectives …........................................................... 1

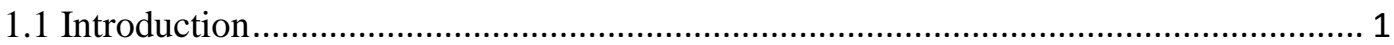

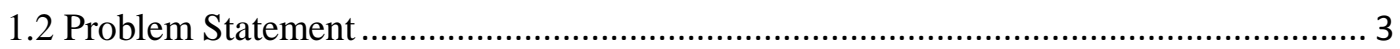

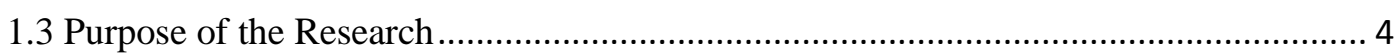

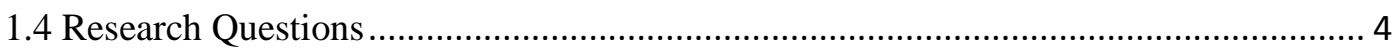

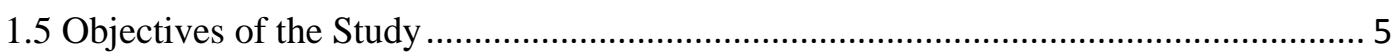

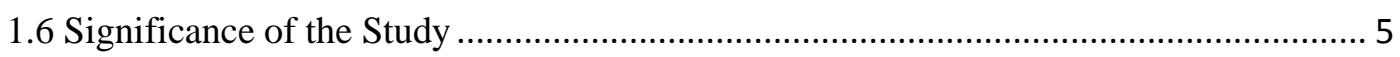

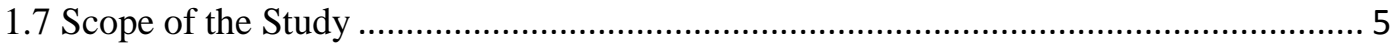

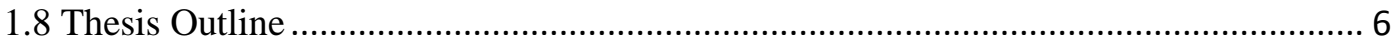

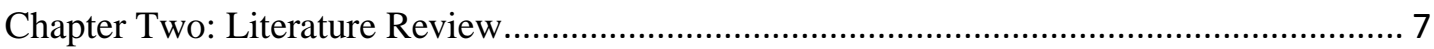

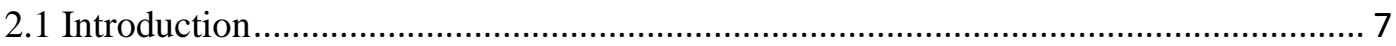

2.2 Differing meanings of accountability ...................................................................... 7

2. 3. NGO accountability in development practice …....................................................... 9

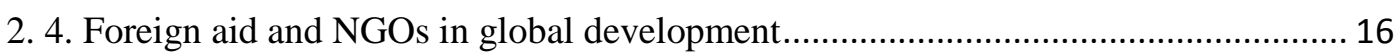

2. 5 NGOs and Partnership in Development ................................................................ 17

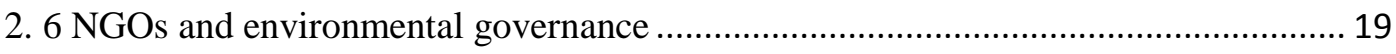

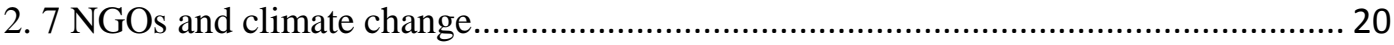

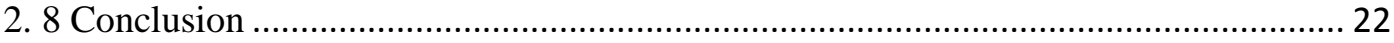

Chapter Three: Approach to Research and Methodology ……............................................. 23

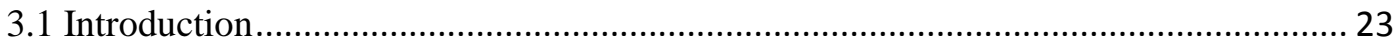

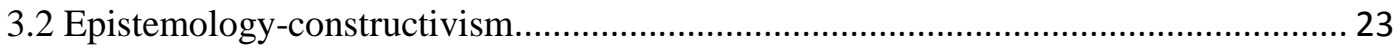

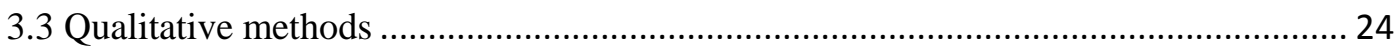

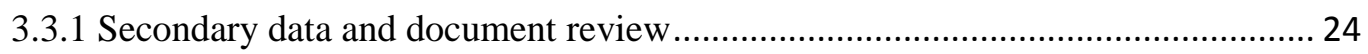

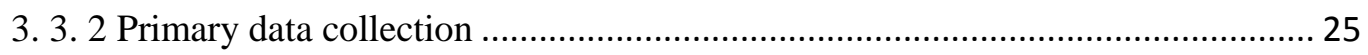

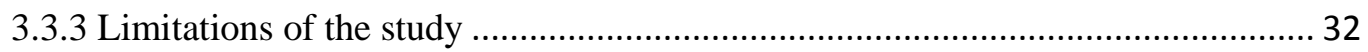

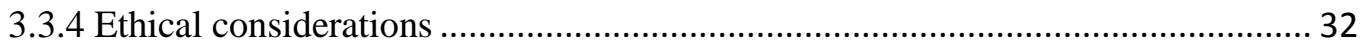

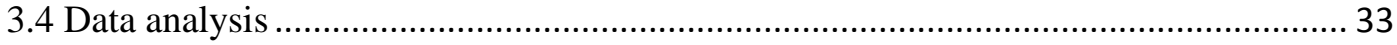


3.5 Positionality. 33

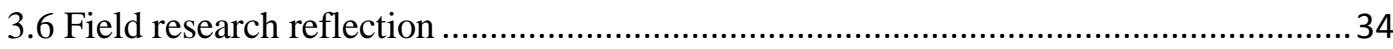

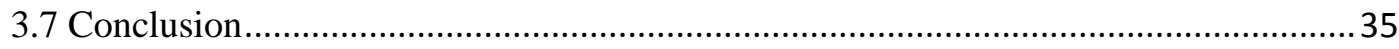

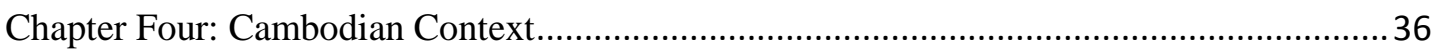

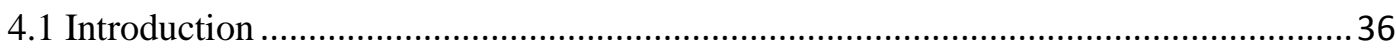

4.2 Overview of Current Political and Socio-Economic Situation in Cambodia ................36

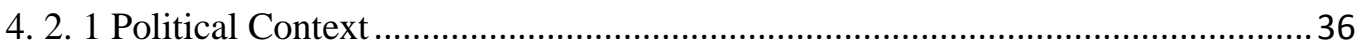

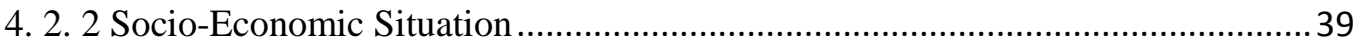

4.3 Cambodian NGOs and Development …..................................................................... 43

4. 3. 1 Overview of Cambodian NGO's Background …..................................................43

4. 3. 2 Cambodian NGOs in Development Projects and Accountability........................44

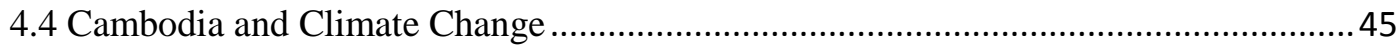

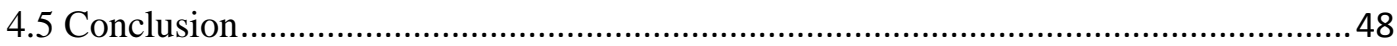

Chapter Five: NGO Accountability and Partnership in Climate Change Projects ..................50

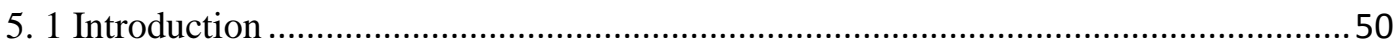

5. 2 NGO accountability and Cambodian NGOs ............................................................. 50

5.2.1 Organisational policies and regulations............................................................. 51

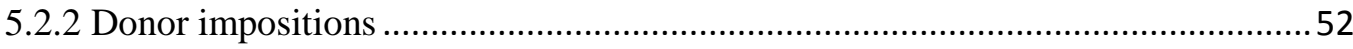

5.2.3 NGO accountability and local participation .......................................................53

5. 3 Cambodian NGO partnerships and project implementation........................................55

5. 4 The emergence of NGO climate change projects .....................................................61

5. 5 Different NGOs working in climate change projects ...............................................63

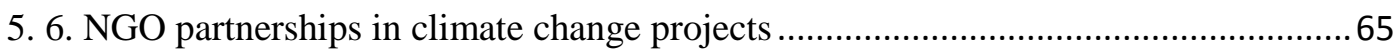

5. 7 How NGOs implement climate change projects at different levels .............................72

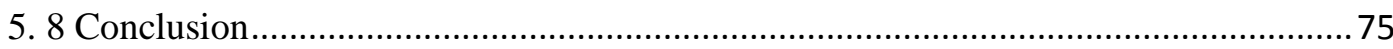

Chapter Six: The Impacts of NGO Climate Change Projects ................................................ 77

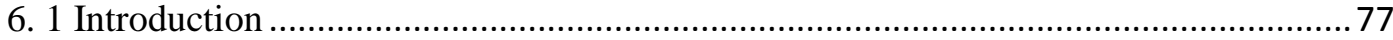

6. 2 The Projects' results from the NGO's perspective ......................................................77

6. 2. 1 Climate change knowledge and capacity promotion among NGOs ....................78

6. 2. 2 Adaptive capacity improved among the local people …………………….......... 84

6. 3. Challenges in climate change partnership projects .................................................87

6. 4. Strategies and solutions in further climate change project implementation ...............91

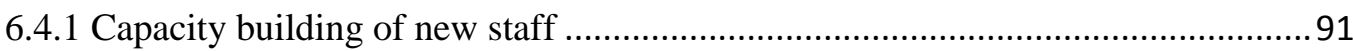

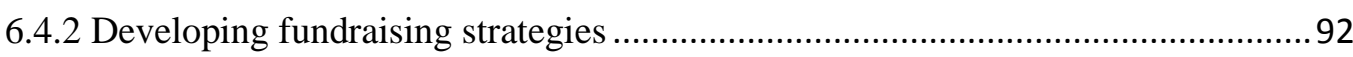


6.4.3 Creating a document library for climate change projects

6.4.4 Strengthening the capacity of commune councils, advocacy initiatives and legal

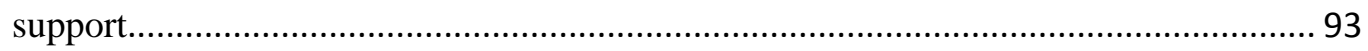

6. 5 The government's role in climate change partnership projects.................................. 94

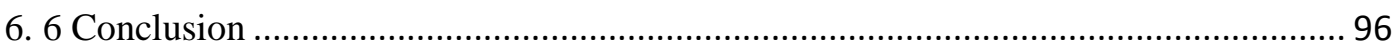

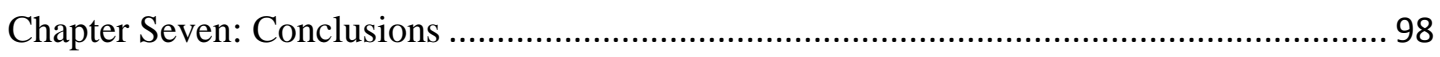

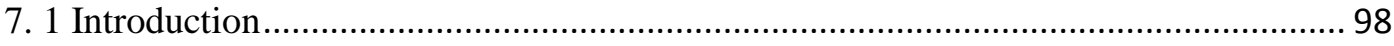

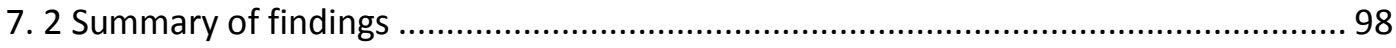

7. 3 Contributions of this study and future research.................................................. 104

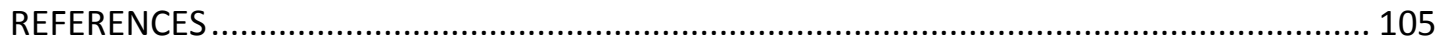

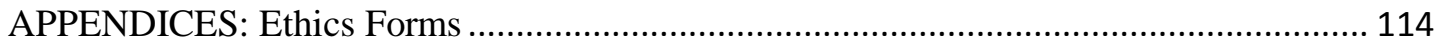

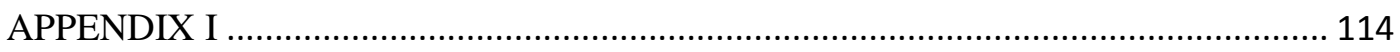

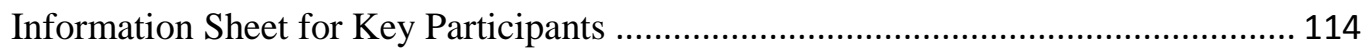

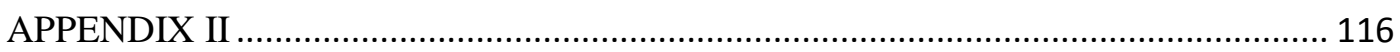

Consent To Participate In Research .................................................................... 116

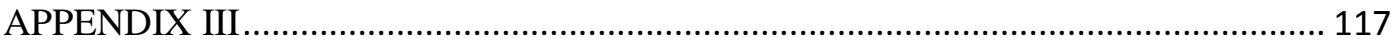

List of Interview Questions for NGO Informants .................................................... 117

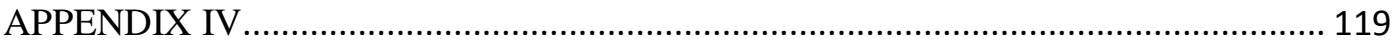

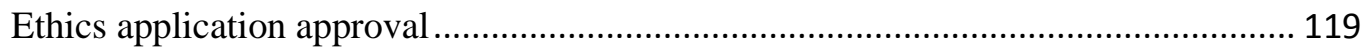

\section{List of tables}

Table 1: List of NGO Climate Change Projects registered at CDC 2014...................26

Table 2: List of NGOs partnering in JCCI............................................................. 28

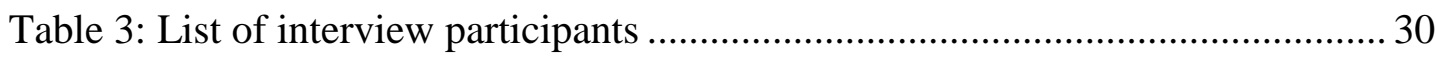

\section{List of figures}

Figure 1: The Bangladeshi NGO chain and accountability ..................................... 14

Figure 2: Cambodia headcount poverty rate, 2004-2011 ........................................ 40

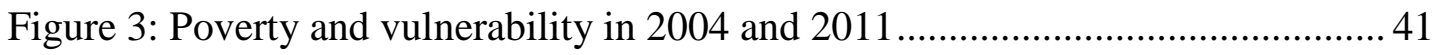

Figure 4: Development partner disbursement in US millions.................................. 42

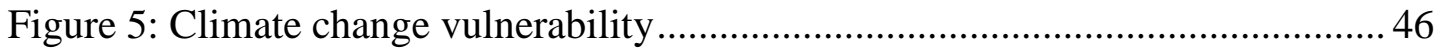

Figure 6: The common flow of NGO climate change project funds..........................6 68

Figure 7: Climate change financing in Cambodia by sources of fund .......................6 68

Figure 8: Climate change financing in Cambodia by donors (US\$ millions) ............ 69 


\section{List of abbreviations}

ASEAN

CCCSP

CDCF

CDN

CDP

$\mathrm{CF}$

CIP

CPA

CPP

CSOs

DNA

DRR

ENGOs

GDCC

INGOs

KII

LNGOs

NAPA

NCCC

NCDM

NEC

NGOs

NRM

NSDP

NTFPs

PCNC
The Association of Southeast Asia Nations

Cambodia Climate Change Strategic Planning

Cambodia Development Cooperation Forum

Clean Development Mechanism

Commune Development Plan

Community Forestry

Commune Investment Programme

Community Protected Area

Cambodian People's Party

Civil Society Organisations

Designated National Authority

Disaster Risk Reduction

Environmental Non Governmental Organisations

Government- Donor Coordination Committee

International Non Governmental Organisations

Key Informant Interview

Local Non Governmental Organisations

National Adaptation Programme of Action

National Committee on Climate Change

National Committee for Disaster Management

National Election Committee

Non Governmental Organisations

Natural Resource Management

National Strategic Development Plan

Non Timber Forest Products

The Philippines Council for NGO Certification 
PPCR

REDD+

RGC

SNAP

SPCR

TI

UNCEP

UNDP

UNFCCC
Pilot Programme for Climate Resilience

Reducing Emissions from Deforestation and Forest

Degradation

Royal Government of Cambodia

Strategic National Action Plan

Strategic Programme for Climate Resilience

Transparency International

United Nations Conference on Environment and Development

United Nations Development Programme

United Nations Framework Convention on Climate Change 



\section{Chapter One: Introduction, Aims and Objectives}

\subsection{Introduction}

Accountability is crucial in development aid. It reveals if development projects are effective and efficient in providing social services to the intended beneficiaries. This has led global institutions to undertake reform to achieve greater accountability because they want to produce better impacts from their projects.

"Accountability should be only increased when its benefits are worth its costs" (Wenar, 2006, p. 9).

Issues around accountability in development have become essential for NGOs, donors and their partnerships in particular. The accountability "implies that some actors have the rights to hold other actors accountable to a set of standards, to judge whether they have fulfilled their responsibilities in light of these standards, and to impose sanctions if they determine that these responsibilities have not been met" (Grant \& Keohane, 2005. p, 29). There have been a number of studies into accountability issues of donor NGOs and local NGOs when implementing development projects (Ahmed and Potters, 2006). It is believed that the good practice of accountability between donors and fund- recipient NGOs has a significant positive impact on the beneficiaries they are working for. On the other hand, there is some criticism from stakeholders. This has pointed to weak credibility and the inability of NGOs to influence policies with regard to development agendas nationally and internationally. This also undermines the legitimacy and significant contributions of NGOs. However, most studies find that NGO accountability is essential to guarantee a positive impact in development project operations performed by different actors. Greater accountability has given credibility and confidence for NGOs to pursue and set up effective principles, regulations and even approaches or mechanisms in organisational management and project operations to achieve better results in their development mission.

The current situation in Cambodia is that often development funds are derived from international institutions but are used to fund 'development' that is not owned or directed by local populations. Some civil society organisations (CSOs) have started to deal with this imbalance. Donor non-governmental organisations (NGOs), the socalled "Northern NGOs", inject money into the Cambodian NGO sector for 
implementing development projects/programmes. The projects are expected to have an impact on local communities. However, Cambodian development projects are usually donor-driven through all stages of the project cycle and this phenomenon has been widespread since 1993 (Godfrey et al., 2002). Non-representative and nonpeople-based NGOs have often replaced civil society groups which were founded on representation and social action. They undertake development projects based on their donors' priorities and mandates while often ignoring local needs. This leads to many criticisms of NGOs by politically-affiliated groups. This, in turn, causes concern about development effectiveness in Cambodia by relevant stakeholders.

The NGOs in Cambodia are now putting their efforts into strengthening accountability in order to maximise local impacts in development project operations and implementation in the form of partnership development and cooperation with other NGOs. This poses the question: how does the accountability of NGOs working in partnership impact on local communities? Parthership is believed to be a key approach to successful project implementation in Cambodia and it is believed that NGO project partnerships produce effective and efficient impacts for local communities. Therefore, NGOs usually partner with other NGOs, whose skills and expertise are similar or the same, to implement the projects.

At the same time, climate change issues have become the main focus and are an interesting target for NGOs in Cambodia's development agenda. As climate change issues have been recognised globally, the impacts and risks of climate change are also evident in Cambodia. Cambodia is recognised as a particularly vulnerable country compared to other countries in the Association of Southeast Asia Nations (ASEAN) because of its lack of adaptive capacity. The potential impacts are situated mainly at the grass roots level and affect Cambodian people seriously. Particularly affected groups are the farmers who are heavily dependent on the climate-sensitive agricultural sector. Climate change in Cambodia also affects health due to irregular changes to weather patterns and infrastructure damage caused by floods during rainy season.

These impacts of climate change are getting worse and continue to deteriorate the livelihoods of Cambodian people who are mostly subsistence farmers. These effects also push the government and development agencies to take actions and measures to 
tackle the problems. Yet climate change awareness and action is new to Cambodia. Overall, agriculture is largely subsistence-based and people do not have sufficient knowledge nor capacity to reduce the risks from climate change. In the meantime, NGOs have paid much attention to attracting funds from donors, development agencies and other intergovernmental organisations to design and implement projects at both the grass roots and national levels in the forms of climate change adaptation awareness and policy advocacy. Climate change projects have been increasingly operated by NGOs since 2010 and the projects are, on the surface, all about partnership and cooperation when being implemented on the ground.

\subsection{Problem Statement}

NGO accountability is critical with regard to the impact on communities in the implementation of development projects. NGO accountability in climate change projects in Cambodia can be enhanced by better performance and management of NGOs regarding decision making, budgeting and project operation in a more transparent manner. NGOs are embracing partnership as their strategic approach as they believe that partnership will improve the local NGO's roles, performance and actions to achieve their objectives. This partnership approach could also help attract more resources and produce huge impacts for beneficiaries.

The climate change issue has become a focus and an interesting target for NGOs to access funds for their development activities. Some NGOs, which have never undertaken climate change projects before, have changed their missions and strategic plans to incorporate climate change into their action plans and have started taking up partnerships with other NGOs working on this issue. Recently, there has been a rise in climate change projects implemented by NGOs with funds and grants from their donor partners. This trend has received some scepticism from relevant stakeholders, particularly the government with regard to NGO accountability in climate change projects. Sometimes NGOs also behave competitively to secure funds from donors. On the other hand, climate change is a cross-sectoral issue that is correlated with other sectors in development. All actors including NGOs should act to engage other key relevant stakeholders to fight climate change and its impacts.

These NGOs now active in climate change issues in Cambodia implement many activities to complement the government's actions in coping with the risks and 
stresses caused by climate change. Not only in receiving funds from large donors and INGOs, they are also forming partnerships and networks with other Local NonGovernment Organisations (LNGOs) and Civil Society Organisations (CSOs) that work at the grass roots level to help communities adapt to climate change, and advocate for policy change and development. These partnerships and networks in climate change project implementation are expected to provide a holistic learning process for local NGOs. The expectation is to build up those NGO's capacity in climate change project implementation in order that they can produce many positive impacts on local communities they are working for in this sector.

\subsection{Purpose of the Research}

The study hopes to encourage all key actors, particularly NGOs to engage with relevant stakeholders in coping with climate change risks and impacts in Cambodia. In this study, I firstly explored the importance of NGO accountability and partnership in development work. Then I examined how partnership and cooperation between NGOs in climate change projects shape the results and aims to produce positive impacts for communites. This uncovered and highlighted key learning processes and experiences among NGO partners in development activities in the climate change sector in Cambodia. Also, the research explores the challenges for the partnerships when implementing climate change projects and solutions to ensure that the results are achieved. Additionally, the study explains why there has been a rise of climate change projects and policies in Cambodia, and hightlighs some milestones of climate change impacts in Cambodia.

\subsection{Research Questions}

This research addresses this main question "how does accountability of Cambodian NGOs working in partnerships impact on local communities, particularly with regard to climate change projects and programmes?

There are also supplementary questions that the research seeks to answer

a) How is partnership between NGOs important to the success of climate change projects?

b) Why are most NGOs in Cambodia very interested in climate change projects?

c) What forms of accountability are being put in place by NGOs? 
d) How is the accountability of Cambodian NGOs important with regard to local community impacts?

e) Are there any particular challenges to working as partners in climate change projects?

\subsection{Objectives of the Study}

This study intends to address how NGO partnerships work in development practice, particularly in climate change programmes/projects. The study also examines why most NGOs are interested in the climate change issue and what the challenges are in working in partnership between NGOs in climate change partnership project implementation.

\subsection{Significance of the Study}

The impacts on communities of NGO partnership climate change projects are very important. Climate change has become a significant challenge to the development of Cambodia, both for government and other stakeholders, particularly NGOs. At the same time, funding opportunities for this sector are on the rise and NGOs are competing to get funds and grants to operate their activities at community level. Moreover, they have been forming partnerships with other LNGOs and CBOs in terms of support such as grant provision, capacity building and other technical supports including reporting, monitoring and evaluation (M\&E) and proposal development. Sometimes they work in partnership as joint-project implementers at the grass roots and national levels. Therefore, the study focuses on the issue of NGO accountability and partnership in climate change projects with regard to impacts of the local communities. Additionally, the practice of partnership and its challenges also need to be examined. Finally, the likely achievement in climate change project implementation of NGOs is also addressed.

\subsection{Scope of the Study}

Climate change has become an important concern in Cambodia and most NGOs are interested in implementing climate change projects to help reduce its impact. It is obviously difficult for implementing NGOs since the issue is quite new and crosssectoral. The NGOs are now working on this issue by forming partnerships with other NGOs to ensure the impacts are reduced for local communities. Therefore, the scope of the research was confined to NGO partnerships in climate change projects. With respect to this, the study explored how NGO accountability and partnerships in 
climate change projects are practised by looking at partnerships some NGOs have undertaken in this sector. From this partnership perspective, I looked at the challenges and impacts achieved by partnered NGOs and analysed the reasons why the climate change issue become a focus for NGOs in development work. The study does not cover all NGOs working in all sectors but selection was determined by the research design which is addressed in methodology section.

\subsection{Thesis Outline}

Chapter One provides an overall introduction to the study by highlighting issues in the development agenda with regard to partnerships and relationships between donors and NGOs. Chapter Two consists of the literature review covering some definitions and concepts of NGO accountability, NGO partnerships in global development and a review of Cambodian NGOs engaged in development. Chapter Three outlines the qualitative methodology of the research including desk reviews, semi-structured interviews and participant observation. This chapter also addresses the process of data analysis and some complexities in the field research. Chapter Four briefly indroduces the context of Cambodia's climate change landscape highlighting some risks and impacts caused by climate change, relevant policies, and roles of NGOs in Cambodia's development. Chapter Five looks at the nature of climate change-implemented NGOs, NGO accountability and local authority cooperation, and the whole practice of partnership climate change project operation. The chapter also highlights some issues when implementing the partnership projects. Chapter Six portrays the results likely achieved by NGOs and issues in climate change project implementation. Last but not least, Chapter Seven concludes the whole thesis and provides some recommendations. 


\section{Chapter Two: Literature Review}

\subsection{Introduction}

This literature review covers the extent of NGO accountability in development practice and its roles in global development. It is critical to address the relevant literature to this study because it lays the foundation of NGO's roles in development framework, particularly in climate change in Cambodia. The first section of the chapter briefly explores the differing meanings of accountability. In the second section, NGO accountability is explored and discussed with respect to what NGOs have done in development practice to improve organisational performance and management. The third section highlights the roles of NGOs in global development and in the fourth section, NGO partnership is discussed with the focus on NGO strategy in development. The fifth section discusses NGO's role in international environmental governance. The sixth section provides the specific roles and activities of NGOs in global climate change actions. Finally, the chapter concludes with aim of the study with regard to NGO accountability in climate change projects in Cambodia.

\subsection{Differing meanings of accountability}

Accountability has wide meanings in terms of its definition. The word 'accountability' has become interesting and widespread in many societies even though the word itself does not translate well into all languages (Lister, 2003). It is a norminative and socially constructed concept and always requires interpretation of particular facts, circumstances, action or inaction (Jordan \& Van Tuijl, 2000, p. 9). People and organisations always think that "to be accountable" is an ideal component for their organisations to achieve a good work performance. Bakker (2002) points out that there are a wide variety of definitions of accountability used or assumed by people working on questions of organisational transparency, responsiveness, ethics, legitimacy and regulations, whether in relation to governments, corporations, NGOs or other organisations (as cited in Bendell, 2006, p. 1).

In a democratic society, political scientists see different models of accountability and it is usually considered as a concern of the public management sphere and government (Ahmed and Potter, 2006). Grant and Keohane (2005) give two models of accountability: participation and delegation. In the former model, power holders have to be accountable to those who are affected by their decision and in the latter 
form, the power holders ought to be accountable to those who have entrusted them to do the tasks.

The Merriam-Webster dictionary defines accountability as "the quality or state of being accountable; especially: an obligation or willingness to accept responsibility or to account for one's action." The phrase "obligation or willingness" allows for different understandings of the term accountability, as obligation suggests being held to account, while willingness suggests giving an account (Bendell, 2006, p. 1). From this definition, people or organisations find much difficulty in capturing the elements of accountability to be practised in their organisations. In practice the full coverage of all types of accountability is not necessarily seen and practised in many North-South NGO partnerships because the impositions from the funding NGOs might create bureaucracy for recipient NGOs in financial and administrative management processes (Murtaza, 2012 and Rauh, 2010). The question becomes, to whom is the NGO ultimately accountable to: the funders or the recipients?

The definitions of accountability might have different meanings according to some other organisations and institutions. In the context of downward accountability to beneficiaries, accountability has been defined by an NGO based in the UK called Mango. Mango's mission is to strengthen the financial management and accountability of development and humanitarian NGOs and their partners, that "provide people with opportunity to understand and influence the key decisions that are made during NGOs' work" (Mango, 2010, p. 2). Accountability is made up of five components: providing information, representing the vulnerable, involving people in making decisions, having complaint precedure and the attitudes of NGO staffs (Mango, 2010). For the Humanitarian Accountability Partnership (HAP) International, whose mission is to promote accountability to people affected by humanitarian crises in the world, "accountability is the means through which power is used responsibly and it is a process of taking into account the views of, and being held accountable by, different stakeholders, and primarily the people affected by authority or power" (HAP International, 2010, p. 5).

A working definition of NGO accountability is offered by Hugo Slim: "it is the process by which an NGO holds itself openly responsible for what it believes, what it 
does, and what it does not do in a way that shows it involving all concerned parties and actively responding to what it learn" (Slim, 2002 as cited in Jordan \& Van Tuijl, 2006, p. 28). Problems can arise, as when there might be internal conflicts whithin an NGO if the NGO has uniformity in all the NGO's activities. NGOs have different regulations, policies and precedures in regards with project implementations to hold the NGO accountable.

Accountability might simply mean responsibility but it is an extra responsibilty for people working in an organisation (Wenar, 2006). People who are responsible for something take actions over and take care of it as it is up to them. For those who are accountable, it means an extra responsibility to fulfill the original ones. These people usually demonstrate that they have done something that is up to them to do. Furthermore, accountability often has a cost. While an organisation may have effective accountability, there may be incentives for its staff for publics through their transparent scrutiny on the organisation's activities.

\section{3. NGO accountability in development practice}

There have been a number of studies into NGO accountability since the growth of NGOs, their funding attraction and public policy influences from the 1980s. Public attention has centred on how NGOs work effectively and efficiently in development with good accountability practices and that the accountability should only be increased when the benefits are worth its costs (Wenar, 2006). Namja (1996) identified three distinctive categories of NGO accountability. Firstly, the NGOs should be accountable for their patrons who provide funds for designated purposes. Secondly, the NGOs should have accountability for their clients whom they are working for. Finally, the NGOs are thought to have been accountable to themselves in providing services in society.

Similarly, Edward and Hulme (1996, p. 8) have pointed out that NGOs have multiple accountabilities - 'downward' to their partners, beneficiaries, staffs and supporters and 'upward' to donors, trustees and host government. But Unerman and O'Dwyer (2006) argue that the ideal of NGO accountability relationships should be broadly identified as the impacts of NGO's activities in community which should be very wide. They suggest that the relationship may not only focus on beneficiaries and 
funders of NGO's activities but also indirectly affected individuals and groups which are unintended and unforseen by these activities

For Northern-based NGOs (NNGOs), they are accountable to both their donors and fund recipients, which are the Southern NGOs (SNGOs), claiming them as legitimate partners in the international development platform (Schepers, 2006). They show upward accountability to their donors in exchange of funds, and downward accountability to SNGOs for information (Jordan \& Van Tuijl, 2000). Finally, Jordan and Van Tuijl (2000) conclude that the donor dependency creates asymetric accountability and criticism of the relationship.

Practicing equality in accountability across NGOs is almost impossibile since each NGO has their own priorities and objectives to be fulfilled (Edwards and Hulme, 1996). Namja (1996) argued that the processes of NGO accountability that generally exist are the accountability to patrons, particularly to donors. Ebrahim (2003a) also points out that accountability in practice has emphasised upward and external accountability to donors whereas downward and internal mechanisms are overlooked. This raises a concern as to how partnership between donors and local NGOs is often inefficient and ineffective to deliver services to their constituencies whilst postive impacts of the development projects implemented by local NGOs are often due to strong downward accountability (Fowler, 2000).

It is believed that participation of relevant stakeholders in project implementation can improve accountability in development frameworks. From a participatory approach to some extent, Brett (2010) asserts that democratic accountability of organisations might result in greater performance in service provisions to the poor in development management because all kinds of decision making are involved by all levels of key stakeholders. However, a significant study into the governance and accountability of environmental NGOs (Jepson, 2005) shows that enormous challenges impede the open discussion of accountability since the environmental NGOs are likely to be part of a bigger power structure and are easily influenced and captured by neoliberal market and political movements. One example of such barriers is that "environmental NGOs will come under pressure from regulators and donors to expand performance metrics and reporting, which will lead to a raft of new and 
costly bureaucracy that will divert scarce resources from the cause and do little to enhance efficiency and impact" (Jepson, 2005, p. 5).

Another study (Walsh and Lenihan, 2006) assert that business tools can be applied for the NGO sector to make NGOs more accountable to their partners, staff and other stakeholders. Quality Management Systems like ISO 9000 can be an applicable tool for NGO structure management and this tool might ensure a significant contribution to NGO accountability and effectiveness. Still, Walsh and Lenihan (2006) argue that there might be some NGOs that are not suitable to this tool because the NGOs that naturally receive funds from donor NGOs are often under pressure to make their projects work in accordance with donors' goals and priorities (Ahmed and Potter, 2006). This can create a lack of space for the NGOs to think of their beneficiaries' needs.

Jepson also claims that environmental NGOs can establish a distinct accountability regime from other society groups that is not merely involved in auditing and reporting on performance assessment, but in the engagement of public constituencies in informed discussion on values, issues and strategies. There are also other tools such as management practices, good governance and auditing used to improve accountability (Ebrahim, 2003a). Public communication is a crucial element in strengthening NGO accountability, and transparency is a part of that (Jordan, 2005). Mulgan (2003) claims it is the degree of "rectification" or changes that measure the strengths of accountability and "this is rarely spelt out for NGOs when it comes to their constituents" (Kilby, 2006, p 954). In addition, most NGO's project beneficiaries, particularly the poorest groups, lack mechanisms and ways for holding NGOs accountable (Ahmed and Potter, 2006). Furthermore, Lloyd (2005) adds that self-regulation, organizational assessment and independent assessment are mutually exclusive, but they are likely to create greater NGO accountability. Mawdsley, Townsend, and Porter (2005) also assert that effective partnership between Northern and Southern NGOs can be enhanced by having more field visits, observation and personal interactions and this can improve both upward and downward accountability.

This raises a question: what kinds of effective partnership can have more impact on project beneficiaries? The partnerships allow donors and the Northern NGOs to 
create a legitimacy for operations in development process (Lewis, 1998). In addition to this, intergovernmental organisations, international donors and INGOs have established genuine partnerships with CSOs with strategic approaches to ensure that they are legitimate from the view point of community (Szporluk, 2009). So how is accountability exercised in development practice and to whom? With regard to the evolution of NGO accountability practices, Songo (2007) finds that the effort of establishing a more proactive environment for NGO accountability is to dissect the different levels at which accountability needs to be promoted. Unerman and O'Dwyer (2006a) conclude that mechanisms for effective accountability of NGOs will usually be different and there is no single set of accountability mechanisms suited to all NGOs. This is because the effectiveness of such mechanisms relies on many factors embedied in those individual NGO characteristics. This leads to the conclusion that NGO relationships should be identified and mapped to fully identify the workings of the partnerships. This mapping is in order to fully understand the project activities that are working to generate positive impacts to the beneficiaries. Without knowing what is going on, confusion can result.

There has been confusion about the integrity and legitimacy of NGOs with regard to accountability. The literature concludes that most NGOs are less accountable to communities and more to their donors and bonds are with the upward accountability (Ebrahim, 2005, 2003a, b; Edwards and Hulme, 1996; Rauh (2010); Lloyd, 2005; Najam, 1996). Murtaza (2012) points out that there should be a reconsideration of NGO accountability approaches that purposely respond to excellent performance in development project implementation and social justice. However, local NGOs are financially dependent on their partnerships with INGO or intergovernmental organisations, therefore this makes them more accoutable to donors rather than their home communities and local institutions (Chambers and Pettit, 2004 and Szporluk, 2009). Some CSOs might pursue projects that are not the top priority of their home communities due to donors' preferences and available resources as they require resources to survive and guarantee their activites (Johnson \& Prakash, 2007). Murtaza (2012) argues that NGO accountability to communities might be strong and improved if there was an accreditation programme managed by NGOs' coordinating bodies with the support of donors, home governments and other key stakeholders. This raises the question of how an NGO can operate smoothly with so many external 
pressures from other outside parties. In the light of global good governance, Szporluk (2009) asserts that an INGO's effort to improving accountablity to communities may be significantly enhanced if other stakeholders including intergovernmental organisations and donor governments address their own accountability to communities as well.

As NGOs have multiple stakeholders, claiming ownership of the NGOs may make internal accountability problematic (Hodson, 1992). Therefore, it is difficult to clarify NGO accountability because accountability goes beyond the task of accounting for financial obligations and immediate tangible outputs which donors tend to demand (Dolan, 1992). Accountability goes beyond a concern for maximising profit to an interest in maximising impact (Clark, 1992), further still, the need to formulate and report on goals (Hyndman, 1991) and to make cost effective use of resources (Jegers and Lapsley, 2001). In addition, accountability also includes recognising the importance of empowerment (Kamat, 2003) and acknowledging social accountability in relation to risk (Unerman and O’Dwyer, 2006b).

From an African NGOs' experience, NGO accountability toward beneficiaries is barely seen in practice since the NGOs are influenced heavily by outside (Northern) donors and the government. An African study by Burger and Seabe (2014) points out that the formal accountability of NGOs is imposed by donors and government and they have no substantive commitment to take any of the essential principles of transparency and accountability to transform their organisations. But they argue that more attention to local recipients and the advocacy of beneficiaries is needed to hold NGOs accountable.

In Nigeria, Akintola (2011) points out that most NGOs are accountable essentially to their owners or those stakeholders with economic power over their organisations. This means that not much accountability is focused on the stakeholders upon whom the organisation has impacts. Akintola studied two NGOs which worked mainly on economic and business development in Nigeria and found that these two NGOs merely cared about reporting their financial reports to their donors and governing boards as there were auditing and evaluation procedures in place. This is obviously contradictory to the overall objectives and mission of the NGOs. From this context, there has been a conclusion that accountability is crucial financially but not to the 
extent of the attainment of the missions and objectives for which they were set up (Akintola, 2011).

In Bangladesh where there are numerous NGOs operating development projects and NGO accountability is even a more complicated matter for public discussion. Reflecting Najam's framework (Ahmed and Potter, 2006), Bangladeshi NGOs have multiple stakeholders to be responsible to, meaning that they are responsible to different development actors in the country including government, donors and other major development agencies (Figure, 1). This causes a complicated situation for the Bangladeshi NGOs and becomes an issue in development debates in Bangladesh. The Bangladeshi NGOs or local NGOs are usually under pressure to conform to their Northern donor's goals and priorities. They have no choice since they need money to operate their projects. It would appear that NGOs inevitably need to accept donors' requirements and priorities to operate their project (Unerman and O'Dwyer, 2006b).

\section{Figure 1: The Bangladeshi NGO chain and accountability}

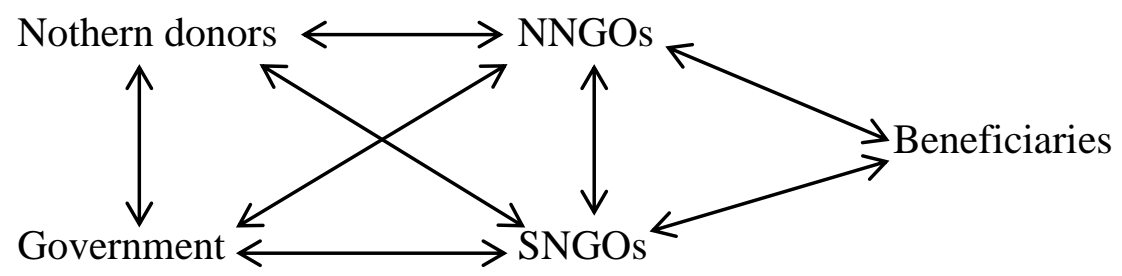

Adapted from: (Ahmed and Potter, 2006. p 136)

In the Philippines, NGO accountability is promoted by an independent organisation called the Philippine Council for NGO Certification (PCNC), having been established to assess and give certificates of authorisation to NGOs. This institution was created in order to collect revenue by deducting taxes from NGOs and ensuring that no corruption occurs in the NGO sector. This mean that the Philippine NGOs have to bear responsibility to the accreditation and requirement proposed by PCNC. The process of certification application may encourage NGOs to think more deeply about accountability in operating projects and in serving their clients, partners and beneficiaries (Golub, 2006). Additionally, PCNC has other major roles to guarantee NGO legitimacy. On the other hand, another main purpose of the PCNC establishment was the tax function in collecting more revenues from NGOs and this can be seen as just a justification of the Philippine government to reclaim tax revenue. The approval of the PCNC for NGO operation is likely to show that NGOs 
will implement their projects in an honest and responsible way but the certification is no guarantee of NGO accountability (Golub, 2006).

Similarly, NGO certification programmes have been used to promote NGO accountability in Indonesia (Antlov, Ibrahim \& Van Tuijl, 2006). Being aware of issues in the development sector in the transitional period of Indonesian democratisation, Indonesian NGOs proposed certification programmes to strenghthen partners' trust in NGOs and to make NGOs capable of serving their clients well. This was also to prevent NGOs from falling into corruption and fraudulent activities. This initiative received input from PCNC. The program intended to promote NGO public accountability by creating a technical task force to be responsible for formulating the vision and mission statements of NGOs. These were to encompass a series of activities that included: the creation of solid instruments, procedures and certification standards; a public campaign for NGO certification; the establishment of an NGO certification agency; advocacy campaign for tax law reform and laws for the non-profit sector; and a programme designed for NGOs' capacity building and implementation of various types of technical assistance that would make NGO more accountable to major stakeholders. Nevertheless, unfavourable experiences have been reported within the development sector in Indonesia. Despite the fact that NGOs have come under the umbrella of a watchdog organisation, most development projects are donor-driven. There is a suggestion that donors need to hold grantees to high standards of public accountability and NGOs themselves should depend on internal funding sources rather than external donors to make Indonesian NGOs more responsive to local development (Antlov, Ibrahim \& Van Tuijl, 2006).

In the discussion of the purpose of accountability in NGO performance management and governance, Schedler (1999) suggests that accountability is the ability to take account from someone, which is the right to be involved in all stages and levels of performance management of an organisation. This definition conceptualises that all other relevant stakeholders of an organisation may also have the right to participate in the performance management processes (Murtaza, 2012). In order to look into the detail of NGO accountability, Murtaza (2012) brings about some insights into his framework and has ultimately added to the meanings of NGO accountability studied by other scholars and researchers. The strengths of accountability depend on the 
active involvement of stakeholders in all processes to get specific performance standards of NGOs by using appropriate data collection tools.

\section{4. Foreign aid and NGOs in global development}

Even though global development has changed significantly, the shifting roles of NGOs still remain critical in basic service delivery and economic development. A number of research studies have been conducted into the roles of foreign aid and non-governmental organizations (NGOs) in poverty reduction and development in developing countries. More than just injecting money into governments of developing countries, donors provide civil society organisations (CSOs) with a large amount of funding for development projects. Most of the studies have assessed and proved that NGOs and CSOs of aid recipient countries play very important roles in fulfilling the development gap in developing countries. An important study (Thorbecke \& Tarp, 2000) indicated that foreign aid is considered as a major contributing factor to the socio-economic development of the less developed countries in a broader sense of development theory and strategy after the Second World War. Another

study (Banks \& Hulme, 2012) pointed out that NGOs have played a prominent role in the development sector in term of filling the gaps of government-initiated development.

The strengths of NGOs have been widely accepted as innovative and grassrootsdriven to pursue people-centred development (Banks \& Hulme, 2012). The positive effects of the increasingly noticeable roles of foreign aid and NGOs in development and poverty reduction have been recognized. As the amount of allocated funds to developing countries still increases, poverty in the developing world will decrease, with significant reductions in Asia but only slight improvement in Africa (Collier \& Dollar, 2001).

The North-South partnership becomes crucial in development practice. It has been seen to enable more efficient use of scarce resources, increase sustainability and improve participation of beneficiaries in development activities (Lister, 1999). NGOs understand that as they work closer to the local level than the governments and other agencies they can use more participatory approaches in development activities (Wallace, Bornstein \& Chapman, 2007). They are capable of carrying out the 
projects much more efficiently than the governments (Ahmed \& Potter, 2006, p. 105). The roles of NGOs have also been shaped by the current aid agenda. They have been actively involved in pro-poor policy development and advocacy to ensure that the aid recipient governments are accountable to the use of aid. But there have been challenges, particularly concerning the legitimacy of NGOs to act as democratic representatives of the poor people (Bebbington, Hickey \& Mitlin, 2008).

\section{5 NGOs and Partnership in Development}

The partnership between North and South NGOs is a widely-debated issue in the development sector (Johnson \& Wilson, 2006). Partnership has been tailored and most are considered as an efficient and effective approach for development. The term "partnership" implies that the NGOs that are in the state of partnership are equal partners. Northern and Southern NGO partnership originally appeared in the 1970s and was a popular term referring to the state of humanitarian, moral, political, ideological and spiritual solidarity between the Northern and Southern NGOs for social change (Fowler, 1998). Authentic partnership should be highly concentrated for NGOs to ensure the effectiveness of development outcomes (Hoksbergen, 2005) because it implies a joint commitment to long-term interaction and shared responsibility for achievement (Fowler, 1998). But Johnson and Wilson (2006) give a view that partnership should be based on equally and mutually beneficial processes and outcomes but it can also involve highly unequal power relations between the partners.

The notion of NGO partnership has risen to prominence and is linked directly to bridge-building and capacity building between Northern and Southern NGOs (Fowler, 1998). It was intended to tailor development to local needs and leverage development expertise and resources so that the Southern NGOs could improve their capacity and empower local resources to serve their constituencies through capacity frameworks and guidelines agreed with their Northern NGOs (Postma, 1994). Therefore, the partnership is a concept that focuses the relations between donors and receivers in the aid framework for development (Baaz, 2005). It is primarily established to improve the effectiveness of aid delivery with conditions to legitimise external agendas from others (Overton and Storey, 2004). 
Even though partnership can involve unequal power relations between NGO partners, it has been largely appreciated since it encourages careful resource use, sustainability and beneficiary participation in development activities (Fowler, 1998, p. 3). There have been many development practitioners identifying many elements for successful partnership. For instance, Postma (1994) highlights some important points, including mutual trust, complementary strengths, reciprocal accountability, joint decision-making and exchange of information ${ }^{1}$.

There has been a continual critique in the literature concerning NGO partnership. The practices of partnership should primarily be based on circumstance and context, but the reality is that a severe constraint to a smooth partnership is the money. Conditions that lead to unequal relations between partners has always been about the flows of money. The money that the Southern NGOs receive from the Northern NGOs for development activities is conditional, meaning that givers have the power to demand the receivers to do something purposely required by them. The Northern NGOs injecting money to their Southern NGOs is for the purpose of establishing legitimacy and adding credibiltiy for them in development operations in the developing countries rather than trying to achieve common objectives (Fowler, 1998, Johnson \& Willson, 2006, Hoksbergen, 2005, Postman, 1994).

Equal partnership has proven difficult in practice and is poorly reflected in the practice of development aid (Baaz, 2005). Partnership has been used as a tactic to promote the legitimacy of developers in the aid environment. It fails in being an equal practice because the developers may never have the intention of establishing an equal relationship in which local actors take the lead in development (Baaz, 2005). Partnership is needed to enhance the sustainability in which ownership and responsibility of partners are featured to maximise development outcomes. But sustainability is attributed to organisational capacity and aid dependence. Crew and Harrison (1998) point out that self-reliance through capacity of partners can improve

\footnotetext{
${ }^{1}$ There are other elements which have been included. In July 2007, the United Nations (UN) and nonUN humanitarian agencies agreed to five principles of partnership at the global humanitarian level to improve the NGO partnership across development projects. Those include equality, transparency, a results-oriented approach and responsibility and complementarity.
} 
partnerships and partners have to focus on the same development goals with open and transparent relationships.

\section{6 NGOs and environmental governance}

NGOs have also become a key player in global environmental governance and actions. They develop projects and make up a large part of the transnational community that works directly or indirectly to protect the environment. These NGOs are usually called Environmental Non Governmental Orgnisations (ENGOs). The proliferation of ENGOs has taken place largely since the end of the Second World

War in order to protect and manage the earth's natural resources (Pease, 2012). These NGOs work on a variety of projects ranging from biodiversity conservation, forest protection, climate change and sustainable development (Ahmed \& Potter, 2006). For instance, the International Union for the Conservation of Nature (IUCN), which was founded after the Second World War, is still a prominent organisation in the protection of the environment. It oversees education and communication about the environment globally, environmental policies and laws, ecosystem management and leads a United Nations (UN) commission for species survival and protected areas.

NGOs have performed a variety of roles in environmental governance. They create strategies to address environmental issues and sustainable development. They participate in the global policy development process at the regular United Nations Conference on Environment and Development (UNCED), held a number of times since the Earth Summit 1992 held Brazil. The NGO presence at UNCED not only became the focal point of transnational environmental activism in the 1990s but also a key vehicle to influence the global policymaking process. The range and intensity of NGO's activities are broadened and strengthened in the UN commission framework with regard to development policy initiative, practice, monitoring and evaluation (Martens, 2005). For example, more than twenty countries had ENGO representatives on their national delegations to international climate negotiations (Ahmed \& Potter, 2006, p. 217). However, NGOs appeared not to be influential in affecting the outcomes of some conferences in policy negotiations. UNCED has helped to strengthen existing ENGOs and has created links among NGOs. DeMars (2005) points out that the emergence of ENGOs does transform world politics but 
often not in the directions that ENGO avocates claim (p. 4). In addition, ENGOs have been actively involved in international development policy monitoring and research to ensure that their own governments address environmental issues and sustainable development. Sometimes ENGOs directly criticise governments in ineffective resource distribution in development actions (Shigetomi, 2002). ENGOs have enhanced professionalism and become bureaucratised, so they now face citizen disappointment and disengagement (Star, 2012). In light of this, local people are likely to turn to grassroots and community-based political actions to ensure democratic accountability of elected officials.

\section{7 NGOs and climate change}

ENGOs have also performed a significant role in global climate change actions. According to a study into the role of ENGOs in Europe and Eurasia, it is noted that a country's NGO strength is a predictor in the timing of ratification to Kyoto Protocol (Dolsak, 2013). Similarly, Wapner (1995) credits NGOs with ushering in politics beyond the state in pressuring states on environmental issues. A number of commentators in the literature argue that NGOs have an important role in influencing the environmental policy agenda at the international as well as at the domestic level (Jancar-Webster, 1993; Arts, 1998; Newell, 2006; Keck \& Sikkink, 1998; Weidner \& Janicke, 2002; and Betsill \& Corell, 2001). ENGOs seek access to the states' negotiation delegations as members in order to affect and even change their policies with regard to climate change (Bohmelt, 2013b). NGO efforts are likely to encourage their respective governments to ratify the Kyoto Protocol because the government could benefit from the implementation of international climate change practices (Dolsak, 2009).

ENGOs are likely to be active in influencing the international climate change negotiations. ENGO representatives who attend the Conference of the Parties (COP) are considered to be more influencial in affecting climate policy negotiations than media, researchers and government representatives (Hierpe \& Linner, 2010). There are some critics of NGO representation in the international climate policy negotiations. Government acceptance of NGO representatives in the national delegations in climate change negotiations remain unclear because the states, which are more central to the network of global governance, seem to be influenced by other 
state's actions and policies toward civil society (Bohmelt, Koubi \& Bernauer, 2014). The recognition of the increasingly important involvement of NGOs in world politics, particularly in policy areas of environmental protection is pronounced (Weiss \& Gordenker, 1996; Raustiala, 1997; Clark, Friedman \& Hochstetler, 1998 and Bernauer \& Betzold, 2012).

There is research that pays attention to whether and how NGOs are able to influence international policy making and its outcomes (Peterson, 1996; Gulbrandsen \& Andresen, 2004 and Betsill \& Corell, 2008). The formal inclusion of NGOs in national delegations offers opportunities for these actors to influence government decision making (Weiss \& Gordenker, 1996; Raustiala, 1997; Gulbrandsen \& Andresen, 2004; Steffek \& Nanz 2008; and Bohmelt, 2013a) because it could improve political responsiveness, transparency, accountability and ultimately, legitimacy in the sense of international and domestic public support (Clark, Friedman \& Hochstetler, 1998; Grant \& Keohane, 2005; Dombrowski, 2010 and Bernauer \& Betzold, 2012). Derman (2014) asserts that neither government nor civil society can act alone to influence global governance and the increased engagement of NGOs can maintain a truly public sphere in the face of well-resourced private interests.

ENGOs remain a key player in global climate change actions and they can also contribute to climate policy formulation and actions at the national level. The inputs that NGOs contribute to the policy process basically come from the local. In light of this, NGOs implementation of proposals and actions to halt global warming through the activities of ordinary citizens is very important. For instance, the Kiko Climate Network, a Japanese ENGO, has wide-ranging activities against global warming including participating in international negotiations over global warming prevention, making policy proposals, conducting research and studies, sharing information, organising seminars and symposia, implementing environmental education programmes and supporting local activities (Nath \& Behera, 2011). Likewise, Greenpeace, a US-based ENGO works across borders in shaping government decisions and actions for a clean environment (Nath \& Behera, 2011, p. 152). Some NGOs have a seat in government institutions. For example, a few Japanese ENGOs participate in the 40-member council under the Japanese Minister of Environment and there is one NGO member out of 29 seats in the council (Zhou \& Mori, 2011). 
NGOs possess the role of a driving force to lead the government to implement environmental policies through awareness, capacity building and organised protests (Nath \& Behera, 2011).

While plenty of research and study efforts have been undertaken to prove the important roles of NGOs in international governance in the development framework, the overall literature does not really cover in depth any work on the accountability of NGOs in climate change projects at the ground. NGOs are becoming increasingly prominent in the development sector with poverty reduction and currently climate change actions in Cambodia, but the nature and extent of their work and accountability in climate change partnership projects is not really known. The literature is not extensive in this area so this research proposes to explore how NGO accountability as working in partnerships impacts on local communities in Cambodia in climate change projects and what forms of accountability are being practised by Cambodian NGOs in climate change projects. The research also explores what the challenges and sollutions there are in implementing climate change projects.

\section{8 Conclusion}

This chapter has presented some literature relevant to the study topic. The review began by discussing the different meanings of NGO accountability in development practices with regard to organisational performance improvement and effectiveness. Often, accountability is carried out to reflect an NGO's credibility in serving the local people. Moving to NGO's roles in global development and poverty reduction, the review discussed how NGOs working in partnerships improve development cooperation, environmental governance and climate change actions. The transformation of NGO's roles in development from humanitarian relief, human rights to advocacy in environmental governance and then to climate change actions was discussed. The changing emphasis in the development sector and the current focus on climate change and working in partnerships provides the contextual background to this study. The following chapter is about the specific research context in Cambodia. 


\section{Chapter Three: Approach to Research and Methodology}

\subsection{Introduction}

This chapter presents my approach to this research and the methodology chosen to answer the research questions. Firstly, my epistemological approach is presented and explained. This approach affected my choice of methods. I was interested in the participants' perceptions of, and experiences in, the climate change project implementations operated by Cambodian NGOs. I chose a methodology which included data collection methods whereby their perceptions are recognised, respected and captured for analysis. In this chapter I describe in detail the research design and methods employed. Data collection included both primary and secondary data sources and I describe the process for locating information sources and recruiting research participants. The chapter concludes by discussing my research postionality and reflection, the ethical considerations and the limitations of the study.

\subsection{Epistemology-constructivism}

My epistemological approach to this research is based on constructivism and a participatory approach which captures interactions between the researcher and their participants. Constructivism, also known as constructionism, is a perspective that views all of our knowledge as "constructed". Knowledge is contingent on conventions, human perceptions and social experiences (Creswell, 2013). Thus knowledge does not necessarily reflect any external or immutable realities. I have employed this perspective towards knowledge because people in Cambodia who are involved in climate change projects are constructing their own knowledge about this process and I am interested in their thoughts. The researcher is the one who seeks and inteprets the meaning of a phenomenon from the views of participants (Creswell, 2013). This contrasts with a positivist, scientific epistemology which is common in much climate change research. Knowledge in this case is seen as observable and absolute and the researcher is neutral and detached.

As I was interested in exploring what people think of the climate change projects and what is informing their perspectives, I designed a methodology that involved qualitative methods of data collection. This is because the primary data was people's thoughts, feelings and experiences of this phenomenon. The participants were interviewed and questioned about what they have learnt and perceived from their 
individual experiences with regard to partnership in development, particularly in the climate change project exercise. Observation is crucial in qualitative research as it allows the researcher to scrutinise the perceptions and feelings of the research participants by using observation methods and note taking during interviews. This direct observation is helpful for the researcher to observe hidden stories and explore more information to supplement what the informants have shared and provided. Prior to the interview I developed relationships with the participants in order to facilitate discussions. Creswell (2003) claims that a qualitative approach is conducted in a natural setting where the research participants are located thus allowing researchers not only to develop a high level of trust and but also to get involved in the actual experiences of the participants.

\subsection{Qualitative methods}

To answer the research questions, several data collection methods were identified and employed. First of all, the secondary data included published and unpublished documents and were collected from Cambodian NGOs, government institutions, and other development agencies, both on-site and through websites. Some relevant information was also gathered from Cambodian newspapers. Then a review of related literature covering the context of NGO accountability and partnership in development and Cambodia climate change was also conducted. The primary data was collected through participant observations and semi-structured interviews. The semi-structured interviews were carried out with the voluntary participation of seventeen representatives from NGOs that work on climate change projects.

\subsubsection{Secondary data and document review}

To get a wider understanding of the context of Cambodian climate change, the secondary data sourced from NGOs, government institutions and other development agencies were reviewed. These documents were considered significant contributions for data collection and analysis for the study. The secondary documents which were accessible are both on-site and websites and included published and unpublished reports, guidelines, and other manuals and research papers from development agencies, government institutions and NGOs related to climate change projects. Some documents such as videos of case studies, posters and leaflets were also found important and collected in order to be used for data collection and analysis in the field. In addition, related academic literature was also reviewed in order to bring 
about a wider understanding about NGO accountability, partnership in development, the aid chain and the role of NGOs in climate change.

\section{3. 2 Primary data collection}

\section{a) Choice of setting}

The location of the research was selected because of my familiarity with the area and the recent popularity of climate change projects occuring there. Cambodia is where I was born and I have worked on development projects with NGOs. Due to my past experience, I was interested in finding out how NGO accountability in working partnerships in climate change projects has significant impacts on local communities over the period of implementation. The changes to some Cambodian NGOs' strategies and plans to incorporate climate change into the NGO development programme is fairly recent and was also a factor for the selection of the study site.

Cambodia is very vulnerable to climate change and funding opportunities for this sector are high. The government has started to take action for climate change adaptation and mitigation. It has developed some overarching policies and regulations to address and cope with climate change impacts. At the same time NGOs are also active in the climate change sector in Cambodia. They complement and fill some gaps overlooked by the government by working with other stakeholders and community people to implement projects at grass roots. They work to promote climate change awareness, adaptation and policy development advocacy in particular. Due to this evolving climate of change in policy there was an added incentive for me to conduct this research to explore how NGOs experience the project implementation.

\section{b) Participants and sampling}

The main focus of this study was to explore the perspectives of those working in Cambodia with NGOs who are adapting to new policies concerning climate change. Thus, I specifically recruited participants based on their positions in various NGOs in which they were working. My target interviewees were representatives of NGOs that work on climate change projects. The total number was eight from INGOs and nine from LNGOs in Cambodia. Most importantly, they were key individuals who are actively involved in the climate change sector of their organisations and networks. 
The participant sampling is purposive but a snowballing technique was used in the field to identify potential NGOs for interviews. In addition, the target NGOs are groups whose climate change projects are registered in the list of development projects of the Council for Development of Cambodia (CDC) (Table 1), and some NGOs that are connected to the Cambodia Climate Change Network (CCCN), which was originally initiated by Cambodian NGOs. The majority of the CCCN members are connected with and involved in, the Joint Climate Change Initiative project (JCCI) which was led and coordinated by three international NGOs (Forum Syd, Cord and Danchurch/Christian Aid) that initially developed the JCCI project in Cambodia. These NGOs work in partnership on climate change projects. Some NGOs from these groups were randomly selected and chosen based on a snowballing technique and their potential actions on climate change (Table 2). However, some NGOs who are not listed in these two groups but who are working on climate change were also selected for the field interviews.

Table 1: List of NGO Climate Change Projects registered at CDC 2014

\begin{tabular}{|c|c|c|}
\hline N. & NGOs & $\begin{array}{l}\text { Title of Registered Projects (and } \\
\text { location) }\end{array}$ \\
\hline 1. & $\begin{array}{l}\text { Action for Environment and } \\
\text { Communities (AEC) }\end{array}$ & $\begin{array}{l}\text { Climate Change Adaptation and } \\
\text { Improving Livelihoods (Kampong } \\
\text { Chhnang) }\end{array}$ \\
\hline 2. & $\begin{array}{l}\text { Association for Human } \\
\text { Resource Development and } \\
\text { Health Education }\end{array}$ & $\begin{array}{l}\text { Climate Change Mitigation and Promotion } \\
\text { of Palm Sugar Production (Kampong } \\
\text { Chhnang) }\end{array}$ \\
\hline 3. & $\begin{array}{l}\text { Cambodia Civil Society for } \\
\text { Partnership (CCSP) }\end{array}$ & $\begin{array}{l}\text { Together for Climate Change Adaptation } \\
\text { and Livelihood Improvement (Pursat) }\end{array}$ \\
\hline 4. & $\begin{array}{l}\text { Cambodian Centre for Study } \\
\text { and Development in } \\
\text { Agriculture (CEDAC) }\end{array}$ & $\begin{array}{ll}\text { - } & \text { Building Climate Resilient } \\
\text { Farming Communities in } \\
\text { Cambodia } \\
\text { - } \quad \text { Promoting Climate Resilient } \\
\text { Livelihood for Small-Scale } \\
\text { Farmers in most vulnerable dry } \\
\text { land areas in Siem Reap and }\end{array}$ \\
\hline
\end{tabular}




\begin{tabular}{|c|c|c|}
\hline & & Kampong Cham provinces. \\
\hline 5. & $\begin{array}{l}\text { Cambodian Organisation for } \\
\text { Women Support (COWS) }\end{array}$ & $\begin{array}{l}\text { Improve the Conservation Management for } \\
\text { Sustainable Community Fisheries to } \\
\text { Ensure on Food Security, Health and Local } \\
\text { Vulnerability Reduction of Climate } \\
\text { Change (Kampong Thom) }\end{array}$ \\
\hline 6. & $\begin{array}{l}\text { Community Resource } \\
\text { Improvement for } \\
\text { Development (CRID) }\end{array}$ & $\begin{array}{l}\text { Community Capacity improvement for } \\
\text { Adaptation to Climate Change (Prey } \\
\text { Veng) }\end{array}$ \\
\hline 7. & $\begin{array}{l}\text { Community Translation } \\
\text { Organisation (CTO) }\end{array}$ & $\begin{array}{l}\text { Mainstreaming Climate Change } \\
\text { Adaptation's Strategy into Community } \\
\text { Livelihood and Development (Siem Ream) }\end{array}$ \\
\hline 8. & $\begin{array}{l}\text { Environment Protection and } \\
\text { Development Organisation } \\
\text { (EPDO) }\end{array}$ & $\begin{array}{l}\text { Sustainable Livelihoods \& Natural } \\
\text { Resource Management (SLNRM), (Pursat) }\end{array}$ \\
\hline 9. & Finn Church Aid (FCA) & $\begin{array}{l}\text { Cambodia Country Program 2012-2014, } \\
\text { (Batambang, Pursat, Kampong Chhnang } \\
\text { and Kampong Speu) }\end{array}$ \\
\hline 10. & Oxfam America (OA2) & $\begin{array}{l}\text { Climate Change Awareness Campaign in } \\
\text { Cambodia (Phnom Penh) }\end{array}$ \\
\hline 11. & Plan International & $\begin{array}{l}\text { Disaster Risk Reduction Management, } \\
\text { (Kampong Cham, Ratanakiri and Siem } \\
\text { Reap) }\end{array}$ \\
\hline 12. & Santi-Sena (SS) & $\begin{array}{l}\text { Rural Livelihood Promotin through } \\
\text { Climate Change Adaptation from Forest } \\
\text { Resources Improvement and Innovative } \\
\text { Agriculture Development at Svay Rieng } \\
\text { Province (Svay Rieng) }\end{array}$ \\
\hline
\end{tabular}

*Highlighted NGOs were the ones selected for this study

Source: CDC (2014) the Cambodia NGO Database 
Table 2: List of NGOs partnersing in JCCI

\begin{tabular}{|c|c|c|}
\hline N. & Names of Organisations & Types of Organisations \\
\hline \multicolumn{3}{|c|}{ Phase I } \\
\hline 1. & Development and Partnership in Action (DPA) & Local \\
\hline 2. & Banteay Srey (BS) & Local \\
\hline 3. & $\begin{array}{l}\text { Cambodia Centre for Study and Development in } \\
\text { Agriculture (CEDAC) }\end{array}$ & Local \\
\hline 4. & Fisheries Action Coalition Team (FACT) & Local \\
\hline 5. & Life With Dignity (LWD) & Local \\
\hline 6. & Non-Timber Forest Products (NTFP) & Local \\
\hline 7. & Ponleu Ney Kdey Sangkhem (PNKS) & Local \\
\hline 8. & Star Kampuchea (SK) & Local \\
\hline 9. & Village Support Group (VSG) & Local \\
\hline 10. & NGO Forum & Local \\
\hline \multicolumn{3}{|c|}{ Phase II } \\
\hline 11. & Organisation to Develop Our Village (ODOV) & Local \\
\hline 12. & $\begin{array}{l}\text { Youth Resource Development Programme } \\
\text { (YRDP) }\end{array}$ & Local \\
\hline 13. & $\begin{array}{l}\text { Cambodian NTFP Development Organisation } \\
\text { (CAN-DO) }\end{array}$ & Local \\
\hline 14. & Highlander Association (HA) & Local \\
\hline 15. & Cambodian Civil Society Partnership (CCSP) & Local \\
\hline 16. & $\begin{array}{l}\text { Committee for Free and Fair Election in } \\
\text { Cambodia (COMFREL) }\end{array}$ & Local \\
\hline 17. & $\begin{array}{l}\text { Gender and Development for Cambodia } \\
\text { (GADC) }\end{array}$ & Local \\
\hline 18. & Khmer Youth and Social Development (KYSD) & Local \\
\hline 19. & Khmer Youth Association (KYA) & Local \\
\hline 20. & My Village (MV) & Local \\
\hline 21. & $\begin{array}{l}\text { Partnership for Development in Kampuchea } \\
\text { (PADEK) }\end{array}$ & Local \\
\hline 22. & $\begin{array}{l}\text { People Centre for Development and Peace } \\
\text { (PCDC) }\end{array}$ & Local \\
\hline
\end{tabular}




\begin{tabular}{|l|l|l|}
\hline 23. & Cord Cambodia $^{*}$ & International \\
\hline 24. & Forum Syd & International \\
\hline 25. & Dan Church Aid/ Christian Aid (DCA/CA) & International \\
\hline
\end{tabular}

The Lead NGOs that initiated the JCCI project and supported the local NGOs partners.

\section{c) Semi-structured interview}

Once several NGOs had been identified, a method of interviewing was developed that could be used with key people in each NGO. These informant interviews were the basis of the primary data collection in the study. The research design intended to explore individuals' experiences working in climate change project implementation and examine NGO accountability with regard to partnership in climate change projects' impact on local communities in Cambodia. I considered the semi-structured interview to be a particularly suitable method as key informant interviews provide researchers with valuable insights into the knowledge and experience of people involved in a given area, highlighting issues concerned with social reality, cultural identity, values and authenticity (Neuman, 2006; Bryman, 2008). Their perspective offered me accurate information and data about why climate change has become an important focus for NGOs and how this work produces impacts for the local people they are serving. The perspectives from the key informants helped to explain partnership between NGOs with regards to how climate change is being managed in Cambodia today.

The key informants were told about the topic, objectives and process of the study before the interviews. Relevant information was provided and other important documents (information sheets, consent forms and question guides) ${ }^{2}$ both in English and Khmer were available (Appendix I, Appendix II and Appendix III). All interviews took place at the participant's office except one that was conducted at a café in a shopping mall. Prior to each interview, there was always an informal talk out of the topic before starting the interview. This helped both researcher and participants to build a relationship at the site.

\footnotetext{
${ }^{2}$ The key information sheets, consent forms and interview question guides were translated into Khmer prior to the field data collection.
} 
There was an interview framework with main questions followed by sub-questions (Appendix III). The interviews started with asking some questions in relation to how NGO accountability impacts on local communities and why NGOs in the country are especially interested in climate change issues. Then the following questions related to NGO partnership in order to capture the significance, challenges and solutions involved in working with others in climate change. The interviews also tried to explore the impacts and results that NGOs have achieved over the period of project implementation.

The interviews were in conversational style and face-to-face. In-depth conversation gives researchers and participants time to further express their opinions and feelings and help the participant concentrate on intimate details and discuss hidden stories which would not normally be discussed (O'Reilly, 2009, Skinner, 2012). Each interview lasted approximately thirty minutes to just over an hour. Even though the interviews had a question guide, a number of supplementary questions were used to seek further information. Some interviewees provided much more information than others. They each had different levels of knowledge, education and experience in the climate change sector. Some interviewees skipped or did not answer some questions. The answers to some questions were short and irrelevant while some were full of good information. The seventeen interviews from seventeen different NGOs were all recorded with a voice recording device and transcribed into English. Data collection took place in Cambodia from May to July 2014.

Table 3: List of interview participants

\begin{tabular}{|l|l|l|l|}
\hline Code Number & $\begin{array}{l}\text { Type of } \\
\text { Organisation }\end{array}$ & Position Title & Location \\
\hline Interview1 & INGO & Executive Director & Phnom Penh \\
\hline Interview2 & LNGO & $\begin{array}{l}\text { Sala Phoum } \\
\text { Coordinator Project }\end{array}$ & Strung Treng \\
\hline Interview3 & LNGO & Climate Change Project Officer & Kampong Speu \\
\hline Interview4 & INGO & Capacity Development Advisor & Phnom Penh \\
\hline Interview5 & LNGO & Climate Change Project Officer & Phnom Penh \\
\hline
\end{tabular}

\footnotetext{
${ }^{3}$ The project name in Khmer language whose objectives are to study and research on climate change issue in the target areas of the organisation.
} 


\begin{tabular}{|l|l|l|l|}
\hline Interview6 & INGO & SEA Change Project Officer & Phnom Penh \\
\hline Interview7 & LNGO & Project Manager & Phnom Penh \\
\hline Interview8 & INGO & $\begin{array}{l}\text { Consortium Coordinator for } \\
\text { Climate Change }\end{array}$ & Phnom Penh \\
\hline Interview9 & INGO & $\begin{array}{l}\text { Climate Change Program } \\
\text { Officer }\end{array}$ & Phnom Penh \\
\hline Interview10 & LNGO & Executive Director & Phnom Penh \\
\hline Interview11 & INGO & $\begin{array}{l}\text { National REDD+ Policy } \\
\text { Advisor }\end{array}$ & Phnom Penh \\
\hline Interview12 & INGO & Land Right Field Project Officer & Phnom Penh \\
\hline Interview13 & LNGO & Program Manager & Phnom Penh \\
\hline Interview14 & INGO & Senior Profram Officer & Phnom Penh \\
\hline Interview15 & LNGO & Climate Change Offier & Phnom Penh \\
\hline Interview16 & LNGO & Senior Program Coordinator & Phnom Penh \\
\hline Interview17 & LNGO & $\begin{array}{l}\text { Project Coordinator for Climate } \\
\text { Change Policy Monitoring }\end{array}$ & Phnom Penh \\
\hline
\end{tabular}

In sum, this research design of secondary sources complemenmting NGO key informant's perspectives was an effective way of exploring the accountability of NGOs working as partners and discovering how the NGO partnership impacts on local communities when they implement climate change projects in Cambodia. The methods allowed for direct sharing of local knowledge, information, expertise and experiences between rmy self and the participants (Mikkelson, 2005). I was able to discuss and draw conclusions from both sets of data that both agreed and varied from that expected by other researchers (Fitzgerald, 2006). Also, the qualitative approach allowed me to explore behaviours, perspectives, feelings and experiences of the research participants in depth (Creswell, 2003, Maxwell, 2012). The design aims to capture how climate change projects are implemented by NGOs working in partnership in Cambodia and what impacts are achieved. Qualitative case studies can provide accurate information on the influence of social, political and other contexts where the study takes place and the results generated from this study are relevant to the Cambodian context (Denzin \& Lincoln, 2005). 


\subsubsection{Limitations of the study}

There are some limitations of this study and gaps in the data collection. There are many NGOs in Cambodia that work on climate change issues but they are not all the NGOs which are experts in this issue. Often, the NGOs work in other areas, such as health or agriculture but by introducing and integrating climate change issues into their programmes they start making partnerships with other NGOs. They situate their projects across the country at local and national levels. The interviews could not reach all areas of the NGOs. I could not travel a long distance to all relevant NGOs to do interviews because the cost was too high and the research funding was insufficient. Furthermore, some interviewees did not completely respond to all research questions and some did not provide project documents to me as they were confidential. The interviews and provided documents reflect only a partial story of NGO accountability and partnership practice in climate change projects related to this time and the scope of this study. In addition, some NGOs rejected the offer to be involved so their perpsective is not present.

\subsubsection{Ethical considerations}

This study is compliant with the Victoria University of Wellington's ethical policy. The ethics approval was granted. Research consent forms and information sheets were prepared so that the participants could decide if they wanted to participate in the study or not. In the field, the information sheets were handed to the research participants so that they could understand the objectives of the research and then consent forms were provided for their signature when asking them to participate. Pseudonyms were used to represent their names and organisations if some respondents did not feel confident to use their names and organisations. Only one informant asked for a pseudonym for the organisation he works for to be used in the research. The majority of the research participants agreed to be quoted and for their names and organisations to be used in the research report. I informed the participants that all collected data would be securely stored in a computer with a locked password and then destroyed after the study is completed.

During the interviews, the respondents voluntarily gave their information to me without coercion. Some questions were skipped when the interviewees felt not confident enough to share an opinion or did not want to answer the question. The rights of the research participants were also served to avoid sensitive issues. For 
instance, when talking about the roles of local authorities in project implementation and cooperation with NGOs, a key informant was reluctant to talk deeply and precisely about the negative attitudes of local authorities toward NGO's actions.

\subsection{Data analysis}

The collected data from the field interviews were analysed using a content analysis approach during and after the field research and the document review. The recorded voices and field notes were translated as text and then organised and prepared for coding and categorising themes. The organised data was coded in a way that offered descriptions of emerging issues. Then the descriptions were identified under different categories and linked to major categories and themes. The major categories or themes were examined and grouped as sub-themes in a way that was consistent with research objectives. The categorised data was reviewed to check if the information was appropriately categorised and if the categories could be merged or subclassified. The procedure of coding and categorising was based on the research questions and objectives. In addition, the basic strategy to determine categories and themes was derived from the broad concepts of NGO accountability, NGO project implementation and partnership, and impacts on communities with regard to climate change projects. During the data analysis I always returned to the original transcripts to ensure that all the information that needed to be categorised had been done. The process of analysing qualitative data tends to be iterative with states being revisited (Denscombe, 2007, p.288-289). When all the information was completely and thoroughly categorised, category comparison was conducted to ensure that the themes were consistent, relevant and not repeated. The categories and themes are discussed in the chapter on the findings.

\subsection{Positionality}

As a development practitioner and field researcher, identifying and placing my own position in the context of various settings of difference, inequalities and situations is the contributional factor to make outcomes of research more ethically and efficiently results-oreinted. St Louis and Barton (2002) show that "understanding positionality is crucial to understanding the subjectivity of researchers" (p. 3). In the field of research the process of producing knowledge and research outcomes are always influenced by one's positionality because identities and subjectivities are dynamic and unstable and even change according to relationships in distinct places and at 
different times. Therefore, examining our positionalities as research participants, by paying attention to our colonial background, the progress of development, global aspects and the local context of the fieldwork, may even avoid the unethical and exploitative research or constitution of dominant relations or biases (Sultana, 2007). It is essential that the researcher acts in different roles as both insider and outsider in the data collection process to create a sense of equality, respect and relational dignity. This awareness of positionality is an important tool and enables the discovery and understanding of relational issues and dissimilarities which are generated by identity and class distinctions to navigate the directions, outcomes and knowledge production in the fieldwork (Chacko, 2004).

My personal identity provided me with a significant advantage for this research. Even though I am a postgraduate student studying overseas, I was acting as both researcher and insider when conducting my research in Cambodia because I used to work for NGOs in Cambodia for six years before pursuing study in New Zealand. This personal background determined to some extent the construction of the research questions for this study. Being familiar with Cambodian NGOs provided me with the capacity to access them for the interviews and build friendships and trust for the research. I did not know most of the participants personally but they were willing to share and provide information concerning their experience in climate change project implementation as they knew that I had been a NGO worker as well. For instance, when asking about political and sensitive issues in relation to the government, they quickly responded to me. Additionally, speaking the same language provided essential help during the interviews as I could understand what the respondants were refering to even when it was not always clear. However, I noticed that some interviewees seemed hesitant to provide me with project documents because of confidentiality and they said that they did not want other people know the organisation's project documents.

\subsection{Field research reflection}

Personal reflection on the data collection was regularly made as part of the research process. I discovered that the participants had different levels of knowledge and education concerning climate change implementation. Therefore, the answers provided differed according to their capacity and knowledge. Some who are more 
familiar with the research topic were much more responsive and talkative while others reacted to the inquiries slowly through the stories about their personal experience during the conversations. Some respondents only tried to answer irrelevant things, but demonstrated their organisation's achievements. For example, when I inquired "what impacts has your organisation achieved in climate change projects?", they gave a narrative of what their organisations produced overall and they usually looked at what I was writing about. However, I found some participants were really willing to share hands-on experience and lessons learnt and gave a lot of important documents for my study. They even asked me if I need more help and additional answers with regard to information.

I reflected that my personal identity and experience offered a substantial contribution to success with data collection in that I could develop a sense of mutual respect with the key informants. Reflection is a central part of research that enhances the interaction and connection when sharing information during interviews in qualitative research (Walker et al., 2013). The research participants felt relaxed and confident to share information when mutual trust and understanding is built during the interviews.

\subsection{Conclusion}

The chapter has described my epistemological approach to research which informed the methodology. The methods used in the study included in-depth semi-structured interviews which involved asking open questions and dialogue in an informal style of face-to-face conversation and discussion, participant observation and a review of secondary data. Furthermore, the process of data collection via interviews was detailed with discussion of participant selection and settings, primary data collection and analysis. In addition, this chapter also highlighted some issues and complexities reflected in the field research experience. Finally, I discussed the significance of positionality and field research reflection for the study. The following chapter will discuss and present the context of Cambodia where the study took place. 


\section{Chapter Four: Cambodian Context}

\subsection{Introduction}

This chapter introduces the context of the research. It provides an overview of Cambodia, the background to the NGO sector and climate change and development in Cambodia. The first section describes the current political and socio-economic development of Cambodia. The second section gives a summary of the NGO sector and discusses its function, roles and contributions towards development practices. The final section provides an overview of the climate change context of Cambodia and its impacts on development.

\subsection{Overview of Current Political and Socio-Economic Situation in Cambodia}

\section{2. 1 Political Context}

The collapse of Khmer Rough regime in 1979 followed by the 1991 Paris Peace Accord has opened new face for Cambodia to pursue socio and economic development. After the Khmer Rough period, the so called 'Killing Field or Genocidal Regime' Cambodia started with zero for its socio and economic development. Since the 1993 election, which was supported by the United Nations (UN), the Cambodian political system has become more liberal and democratically plural. The mandate for holding national elections is five years according to the Constitution. The King is the head of state and oversees three separate powers including the executive, legislative and judiciary but he is not involved in politics and has no absolute power in the government. Technically, the king serves as symbol of unity, peace and eternity of the nation.

Theoretically Cambodia has been transitioning from a one-party rule to a multi-party democracy. Progress has been slow, hampered by corruption (Alley, 2012; Global Witness, 2010 and Kinnock, 2012), with weak accountability, a lack of a credible opposition and the continued precedence of patrimonial and patron-client relationships. Many of these restrictions have been noted as commonly occuring and even reinforced by the larger scale neo-liberal economic development paradigm that Cambodia has embraced. 
Within the country, the Cambodian People's Party (CPP) dominates the political scene and has secured senior positions throughout the country's governance structures, including the Senate and National Assembly. The CPP won approximately 73 per cent of seats in the 2012 third Senate election. In the local commune council elections in June 2012, the CPP also won with a predicted landslide victory, securing around 62 per cent of the vote and 72 per cent of the commune council seats. In the 2013 national election CPP still won a dominance of 68 seats from a total 123 seats in the assembly, although noting a significant decrease of its popularity among the public (COMFREL, 2014). The only one main opposition party, the Cambodian National Rescue Party (CNRP) received 55 seats, which was remarked as an impressive result. The 2013 election was percieved by the opposition party as fraudulent and unfair (COMFREL, 2014). The government which has been ruled by the CPP arguably cheated in the election because the National Election Committee (NEC), whose responsiblities was to prepare and coordinate the election, were closely affiliated with the CPP. With the continued dominance of the $\mathrm{CPP}$, the space for political debate continues to diminish.

Development partners have played an important role at least in the façade of implementation of some democratization of Cambodia for many years and have been active in cooperating with LNGOs to ensure freedom of assembly and expression and to encourage adherence to human rights. The development partners that participate in the government aid consultation mechanisms, such as the Cambodia Development Cooperation Forum (CDCF), the Government-Donor Coordination Committee (GDCC) and the Technical Working Groups (TWG), have also been strong advocates for civil society engagement. Despite this, there are fears of an increasing access of the Royal Government of Cambodia (RGC) to financial resources from donating countries, particularly China, which is not engaged in human rights and environmental issues. This trend of looking towards China, may reduce the influence of the OECD/DAC development partners and turn the agenda away from so-called rights-based approaches and an enabling environment for civil society, toward lesser known approaches.

The Royal Government of Cambodia (RGC), however, is said to have made significant progress in putting into place national policies, mechanisms and processes 
to support aid and development effectiveness. It also publicly advocates partnership in development that constitutes a space for civil society, the private sector and external partners in development activities. Political reform, such as the decentralization and deconcentration policies following the 2002 establishment of the commune councils also offers new space and opportunities for interaction between local authorities and CSOs. While the Cambodian government views NGOs as important partners in terms of the delivery of basic services, the space for human rights and advocacy groups is much more limited. With dominant voices within the National Assembly, the CPP continues to use the judiciary system, the penal code and legal action to restrict freedom of speech, to silence any opposition parties and to disperse protests. The main opposition party, the CNRP, has shown support and solidarity with the victims of eviction and land grabbing, although in many cases this has allowed the CPP to claim that the demonstrations are focused on party-political issues rather than basic human rights.

The government currently demonstrates a lack of downward accountability and participatory decision-making processes, and limits the basic rights and freedoms of citizens, such as access to information and freedom of expression and participation. Often these are acknowledged but not yet fully implemented or guaranteed ${ }^{4}$. Furthermore, the government has increasingly made use of legislative, judicial and extra-legal means to restrict democratic space, both for civil society and citizens. The 2009 penal code retains defamation and disinformation as a criminal offence and extends its scope to those expressing peaceful views against the government. According to reports from the Cambodian League for the Promotion and Defense of Human Rights (LICADHO) and Cambodian Human Rights and Development Association $(\mathrm{ADHOC})^{5}$, the number of community activists charged in connection with land disputes rose from 319 in 2010 to 427 in 2011. For instance, a case in April 2012, saw 13 women from an inner city area arrested and imprisoned after a peaceful protest against CPP senator Lao Meng Khin's Boeung Kak lake development project, which has forced around 3,000 families from their homes ${ }^{6}$. NGOs have also been

\footnotetext{
${ }^{4}$ World Bank, 2009. Cambodia. Linking Citizens and the State: An Assessment of civil society contributions to good governance in Cambodia. Phnom Penh: World Bank.

${ }^{5}$ ADHOC Land and Housing Rights report 2011-March 22, 2012

${ }^{6}$ International Federation for Human Rights (FIDH) - briefing Note, Mr. Surya Subedi, UN Special Rapporteur on the human rights situation in Cambodia, July 2012.
} 
affected, with NGO staff imprisoned and organizations threatened or even suspended from operating ${ }^{7}$. The draft Law on Associations and NGOs (LANGO) was released at the end of 2010 and is viewed by many civil society organizations as an attempt to limit space for independent civil society and freedom of association ${ }^{8}$.

Corruption further hampers democratic and transparent governance in Cambodia. The 2011 report of the US based Transparency International (TI) rates Cambodia as the 20th most corrupt nation in the world, ranking 164th out of 182 countries, putting it in the company of Guinea, Kyrgyzstan and Yemen, while neighbouring Laos and Thailand rank 154th and 80th respectively. Corruption has become "systemic," where people are habituated to bribery from the level of the street up to high levels of government and the service sector. Falsification of documents, embezzlement and nepotism are all commonplace. The executive director of Transparency International Cambodia (TI) notes that "beating corruption requires political will and a strong rule of law, without exceptions ${ }^{9}$.

\section{2. 2 Socio-Economic Situation}

Cambodia has been praised internationally for a theoretically-conceived rapid economic growth over the decade of the 2000s. Cambodia's Gross Domestic Product (GDP) is USD 15.25 billion with a population of 15.14 million in 2013.The country's economy relies primarily on agriculture, which is equal to 33 per cent of GDP employing 57 per cent of the country's labor force (World Bank, 2014). Annual GDP growth rate has fluctuated widely from five to 13 per cent in the 2000s. In 2008, GDP grew by 6.5 per cent, with agriculture, fisheries and forestry accounting for 32.4 per cent of GDP (World Bank, 2014). The contribution of industry to GDP has doubled since 1993, but a substantial proportion of the population is still dependent on the farming and fisheries sectors. Cambodia is vulnerable to floods and droughts, and these adversely affect these key sectors.

\footnotetext{
${ }^{7}$ In July 2011 the government suspended a local housing and land rights NGO for five months. While administrative oversight was cited as a rationale for the suspension, it is widely believed that the real reason was the organization's work on land rights abuses.

${ }^{8}$ Key issues of concern to civil society include ambiguity in terms of the law, complex mandatory registration and no safeguards to ensure that denials of registration or involuntary dissolutions are imposed objectively.

${ }^{9}$ http://khmerization.blogspot.com/2012/04/widespread-corruption-in-cambodia-now.html
} 
Along with the rapid economic growth, Cambodia has also been praised by development partners in its efforts towards poverty reduction. According to a new World Bank Poverty Assessment Report (2014), the poverty rate more than halved, from 53 per cent in 2004 to 20.5 per cent in 2011 thanks to increased rice prices and production. However, the report finds that Cambodia's "near-poor", those who live on less than $\$ 2.30$ per day person, may have escaped poverty but remain vulnerable to even the slightest economic shocks (World Bank, 2014).

"Despite impressive reduction in poverty, these hard won gains are fragile. Many people who have escaped poverty are still at high risk of falling back into poverty. For example, the loss of just 1,200 riel (about \$0.30) per day in income would throw an estimated three million Cambodians back into poverty, doubling the poverty rate to 40 per cent", said Neak Samsen, Poverty Analyst of the World Bank in Cambodia and the co-author of the Poverty Assessment Report.

Figure 2: Cambodia headcount poverty rate, 2004-2011

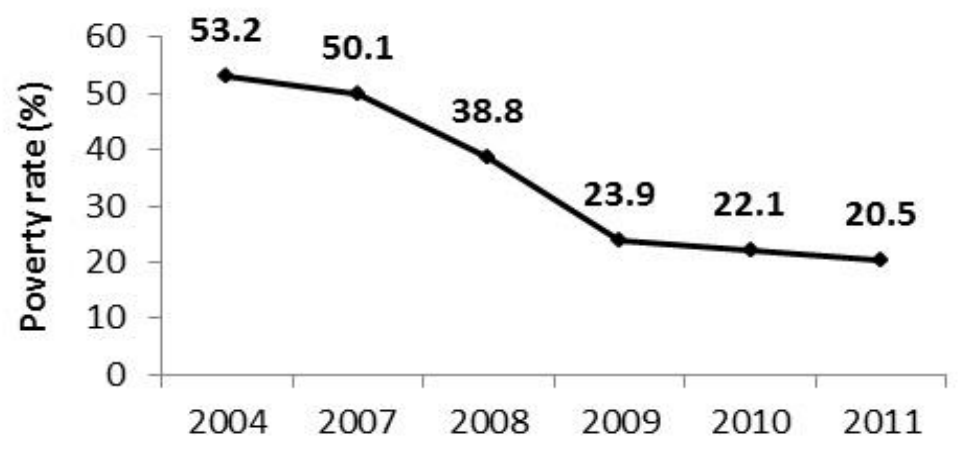

Source: World Bank, 2014 

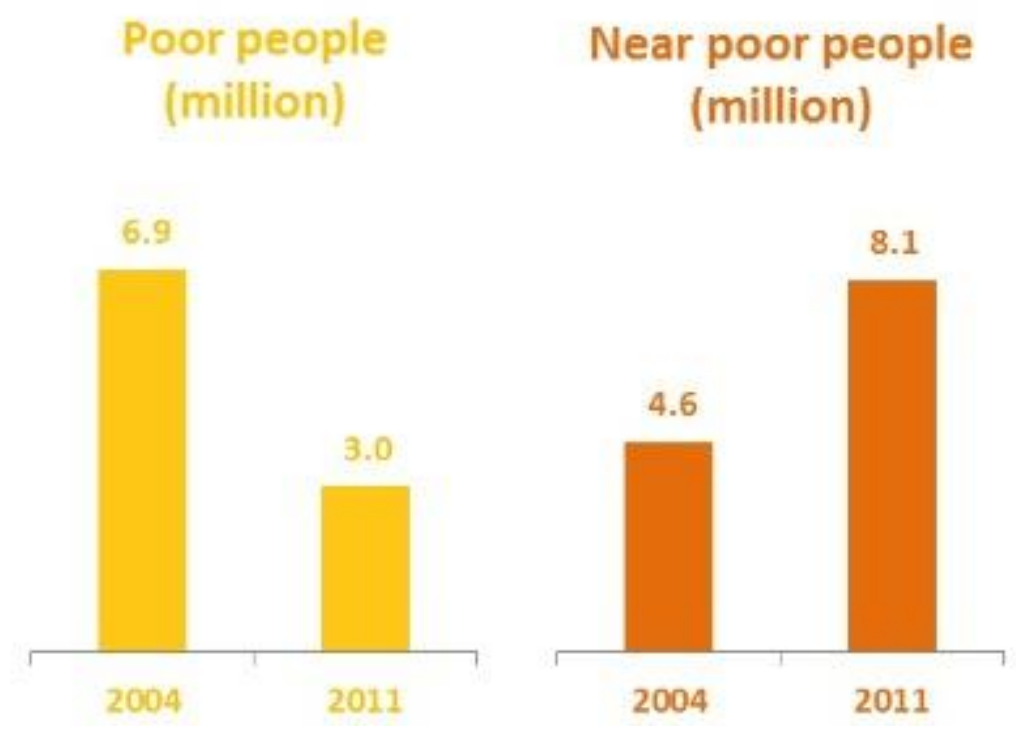

Source: World Bank, 2014

Cambodia's hope for improving its people's livelihoods is to integrate into the ASEAN Economic Community (AEC) in 2015. Cambodia does not seem ready to compete economically with other partners. Weak logistics have long hindered Cambodia's progress in trade potential and export costs are much higher than other neighbouring countries, Thailand and Vietnam. This makes it difficult for farmers and manufacturers to transport goods to markets. The exporters encounter challenges in supplying overseas customers and integration into regional production networks remains challenging (World Bank 2014).

Cambodia is a highly aid dependent country, with almost half of its annual budget sourced from multilateral and bilateral donors (World Bank, 2007). Aid disbursements have been on the increase over the past five years, from USD 555 million in 2005 to USD 1,075 million in 2010. Projections for 2011 and 2012 show that aid disbursements remain relatively stable ${ }^{10}$. New investments from emerging donors are increasing, as the economic crisis impacts on the funding abilities and priorities of the traditional OECD/DAC donors. China has become Cambodia's biggest source of direct foreign investment and is also the leading donor for the

${ }^{10}$ CRDB/CDC (2011). The Cambodia Development Effectiveness Report. Phnom Penh: RGC 
transportation and energy infrastructure sectors, disbursing an estimated USD 172.3 million in 2012, primarily in the form of loans.

Figure 4: Development partner disbursement in US millions

\begin{tabular}{|c|c|c|c|c|c|c|}
\hline & 2009 & 2010 & 2011 & 2012 & & 2013 \\
\hline & & & & USD & $\%$ & (est) \\
\hline UN (core) & 101.8 & 73.9 & 56.5 & 54.8 & 3.7 & 60.4 \\
\hline World Bank & 64.4 & 56.9 & 73.8 & 66.0 & 4.4 & 34.5 \\
\hline IMF & 0 & 0 & 0 & 0 & 0 & 0 \\
\hline ADB & 89.4 & 75.4 & 126.9 & 79.6 & 5.3 & 170.3 \\
\hline GAVI Alliance & 1.7 & 3.6 & 6.7 & 4.9 & 0.3 & 10.7 \\
\hline Global Fund & 46.5 & 61.2 & 60.2 & 15.1 & 1.0 & 41.4 \\
\hline UN \& multilateral & 299.7 & 271.0 & 324.1 & 220.4 & 14.8 & 317.3 \\
\hline $\mathrm{EC}$ & 49.4 & 32.9 & 61 & 42.1 & 2.8 & 52.7 \\
\hline Belgium & 4.8 & 2.2 & 2.1 & 0.1 & 0 & 0.4 \\
\hline Denmark & 13.8 & 15.7 & 5.7 & 4.9 & 0.3 & 0 \\
\hline Finland & 6.0 & 6.7 & 6.9 & 4.4 & 0.3 & 5.4 \\
\hline France & 25.4 & 22.4 & 19.5 & 24.2 & 1.6 & 16.6 \\
\hline Germany & 27.9 & 35.3 & 43.7 & 44.4 & 3.0 & 28.6 \\
\hline Ireland & 0.7 & 0.7 & 0.7 & 0.9 & 0.1 & 1.2 \\
\hline Netherlands & 0.7 & 1.1 & 0.1 & 0 & 0 & 0 \\
\hline Spain & 16.6 & 26.3 & 33.6 & 25.5 & 1.7 & 4.1 \\
\hline Sweden & 22.8 & 24.7 & 28.6 & 30.2 & 2.0 & 34.2 \\
\hline UK & 32.6 & 24.7 & 34.2 & 28.2 & 1.9 & 13.3 \\
\hline EU partners & 200.7 & 192.7 & 236.0 & 205.0 & 13.7 & 156.5 \\
\hline Australia & 47.8 & 63.4 & 78.2 & 79.6 & 5.3 & 63.5 \\
\hline Canada & 16.7 & 12.8 & 18.5 & 20.5 & 1.4 & 10.4 \\
\hline China & 114.7 & 154.1 & 332.0 & 460.7 & 30.9 & 414.4 \\
\hline Japan & 134.0 & 140.0 & 114.4 & 172.3 & 11.5 & 155.8 \\
\hline New Zealand & 2.3 & 5.2 & 4.4 & 3.8 & 0.3 & 3.4 \\
\hline Rep of Korea & 15.8 & 35.2 & 45.3 & 46.2 & 3.1 & 53.8 \\
\hline Switzerland & 3.0 & 3.1 & 4.5 & 4.3 & 0.3 & 7.7 \\
\hline USA & 56.9 & 63.3 & 64.4 & 74.6 & 5.0 & 70.3 \\
\hline Other bilateral & 391.3 & 477.2 & 661.7 & 861.9 & 57.7 & 779.2 \\
\hline NGO (own funds) & 108.5 & 165.0 & 198.8 & 206.9 & 13.9 & 209.3 \\
\hline TOTAL & $1,000.2$ & $1,105.8$ & $1,420.7$ & $1,494.1$ & 100 & $1,462.4$ \\
\hline
\end{tabular}

Source: Cambodia ODA database (March 2014)

In contrast to economic growth, the 2011 Human Development Report, Cambodia's Human Development Index (HDI) is 0.523, which gives the country a rank of 139 out of 187 countries with comparable data. The HDI of East Asia and the Pacific as a region increased from 0.428 in 1980 to 0.671 today, placing Cambodia below the 
regional average. Countries close to Cambodia in the 2011 HDI rank are Laos, ranked at 138 with an HDI of 0.524 and Vietnam ranked at 128, with an HDI of $0.593^{11}$.

\subsection{Cambodian NGOs and Development}

\section{3. 1 Overview of Cambodian NGO's Background}

In Cambodia, there are International Non-Government Organizations (INGOs), Local Non-Governmental Organisations (LNGOs) and Community-Based Organisations (CBOs). The latter two are usually Civil Society Organisations (CSOs) since they are founded by both local people and foreigners (Mansfield \& MacLeod, 2002). Sometimes the LNGOs have transformed from INGOs while the former developed originally as country-based but carry out their activities within Cambodia. In Cambodia, INGOs resumed their development activities after 1979 in the refugee camps along the Cambodian-Thai borders and inside the country by the Vietnamesesupported government (Chum, 2010). When the Cambodian political deadlock finished in 1979, a group of INGOs, a consortium for Cambodia, targeted some certain areas for development activities backed by the Cambodian Socialist Government (Minear \& Smith, 2007).

From 1991 to 2001 the INGOs involvement in Cambodia was limited (Chum, 2010). On the other hand, a large number of INGOs had been established before the national election of 1993 (ADB, 2011). The funds that they received from mostly bilateral and multilateral donors not only delivered services on a huge scale for reconstruction and infrastructure development, but were also given to the government for structural and institutional capacity building (Chum, 2010). These LNGOs were established before the 1992-1993 period of the United Nations Transitional Authority in Cambodia (UNTAC) (ADB, 2011) and the number of LNGOs rapidly increased to several hundred by 2000 (Downie \& Kingsbury, 2001; Landau, 2008). These LNGOs have a very strong relationship with INGOs or donor NGOs and are supported by the latter financially and technically through creating community development programmes and projects (Mansfield \& MacLeod, 2002).

These LNGOs do not seem to be powerful in local decision making as they are donor-driven and they tend to be more attuned to the needs of the powerful (Western

\footnotetext{
${ }^{11}$ UNDP, 2011. UN Human Development Report 2011. New York: UNDP.
} 
donor-driven NGO) rather than listening to the demands of the less powerful people and communities. Nevertheless, they work very closely with the grassroots of society and aim to contribute to Cambodian development in the fields of human rights, natural resource management (NRM), education, sanitation and health etc. Other types of CSOs are grassroots organisations or CBOs which are present in almost all villages of Cambodia as certain interest groups. They are endogenous to communities but reliant on outside support including from INGOs and LNGOs. The Royal Government of Cambodia (RGC) and development partners have recognized that CSOs have made a substantial contribution to development over two decades (ADB, 2011). For instance, World Vision Cambodia has expanded its community development programmes almost throughout the country to take part in poverty reduction.

\section{3. 2 Cambodian NGOs in Development Projects and Accountability}

A number of studies have been conducted into the various aspects of NGOs and CSOs in Cambodia's development framework. A significant body of study (Godfrey et al, 2000) indicates that CSOs might be important government partners to reforming and encouraging good governance in Cambodia. According to another study, the relationships between NGOs, grassroots organizations, donors and government should be partnership-focused and transparent to achieve downward accountability (Yukiko, 2000). In contrast, NGOs are likely to be close to the powerful but not always their constituencies in the development process. Therefore, an important consideration is how empowerment is exercised at the grassroots. Who is making the decisions regarding development?

Another study by Fforde \& Seidel (2010) also show that a lack of social accountability also tends to be found with Cambodia CSOs. Cambodia's LNGOs have become more influential in development since they receive a large amount of funds from donors and the Northern NGOs to carry out their activities. This means that they are more accountable to their donors (Mayhew, 2005) doing projects based on donors' mandates and priorities (Chum, 2010).

The relationship between donor NGOs from developed countries and Cambodia CSOs has become stronger in the past decade. The former usually put pressure on the RGC to respond to the needs and requests of the LNGOs. It is clear that CSOs are 
heavily reliant on their donors even though they do a good deal of approaching and accessing the grass roots. The grass roots level tends to be less active in decision making and advocacy work although people will do these aspects if told to do so. In this aspect, Wright (2012) explains that NGOs seems to play a role in raising some ideas for change at local levels whilst the power imbalance is at global level. This raises a concern that some Cambodian CSOs tend to be creating a power imbalance with community people, by working in a favour of donors (Frewer, 2013). But over the decades Cambodian NGOs have received significant support in terms of knowledge, technical and financing from donors in socio-economic development (ADB, 2011).

The LNGOs have not been very influential in aid coordination mechanisms as donors. Although the NGOs are part of the technical working group (TWG), which comprises the government body and donors, their implementation and advocacy role is not entirely clear in the aid coordination process (Greenhill, 2013). Another study also indicates that development projects, which focus on the land reform in Cambodia, are a donor playground. The donors usually set the agendas for the process of development whereas those agendas are sometimes contradictory to their constituencies (Fforde \& Seidel, 2010).

A study into the improvement of NGO accountability in Cambodia (Ngin, 2004) indicates that beneficiary participation can make NGOs more accountable. Ngin points out that the early involvement in development projects of beneficiaries can hold NGO accountable for partners, particularly its constituency. On the other hand, there is usually a limitation of circulating project information during project implementation to the beneficiaries. NGOs have often overlooked the importance of this matter and instead have often done projects that only favour their donors. Weiss, (2010) makes a suggestion that the involvement of actors such as individuals, communities and local NGOs can make the powerful donor accountable to the people it is working for. This is perhaps the crucial question: for whom does the NGO exist for?

\subsection{Cambodia and Climate Change}

Cambodia is highly vulnerable to the impacts of climate change and variability, due to the high dependence of its economy on climate-sensitive sectors, and the low 
adaptive capacity of its populations (Yusuf \& Francisco, 2009). Agriculture and water resources management are the most important sources of the economy, with 84 per cent of the population relying on agriculture for their livelihood. The country's agricultural production system is dependent on the annual flooding and recession of Tonle Sap Great Lake, and is therefore particularly sensitive to potential changes in local climate and monsoon regimes (D’Agostino \& Sovacool, 2011). Rural infrastructure including roads, water supply, and sanitation, suffers from the impacts of floods and cyclones. Weather and climate data are not easily accessible and monitoring sites are insufficient for effective early warning, meaning rural residents rely largely on word of mouth to ready themselves for floods and other extreme climate events. Cambodia's rural residents and critical basic infrastructure remain vulnerable to regular and costly weather shocks that undermine growth and development.

\section{Figure 5: Climate change vulnerability}

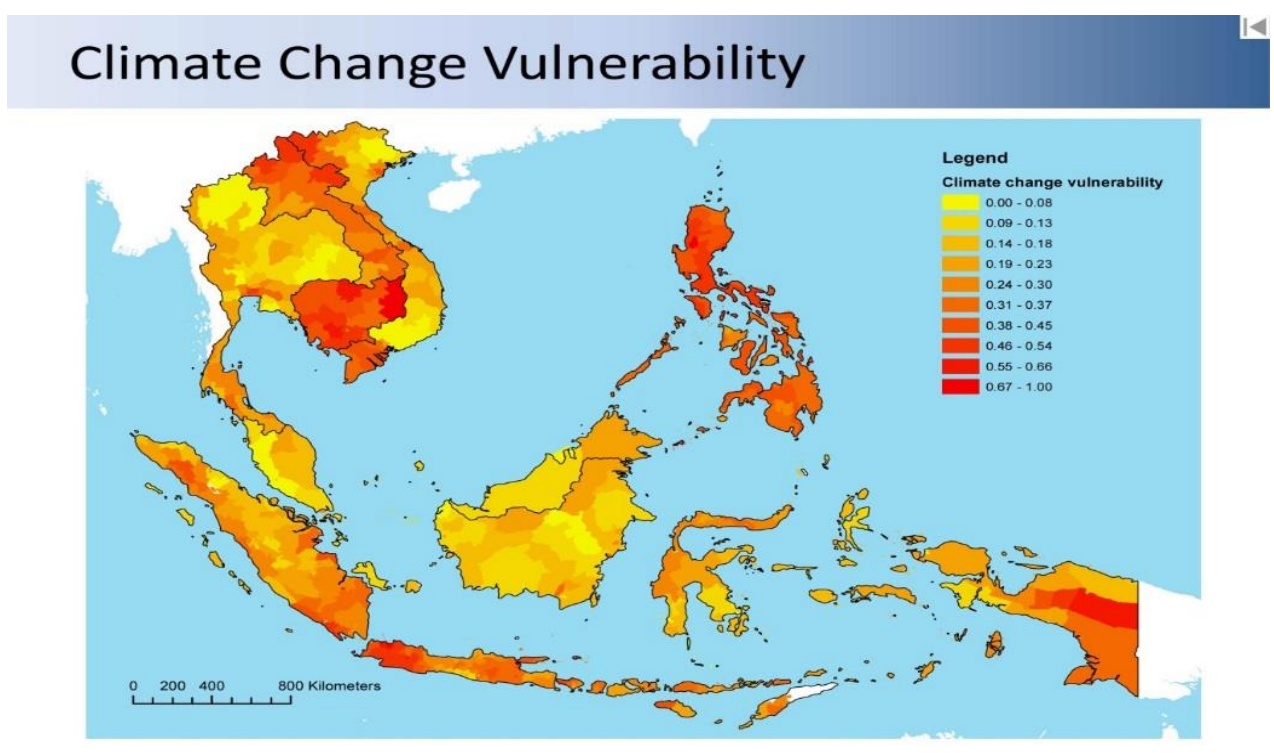

Source: Yusuf \& Francisco (2009)

Cambodia is one of the countries chosen for the Asian Development Bank's Pilot Program for Climate Resilience (PPCR), which aim to integrate climate effects and risks into development planning (ADB, 2012). The program is supported by the World Bank and Asian Development Bank (ADB) Group. The RGC has established 
the Strategic Program for Climate Resilience (SPCR) which encompasses seven investment projects with proposed technical assistance from donors. Even though it is ranked as the lowest adaptive country to climate change (Yusuf \& Francisco, 2009) and relies heavily on climate sensitive sectors such as water resources and agriculture, Cambodia has demonstrated a strong commitment to address climate change after ratifying the United Nations Framework Convention on Climate Change (UNFCCC) in 1995 and the Kyoto Protocol in 2003 (Am et al, 2013). Cambodia has developed some policies, legislation and plans since 2001 to address climate change adaptation, disaster management and other development issues but coherent and detailed adaptation policy and framework is not explicitly included in national strategies and plans (Lian \& Bhullar, 2011).

The Ministry of Environment of RGC established the National Committee on Climate Change (NCCC) in 2006, consisting of high-level representatives from twenty ministries presided over by the Prime Minister since 2009. The committee completed the National Adaptation Program of Action (NAPA) in late 2006 which included thirty nine priority adaptation projects in sectors such as agriculture, water resources, coastal zone management and human health (ADB, 2012). Furthermore, the government launched the Strategic National Action Plan (SNAP) for Disaster Risk Reduction (DRR) which also covers climate change adaptation within the time frame 2008-2013.

There is a clear structure of DRR and climate change adaptation and mitigation activities in Cambodia and those institutions are coordinated and managed through four main bodies: a) the National Committee for Disaster Management (NCDM), b) Climate Change Department (CCD), c) Designated National Authority (DNA) for the Clean Development Mechanism (CDM) and d) the National Climate Change Committee (NCCC). The management roles function through several relevant ministries in the country and support departments. Each ministry is also supported by the national and international NGOs, UN bodies and external development partners. These institutional bodies are primarily involved in the governance of climate change adaptation, mitigation and disaster risk managerment activities in Cambodia (Ahmed, 2010). 
Some studies have proved that the effects on Cambodia from climate change will increasingly result in extreme weather such as heavy storms, heat waves, droughts and floods. According to the government's report (ADB, 2012), an estimate of the 2011 flood cost Cambodia US\$451 million in damage and \$174 million in loses. There have been concerns that severe damage to rice harvests and other infrastructure may markedly increase due to the changing climate.

A study by Khim and Phearanich (2012) assert that Cambodia is recognized as the most disaster prone country in Asia, having been severely affected by natural disasters such droughts and floods virtually every two years over the last decade. It is anticipated that Cambodia will face many problems due to sea level rises, which can make some areas vulnerable to floods, salinization and coastal inundation with adverse implications for food and water security, and infrastructure stability (ADB, 2012) and this consequence may also lead to human health impacts (Khim \& Phearanich, 2012). These expected risks have encouraged all key relevant stakeholders to be involved in reducing climate change impacts which is compliant with adaptation strategies. In Cambodia, NGOs are among the key stakeholders to have a joint commitment with government and other donor agencies in climate change adaptation and mitigation (Schaffer \& Ding, 2012).

\subsection{Conclusion}

Cambodia has experienced rapid economic growth over the last decade thanks to the efforts of the government, development partners and NGOs. But the country is still dominated by a continued political system plagued with nepotism and patronage that dominates and obstructs progress. This contributes to corruption that hampers the development progress at all levels. Cambodia's NGOs have an important role in poverty reduction and development. The contributions of NGOs to Cambodian socioeconomic development is significant. Many projects operated by NGOs are helping poor Cambodians to improve their livelihoods and escape poverty. However, some NGOs that work in the human rights sector and advocacy are still perceived by the government as opposition groups so there is suspicion of their intent. In addition, Cambodia is vulnerable to climate hazards and events, particularly floods. This creates obstacles for economic growth. The loss of economic value has been huge from floods and the country does not have adaptive capacity to cope with future 
climate change, both financially and technologically. Climate change policies are not yet fully developed to be comprehensive and, coupled with ineffective implementation of relevant institutions, a poor planning situation has emerged. This has provided NGOs a unique position in planning for various scenarios in climate actions. They have joined the commitment to the government in climate change adaptation and mitigation, hoping to improve local livelihoods. 


\section{Chapter Five: NGO Accountability and Partnership in Climate Change Projects}

\section{1 Introduction}

This chapter details the findings that came from the data collected to answer the research questions. It discusses several complexities and provides some thoughts with regards to NGO accountability and partnership, particularly in climate change projects in Cambodia. The findings are based on the field interviews. What is clear is how important NGO accountability and partnership are in project implementation in climate change work in Cambodia. The chapter details some key factors that enforce the accountability of NGOs and describe how partnership climate change projects are implemented.

NGO accountability is important in ensuring the effectiveness of NGO's performance in climate change project implementation as well as its crucial role in the overall development framework of a country. Partnership is a synergic approach considered to be significant for NGOs to enhance their accountability in climate change actions. In light of rights-based approaches in development, NGOs as a nonstate actor, have power and rights that can enable them to hold the government accountable and make sure that the government fulfills its responsibilities in development work. The following sections discuss the findings concerning these issues, with evidence from the participants.

\section{2 NGO accountability and Cambodian NGOs}

Accountability is important for organisations in development work because it encapsulates overall values, principles and the reputation of the organisations. With appropriate accountability organisations can achieve a great deal of benefits to beneficiaries they are serving and give credit to NGO's performance in development activities (Edward \& Hulme, 1996; Jordan \& Van Tuijl, 2000; Namja, 1996 and Unerman \& O'Dwyer, 2006). In this context, the accountability is meant to be a full responsibility of the NGO in a project's operation that maintains positive impacts on local communities.

In maximising the impacts, the accountability of NGOs is affected by organisational policies, donor support and local participation. Lloyd explains that NGOs may have 
greater accountability if they have proper organisational policies and management standard (Lloyd, 2005). One NGO official explained:

"As an NGO, we are accountable to our donors that provide funds, our organisation and beneficiaries. We have to make sure that every single USD is efficiently and effectively spent and reached people.We have to ensure transparency in project implementation” (KII, 08).

\subsubsection{Organisational policies and regulations}

All activities must be transparent so that the process of project implementation will be smooth. Wenar (2006) asserts that accountable people of an organisation should demonstrate that is up to them to build a transparent image for their organisation. The involvement of stakeholders is important because it should result in good performance in service deliveries to the poor (Brett, 2010).

NGOs basically establish regulations, policies and codes of conduct in organisational management to ensure that all levels of staff are accountable to their beneficiaries and donors. This is demonstrated by the fact that all operations of the organisation are compliant with those established regulations. The study found that directors and the organisational management team are responsible to the board of directors and donors who observe the NGO's activities. These people are key to ensuring the good performance of the NGO. They are in charge of leading, coordinating and managing and facilitating the main activities as well as decision making. These people take part in encouraging and assuring transparency in project implementation at ground level is based on the established policies and regulations as mentioned above. Likewise, project staff are also responsible for the organisation of individuals and their activities during project implementation.

"For development projects, the significant impacts on local people are associated with good performance of NGOs that serve them. That is why NGOs try to establish policies and precedures in order to guide and lead the organisation's operation" (KII, 6). 


\subsubsection{Donor impositions}

Donors that provide funds to NGOs in Cambodia also play an important role to guarantee NGO accountability. The donors usually put more pressure on NGOs to ensure that funds are efficiently spent with tangible results. The study discovered that some donors require project evaluation and auditing to be conducted by external consultants as they do not trust internal consultants. Some donors are very strict about financial matters. This implies that to some extent donors might not trust internal policies or consultants. These requirements are critical for the fund-recipient NGOs in their project operation. Donors usually provide other support such as capacity building, project management and budgeting etc. Ultimately, they have to perform better to provide services to their beneficiaries, according to their donors. An interviewee explained:

\section{"Personally, we should be thankful to donors that provide funds and supports for our projects. What donors want is to achieve project goals. So we should follow their requirements, it is not as hard as swimming across a river" (KII, 09).}

Based on the interviews, I found that in project implementation, staff have to be involved in document preparations to comply with the policies in order to proceed with the activities and they need to arrange documents again when finishing the activities to settle the spending over the activities. This is time-consuming and frustrates front-line staff to focus on such details and paperwork as it means they spend less time with the beneficiaries. Essentially, the paperwork must be done to ensure transparency and avoid fraud or mis-spending of funds. It is important that the practice of those policies is tranparent, responsive and no corruption is present (Wennar, 2006). In addition, all actions involve all key stakeholders, particularly local communities and governments (Schedler, 1999).

With regard to fund negotiations between Cambodian LNGOs and their donors ${ }^{12}$ the study found that decisions are mutually made. Contradictions or disagreements on fund disbursement are rare during this process. Usually, local needs and donor's

\footnotetext{
${ }^{12}$ The donors might be large international organisations, such as a UN agency and other development agencies.
} 
priorities are normally consistent with each other. This is due to the fact that Cambodian people are dependent largely on agriculture and natural resources, so there are large donors, INGOs and LNGOs focusing on these sectors in their development operation plans.

"We assess the local needs and then incorporate those needs in our strategic planning. In fund negotiation we usually find that donor's priorities and organisation's strategies have consistency. Therefore, there have been no contraditions when we propose the fund package. The problem is do we have capacity to write a good quality proposal or not?" (KII, 02).

\subsubsection{NGO accountability and local participation}

Despite the fact that local impacts are due to strong NGO accountability, local government participation and cooperation in project implementation has been counted as a crucial factor in the success of NGO projects in Cambodia. Local governments have to take lead role in development work because they are the guardians of the local people. The NGO's role is seen as filling any gaps overlooked by the government.

"The government is the implementer and NGOs are the facilitators. We just have funds to initiate development project and we need the government officials to participate in the projects" (KII, 12).

But NGO staff must be a good model for local authorities and communities to learn and follow. They must have the capacity to facilitate and mobilise relevant stakeholders to participate in using local resources as much as possible. An interviewee provided a simple explanation that all parties including everyone in the whole organisation, community people and local authorites are important for the accountability of an NGO as this is significant for project results.

"We can achieve results based on mutual cooperation and participation from local authorities. It is a regret if they do not participate because they are the ones who are mainly responsible 
for communities. We, organisations, only want communities getting advantages from projects, and try to convince them to join us" (KII, 1).

The relationship between project staff and local authorities is important. The accountability of NGOs is proved with the results they produce for community. Nevertheless, the results are based on a high degree of local authorities' cooperation in project implementation. The cooperation of local authorities determines positive impacts for communities in project implementation in Cambodia. "Local authorities are key partners in project implementation and we always need local authorities as partners" (KII, 1). The cooperation and participation should be included from the beginning to the end of the project cycle.

Ngin (2004) stresses that the more beneficiaries participate in the projects in Cambodia the more NGOs become accountable to them. However, the project's beneficiaries are usually the groups who are likely to not be able to hold NGOs accountable in project implementation (Ahmed and Potter, 2006). Furthermore, the level of accountability in the organisations is obviously different due to different political and economic situations ${ }^{13}$, therefore local government cooperation is critically important in NGO project implementation and this cooperation is a key to a project's success.

On the other hand, there are many frustrations in project implementation at the grass roots level. These challenges vary greatly in different areas where NGOs are doing projects. Some people are interested in the development activities of NGOs and get involved and actively participate. Nevertheless, the projects are known to be not interesting to some interest groups of different areas because they do not understand what the projects will offer to them. This can lead to a central issue in project implementation as the expected outcomes are not fully achieved. Also, the difference in behaviour of local authorities and people is geographically different. Some are

\footnotetext{
${ }^{13}$ NGOs are usually considered and called by the government as 'the groups against the government'. The reason is that NGO projects are about community empowerment and advocacy that allow local people, who are affected by the government's decision, to protest and claim their rights from the government. However, some NGOs that work on other sectors including health improvement, education and agriculture are not usually in the same list. They are on good working terms with the government.
} 
very active, while others do not welcome NGO's projects. It is also common that some local authorities are unhappy about participating in the project activities since they assume that they will only benefit a little. "However, there are some not happy because they have no advantage or get only a little from the project implementation" $(K I I, 1)$.

However, organisations may not have the choice to put the projects in the target areas in Cambodia if the local authories do not agree in the place they are occupying. There are so many rural areas where the people are in need of development projects. "If the authorities do not participate, we can have other choices to work and implement the projects elsewhere" (KII, 1).

Brett (2010) asserts that participation from stakeholders in all processes in development is important because those people are making decision and choices that meet their needs. Therefore, each NGO should address the participation of stakeholders, particularly the beneficiaries to be involved in the project process.

\section{3 Cambodian NGO partnerships and project implementation}

Partnership is a strategic approach of international donors, inter-governmental organisations and INGOs to guarantee their legitimacy (Szporluk, 2009). It can, however, create a power imbalance between partners (Johnson \& Wilson, 2006) and NGOs can implement the projects based on donor's priorities and demands (Chum, 2010). Thus partnership needs to be authentic to ensure that development objectives are achieved (Hoksbergen, 2005). The partnership should apply to all NGOs that work on sensitive issues such as human rights, land and natural resource management and advocacy. NGOs can establish networks which are grounded in joint commitment, shared responsibility and long-term interaction to accomplish the goals (Fowler, 1998). The notion of NGO partnership has risen to prominence and is linked directly to bridge-building and capacity building between North and South NGOs (Fowler, 1998) and it intends to tailor development to local needs and leverage development expertise and resources so that the South NGOs could improve their capacity and empower local resources to serve their constituencies through capacity frameworks and guidelines agreed with the Northern NGOs (Postma, 1994). Therefore, the partnership, unlike participation, is a concept that focuses on the 
relations between donors and receivers in the aid framework for development (Baaz, 2005). In Cambodia, NGO partnership is important, particularly in the projects that are about sensitive issues because most NGOs usually endure threats from the authorities.

The research participants had different views on NGO partnership. The partnership for project implementation is a potential approach to succeed in development work for NGOs in Cambodia. It is believed that the partnership can apparently prove NGOs more accountable to their beneficiaries. NGOs now view partnership as a significant method to ensure that the flow of service delivery and development address accountability, transparency and good performance. Some NGOs call partnership 'beyond cooperation' and it is more important for project enumeration because many actors will be involved in development activities. From the data collection, I noticed five themes around which the partnerships raised concerns regarding partnership. They are discussed as follow:

\section{Stronger voices in development}

The NGO partnership on the ground gives a broad picture of a stronger development voice and a view of participatory development. The NGOs can help and support each other not only in co-financing and other technical supports but also in policy advocacy when they establish networks or coalitions to take comments and inputs from the local to the central government in the process of regulation and policy formulation. In addition, they are able to participate in project management and reflection so that they can share knowledge and experience together. The more they have learnt, the more success is likely to be in project implementation. Nevertheless, inequality in relationships is significant. Power is always dominated by large and financially capable NGOs, and they usually set agendas and requirements for their partners to follow (Johnson \& Wilson, 2006). This impostion can dilute the strengths and commitment of smaller partner NGOs that work on the ground, particularly in decision making with regard to project implementation.

Despite the fact that unequal power exists in partnership, the interviewed respondents mostly credit partnerships but also raise some concerns and challenges. There are both positive and negative points for them when working as partners in project 
implementation. The project results are significant, effective and efficient when NGOs work together in development. Some NGOs embrace partnership as a core principle in development work.

"Our organisation has a philosophy to work and take partners with other stakeholders, particularly like-minded NGOs to implement projects and we want significant impacts and it is how we learn from each other in the processes of coaching, mentoring and training to our partners" (KII, 4).

\section{Strategies used by large NGOs and donors}

Some controversial views were discovered among the participants regarding NGO partnerships in Cambodia. Partnership is seen as a very complicated network or coalition of NGOs in development. Sometimes, it is seen as a tool used by large NGOs and donors to take advantage over small local NGOs or CBOs in development agenda (Lewis, 1998). Concerning this, transnational NGOs take up partnership with local NGOs as they offer grants with other conditions of capacity development and technical supports to operate projects in target areas whereas the latter need funds to continue the operation. This leads to a question of who or what the partnership is for when those large international organisations already have their projects at full capacity? From my experience, it is even more of a surprise when local and INGOs receive donations from large donors and other international organisations, and they disperse differing amount of money to LNGOs or CBOs that are based at the grass roots to implement projects.

I was really keen to know about this when interviewing the research participants. The majority of the respondents provided reasons that the grass roots NGOs know clearly about the social context in their areas and it is easy to work through those partners because they have developed a good relationship with local authorities already. An INGO representative explained that:

"We provide capacity building and other technical supports and bring essential information to the local level. Therefore, most inputs achieved are from the grass roots-located NGO" (KII, 7). 
This shows that partnership is a provision of an array of mutual benefits in development work exercised by NGOs. Taking partnership with grass roots-based NGOs might help form a foundational pathway for sunstainability ${ }^{14}$ and community ownership. This is due to the fact that those NGOs have a strong relationship and firm ideology which strongly represent the local people. They are formed and established because of local demands and initiatives so when their international or non-local partners withdraw, significant resources ${ }^{15}$ are left over for them to persist with development activities at the local level.

"We work with other NGOs that are based at local target areas because we want sustainability when the project is completed and the partners will continue their activities as they are already equipped with knowledge and skills" (KII, 13).

\section{Protect the risks and threats}

Adding to the views mentioned above, NGO partnership does not only give a strong voice in development but also it is a shield to protect NGOs from risks or threats. Unfortunately Cambodia is a country in which democracy and rule of law are not fully upheld and practised. An example was provided by a respondent that a NGO received warning of their office closing from the government of Cambodia. She explained that all partnership members and networks participated in making a joint statement requesting the government not to close that NGO's office. Furthermore, the partners also sought legal support from NGOs that specialise in legality and human rights for help then reported to donors and embassies to put pressure on the government. In the end, the government agreed with the proposal and did not close the office. With this situation, NGO partnership is vital and a NGO cannot stay alone in development activities. Partnering with other NGOs could have more influence and capability of lobbying and changing the behaviour of the government. When asking one respondent how important partnership is for NGOs, she replied that:

\footnotetext{
${ }^{14}$ Some NGOs that only have a partnership with the government add that there needs to be financing sustainability to continue their activities which might be operated by the government as there are implementation roadmaps and guidelines left over after the projects withdrawal. (confusing)

${ }^{15}$ The significant resources are knowledge, skills and technical staff which are provided by the partner NGOs while implementing the projects. These resources are critical to local NGOs and people to continue their activities at grass roots level.
} 
"It is important. We cannot stay alone, particularly when we work on human rights projects and we can have high risk if there is no partner. Therefore we need partners to help and support each other" (KII, 9).

\title{
4. Advantages of partnership for project implementation
}

There are a lot of advantages for NGOs in working with other partners on the ground. The partnership may constitute of multiple purposes with respect to project operation and local impacts. It can significantly enhance work quality and results more effectively and efficiently. The NGOs can share responsibilities and expertise in working in most areas and reduce costs. In practice NGO partnership can share visions, values and themes which overall contribute to the same common development objectives and goals. Concerning the development goals and objectives, their activities are complementary and fill gaps to contribute to the same objective ultimately. In the meantime, they can share different skills, experiences and expertise in the operation of projects. A respondent explained:

\begin{abstract}
"NGOs whose expertise and skills are livelihood improvement can complement the other NGOs that specialise in biodiversity conservation and natural resource management (NRM), thus enabling them to enhance results and work faster in partnership projects and learn from each other" (KII, 05).
\end{abstract}

The alternative benefit of partnership is mutual help with regard to problem solving. Working alone to implement projects can be alienating for every NGO. There might be a variety of challenges in the project operation. With this regard, the partners can support, fund and provide human resource development in terms of sharing costs and training if their partner lacks funds or human resources. Furthermore, when other technical problems accidentally happen during the implementation, they can pool resources to share ideas and find solutions together. This would be more effective than working alone to confront the technical problems. Sometimes, the process of problem solving to provide a substantial contribution to enhance knowledge among project staffs is because they can learn by doing together as this respondent stated: 
"I think partnership is a learning process. We can share with and learn from partners and encourage them to share lessons learnt and hands-on expereiences in the purpose of learning together and we cannot stay alone and we give feedback to each other in project exercise" (KII,9).

In addition, working in partnership can make NGOs easier to pull funding from donors. The results of project may be even more effective and efficient.

\section{Information sharing and communication}

From another point of view on the importance of partnership is information sharing and communication. The basic idea comes with the fact that information sharing and communication play a vital role to the project operation in development. When partnering with other NGOs, there is a diverse information disclosed so that all NGOs can update the information on time and reduce risk in project implementation ${ }^{16}$. They can predict risks and measure the feasibility of project success in the project target areas and even take action over the challenges very quickly.
"Partnership between NGOs that are based at the national and grass roots level can have a distinct advantage in information communication and sharing. The city-located partner NGOs can receive information about development-related issues ${ }^{17}$ faster and have capacity to facilitate, coordinate and bring the information to the local while the other grass roots-located partner NGOs might bring a unique knowledge about social context at community level" (KII, 04).

\footnotetext{
${ }^{16}$ In Cambodia, even though people are entitled to express and share information freely, the information which is related to development is not widely known to the people. This is demonstrate by the fact that most Cambodians are not well educated and another reason is due to the intent of the government.

${ }^{17}$ The issues might be related to policy and regulation change and formulation by the government and the NGOs that are situated in the capital city play an important role to coordinate and communicate information in Cambodia as they have to network to work on this issue.
} 


\title{
5. 4 The emergence of NGO climate change projects
}

NGO partnerships in climate change projects are formed and acknowledged as a synergic approach to cope with the climate change issue in Cambodia. The issue is known, informed and addressed by all sectors through means of awareness raising and information coordination by key relevant development stakeholders. NGOs are also included and act as active players to bring about knowledge and skills to local people to cope with climate change risks and impacts. Moreover, most NGOs that work in this sector have provided invaluable insights and inputs for policy development that fit into the local needs and social compliance. A respondent said:

\begin{abstract}
“Even though NGO's activities do not cover all related sectors and work in most vulnerable areas affected by climate change in Cambodia, they have done so well in Takeo province recently and accomplished a lot of results in their target areas. They usually work with other NGO partners at the ground by engaging with other key stakeholders in project implementation. They actively participated in pond digging for water storage” (KII, 1).
\end{abstract}

In Cambodia, the climate change issue has become remarkably and increasingly noticed by NGOs from 2010. From that time, many climate change projects were implemented and have become popular and attractive in development frameworks among NGOs because they can attract large amount of funds from various sources for project operation.However, 2010 was not the only time when NGOs in Cambodia started focusing on climate change because some NGOs had already put climate change issues in their mission and strategic plans before that year. Due to a lack of funding support, they worked on other issues that were higher priorities in their organisation' missions and visions.

Following that period, this issue is getting more crucial in project exercises as the impact of climate change is getting worse and it has negative effects on development results and efforts in other sectors. Therefore, there has been an influx of NGOs that work primarily on other sectors such as education, youth development and women's empowerment etc, starting to concentrate on climate change for their project operation. The organisations start the projects with climate change awareness and 
involve their main beneficiaries in the implementation. For example, the organisations that work on youth empowerment engage youth and link them to climate change action awareness at local level and policy advocacy. The youth are usually trained and provided with training first. There are several underlying reasons that show the interest of NGOs towards climate change issues according to answers provided by most research participants. They explained that:

\begin{abstract}
"Firstly, climate change is global and its impacts have already been sited and reached out the local and vulnernable people, particularly in developing countries, and the world is addressing and fighting. Secondly, it is a cross-cutting issue so the issue has to be addressed. This is illustrated by the fact that if our NGO's projects were undertaken without realising and addressing climate change impacts, the projects might fail and the implementation is not successful" (KII, 8).
\end{abstract}

Another reason is government-led policy change. As natural disasters including floods and droughts had caused a huge loss of benefits to citizens and the country's economy, the government of Cambodia started realising that the effects were due to climate change. Therefore, the government began establishing some relevant regulations and policies to reduce and mitigate the risks which are caused by climate change. However, when interviewing the research participants, the majority did not seem aware of any policy change but they addressed other reasons and they just replied that they knew some but were not sure about policies.

Finally, the funding opportunity for climate change projects was highlighted as the other reason NGOs were interested in partnership. Most NGOs in Cambodia implement climate change projects because they can attract large amount of funds from donors to support their operation. It is the nature of NGOs being flexible to funding trends for development due to relying entirely on external fundings that are channelled through international organisations (Lister, 1998) Therefore, the reasons may even rest on the fact that they want to address this cross-cutting issue as it might cause failure of their other existing projects. 


\section{5 Different NGOs working in climate change projects}

As the climate change issue has become popular and a good opportunity for funding, many NGOs have incorportated this issue into strategic plans to run climate change projects. Other NGOs that work on completely different sectors for development try to adjust their projects to be related to climate change sector while the other NGOs already have it in their objectives and missions. Climate change is a cross-cutting issue that require all types of development actors to pay close attention. Those NGOs that now implement climate change projects are both international and local regardless of scope and scale of the organisations and projects.

The capacity of these NGOs is different according the scope and expertise of the organisations. Most projects are about climate change adaptation and mitigation ${ }^{18}$. As mentioned above, the projects are mostly established and implemented based on existing projects of the organisations in which projects are adapted or linked to climate change, particulary in the agricultural and forestry sectors, biodiversity conservation and natural resource management (NRM).

\section{a. The environment sector}

NGOs working on the sustainable use of natural resources, biodiversity conservation, environmental education and forest protection are now doing climate change projects in Cambodia. According to the interviews, overall, most NGO objectives are about promoting rural livelihood and sustainable development. They usually introduce and integrate the concept of climate change into their NRM projects ${ }^{19}$ such as community forestry $(\mathrm{CF})$ and community protected areas (CPA). They target the places which are identified as protected areas by the government. The projects assist in establishing law-abiding CFs and CPAs to protect forests and biodiversity and provide training about the concept of climate change to local people. Then they manage these legally recognised areas by themselves by integrating activities including furit tree planting, local non-timber forest product (NTFP) enterpreneurship, community eco-tourism etc. The protected forests are believed to

\footnotetext{
${ }^{18}$ The mitigation projects are believed to be involved in forest protection and conservation. ${ }^{19}$ NRM projects are very popular for NGOs as the funds are largely available and the projects might be involved in community forestry and fishery and eco-tourism, which is under forestry administration coordinated bythe Ministry of Agriculture while community protected area projects are under the coordination of the Ministry of Environment.
} 
have the potential capacity to stock significant amounts of carbon dioxide $\left(\mathrm{CO}_{2}\right)$ to reduce global warming.

\section{b. The agriculture sector}

In the agricultural sector, many NGOs implement climate resilience agriculture projects. They integrate climate resilience into the existing projects of the organisations and the activities of the projects often with climate change awareness and training which address its causes and consequences. Then they teach local farmers about the adaptation techniques, particularly in the agricultural sector, to help them resist major climate events including droughts and floods. These methods can reduce the risks of climate change and help improve local livelihoods. The techniques include climate-resistant crops and seed selection, watering systems (drip) in vegetable planting and pond digging in the dry season. For example, the Cambodian Centre for Study and Development in Agriculture (CEDAC) and Farmer Livelihood Development (FLD) are implementing projects that aim to improve agriculture resilience and adaptation to climate change. Additionally, the projects also work to improve community financial capital. Some NGOs have broader objectives to promote food security. The projects provide funds and work with other key stakeholders to develop water stock or irrigation reconstruction so that people can have water for daily use and farming purposes.

Some NGOs which work on local governance, youth development and gender empowerment also have climate change awareness and mainstreaming projects. They focus on the activities of mainstreaming climate change in gender and youth perspectives and education for school kids. They integrate climate change into local development plans, particularly commune investment programmes (CIP). These projects usually involve many activities of improving knowledge and promoting awareness of climate change to local people and authorities. Furthermore, the activities might involve some emergency response to floods with local government ${ }^{20}$. Therefore, climate change awareness is widely spread across some sectors in development. This is encouraging and promotes awareness to all relevant stakeholders to focus on the issue.

\footnotetext{
${ }^{20}$ At the sub-national level there are disaster management committees holding responsibilities for emergency responses to climate events. They are the main actors who intervene in emergency work with other stakeholders, particularly NGOs.
} 


\section{c. Policy advocacy and communication}

Climate change policy monitoring and advocacy projects are also implemented by some NGOs in Cambodia. The activities monitor the progress of climate change policy, draft guidelines and regulations and provide some valuable inputs and insights for policy formulation. They work closely with other NGO partners and networks to bring common concerns from grassroots level to policy makers and ensure that concerns and voices are heard and reflected in policy framework. They use evidence-based approaches, best practices and case studies and documents learned from local communities then take them to policy makers for a bridge to policy development. The NGO Forum on Cambodia is the organisation that work to coordinate civil society organisation network members involved in climate change policy development. The voices and concerns of local people are brought to policy makers through this network.

Even though there are many climate change projects implemented by NGOs in Cambodia, the projects do not cover all affected areas. This is due to the fact that funds that local NGOs receive from donors are limited and most projects are not long-term. The NGOs can only contribute to climate change awareness depending on available funds and their capacity. There have not been any climate change projects implemented by NGOs that focus on health issues to date, though the issues are somehow mentioned in the other projects ${ }^{21}$. A large number of the projects are about awareness and mainstreaming of climate change to the development process and all NGO climate change projects are funded by donors including United Nations Development Program (UNDP), international organisations and other development agencies. Besides financial support, they even provide capacity building and other technical supports.

\section{6. NGO partnerships in climate change projects}

Partnership in project implementation is an effective approach undertaken by most Cambodian NGOs that work in the climate change sector. The majority of NGOs believe that partnership can enhance the project results and impacts significantly, effectively and efficiently, which can reach end beneficiaries (Fowler, 1998;

\footnotetext{
${ }^{21}$ In climate change awareness of some projects, health problems are mentioned as they are also caused by climate change, but not in detail.
} 
Hoksbergen, 2005 and Postma, 1994). Furthermore, partnership takes the moment of complementing cooperation development and sharing common voices to accomplish development objectives and goals as mentioned above.

In climate change projects, there are two basic forms of NGO partnership in Cambodia. Firstly, the partnership takes place when large donors, for instance the UNDP, European Union (EU) and other development agencies provide funds or grant packages to some $\mathrm{NGOs}^{22}$ that have enough organisational capacity to implement the projects. Secondly, the partnership happens when those funded NGOs continue to provide sub grants plus other technical supports to the other smaller $\mathrm{NGOs}^{23}$ which work closely with local people.

NGO partnerships in climate change projects are required by donors. This is quite similar to what Szporluk (2009) says. The donors are very influential and dominant in development agenda so when they fund NGO projects in terms of grant package or co-funding in climate change projects, they set requirements and guidelines for their grantees to follow, particularly in financial management and project operation ${ }^{24}$. Szporluk (2009) and Baaz (2005) prove as mentioned in the literature review. The fact is that NGOs entirely depend on external funding support for project operation and at least they can do development activities to serve the local people. So they have to accept the donor's guidelines and principles. For instance, some donors require their grantees to accept formats of their financial and progressive reports and periodically submit reports according to an agreed timeframe. Usually the funded NGOs have to comply with their demands and needs to get funds for project operation. But in some cases there are some spaces for the NGOs to have some compromise with their donors.

"They sometimes give recommendations and comments to donors about how the projects would respond and meet the local needs

\footnotetext{
${ }^{22}$ The NGOs are both local and international but they are assumed to be full of capacity or expertise in the field in climate change. They are usually more capable of obtaining large amounts of funds from big donors and also have some projects at the ground level.

${ }^{23}$ They mostly implement projects and base their offices at grass roots. Most are local NGOs or CBOs.

${ }^{24}$ The financial management is budget spending, financial reporting and auditing whereas the project operation is related to project results, monitoring and evaluation etc.
} 
and make some changes in report formats because some NGOs find it difficult and are unfamiliar with the new formats. Therefore, some guidelines are compromised and adjusted. But this is not a big deal when most financial and progressive report formats look fundamentally and literally similar and the project/programme staffs can be used to it quickly" (KII, 03).

The fact is that the donors require their grantees to make partnership with other NGOs, which are primarily located and implement projects at the grass roots level because they want to leverage development agenda to the local and those local NGOs are assumed to be working closely with communities in development activities. The donors hope that the NGOs they fund will provide sub grants and other technical supports to those smaller LNGOs with regard to climate change concepts and project management.

In some cases the donors are required to have co-funding and joint proposals for NGO partnership projects, therefore the NGO partners act as joint implementer.

\footnotetext{
“Donors, particularly European Union (EU) require us to partner with other NGOs and they want us to build capacity to local NGO partners to ensure that they perform work well to serve communities and another requirement from donors is that we have to find co-funding NGOs as partners" (KII, 14).
}

The flow of funds in NGO climate change projects in Cambodia is likely to create a heirarchical structure as shown in figure 6 . The fund flow takes long time to reach the end beneficiaries. 
Figure 6: The common flow of NGO climate change project funds

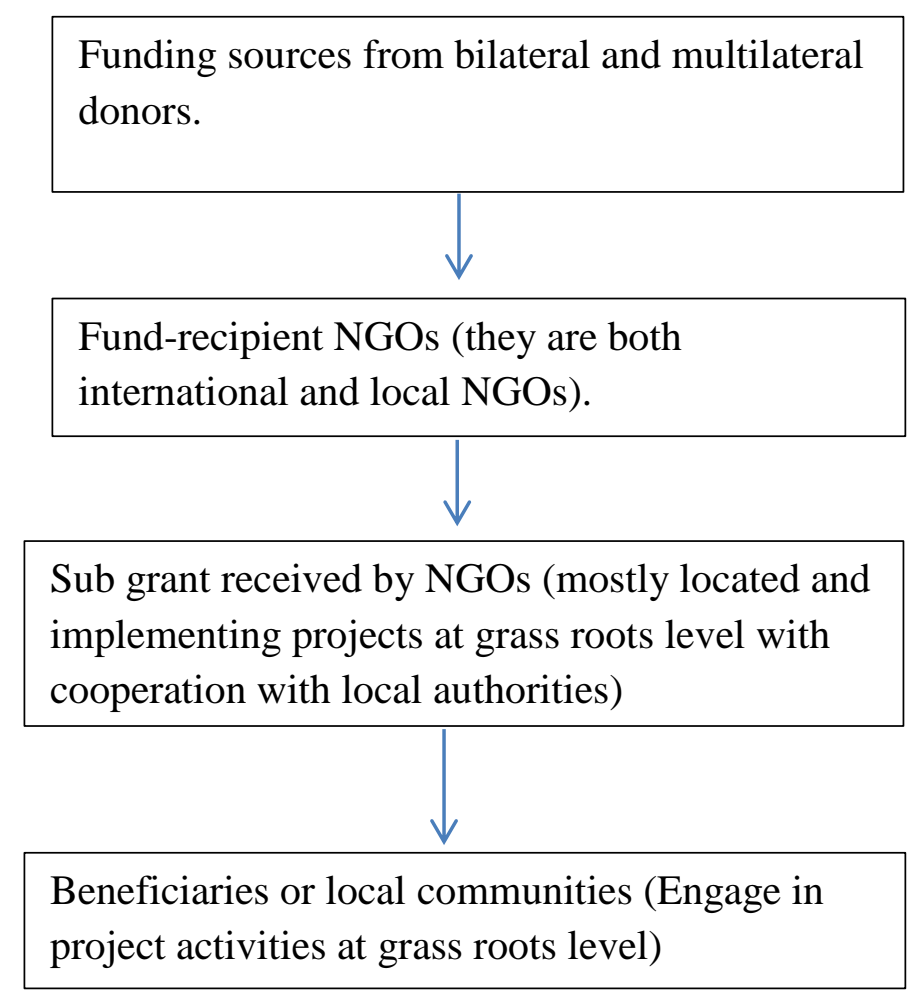

Overall climate change financing comes through two main sources: bilateral and multilateral donors. The forms of funding are both grants and loans. The bilateral funds have accounted for 48 percent, which is equal to US\$ 317.7 million while multilateral financing is 58 percent that of US\$ 337.8 million (Enrich Institute for Sustainable Development, 2013). Those funds are channelled to climate change projects which are operated by both government and NGOs.

Figure 7: Climate change financing in Cambodia by sources of fund

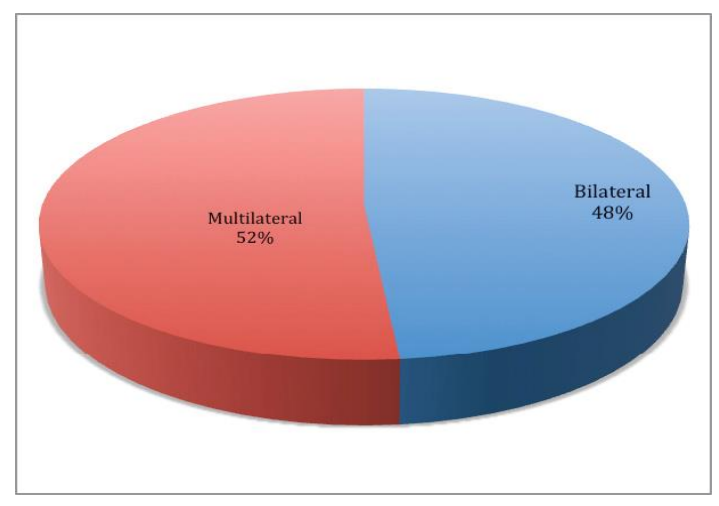

Source: Enrich Institute for Sustainable Development, 2013 
Figure 8: Climate change financing in Cambodia by donors (US\$ millions), 2013

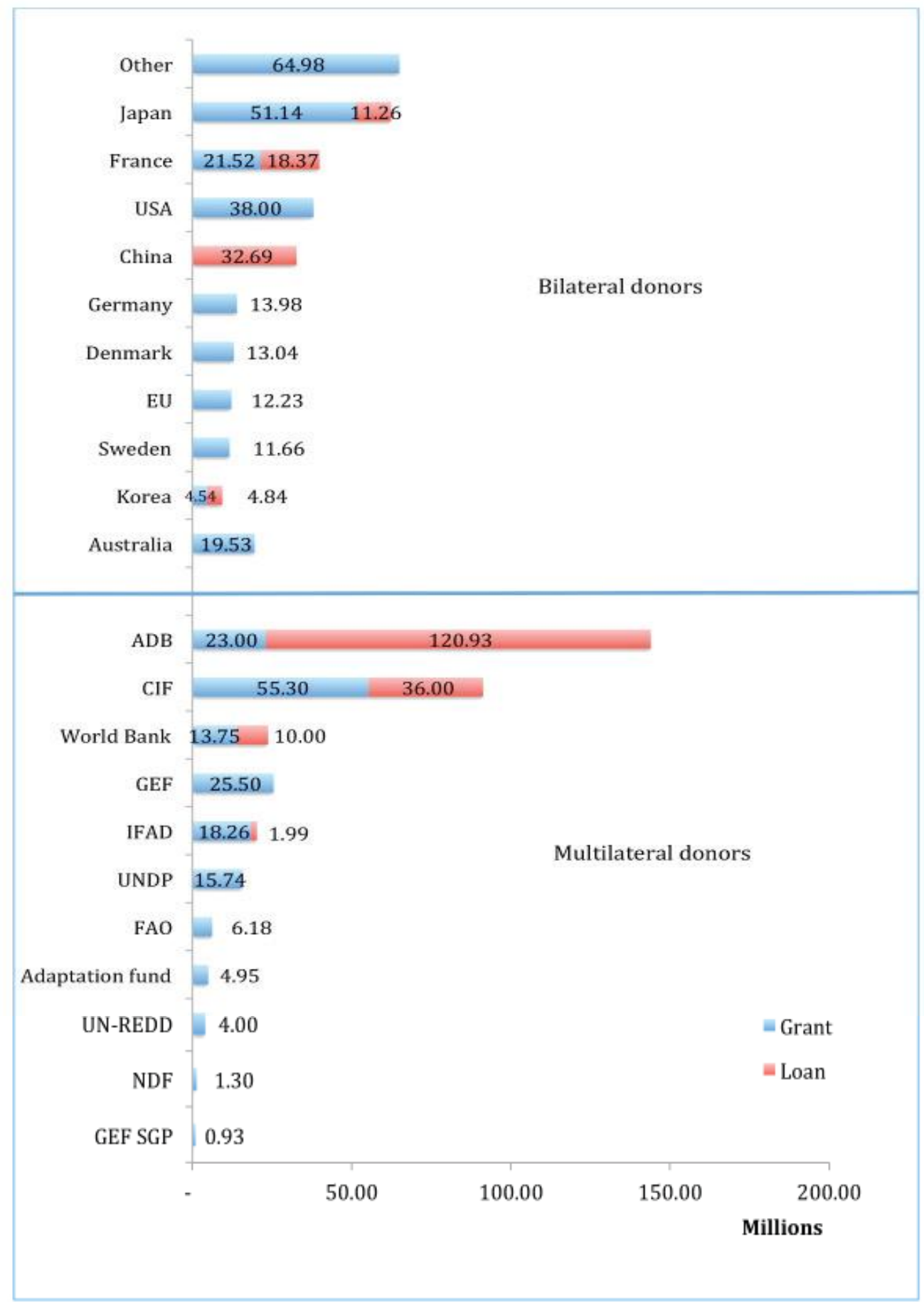

Source: Enrich Institute for Sustainable Development, 2013

When asking about funding and NGO accountability, most interviewess suggested that local authorities cooperation and participation in the project cycle is significantly important to accomplish the project goals. But it is not a surprise when all NGOs say 
that they are accountable to both donors and communities because they want to prove that organisations have good governance and are able to produce impacts for the local people.

In reality NGOs are much more accountable to their donors than beneficiaries (Najam, 1996 and Edwards \& Hulme, 1996) because they are largely dependent on external funds. They usually implement projects based on donor's priorities (Chum, 2010). With this regard, accountability is likely to be a fancy word used by both donors and NGOs in development work to address their legitimacy. On the other hand, NGOs may have choices to negotiate funds or grants with donors. Some NGOs do not completely follow the demands and priorities of donors as they consider the local needs. "We try to balance out and we convince donors to understand about the needs and priorities of communities or beneficiaries" (KII, 2). It is true that they need money to operate the organisation but they also think about the requirement of the donors whether it will or not it will meet the needs of real people who are the final beneficiaries.

\begin{abstract}
"If what we do is not a response to the needs of donors and beneficiaries, we will not get anything. So we balance by looking at donors' priorities and beneficiaries' needs at the same time. We are implementers but we can have recommendations to donors about the real needs of the local people" (KII, 1).
\end{abstract}

Even though most key interview informants pointed out that partnership is required by donors, they also provide some other reasons. Firstly, NGO partnership is the organisation's strategy. Partnership can have a strong common voice and effectively influence policy makers with regard to development issues, particularly in climate change issues. The NGO partners can share the same visions and goals, different responsibilities and skills in climate change projects. So they can help each other in terms of financing, capacity development and policy advocacy.

\footnotetext{
"We share different responsibilities and expertise in our joint climate change project and we have grant packages for project costs when the other partners are good at policy advocacy and
} 
capacity building. We want it as a model for climate change project in Cambodia and we see that now we are successful" (KII, 9).

Furthermore, partnership can make a better flow of information sharing from the grass roots to national level. The concerns of people are brought through the NGOs that work directly and closely to local communities. For example, a respondent from a NGO that works on climate change policy monitoring and advocacy explains that:

"NGOs that focus on policy advocacy mostly deal with the tasks at national level so they barely receive people's voices from the ground for consultative meetings or workshop with the government without their partners' help in deploying information gathered at grass roots" (KII, 17).

Therefore, mutual help in information sharing is essential in policy advocacy. Reversibly, partners which work at national level can also spread the information of newly-established policies and regulations to the grass roots. In this regard, NGOs seem to play an advocacy role to influence the government in policy development by improving its accountability by putting pressure through civil society voices on the government to hold it accountable to its constituecies. Therefore, NGOs are non-state actors who have the right and power to hold the government accountable to a set of standards, to judge whether the government has fulfilled responsibilities in public service delivery (Grant \& Keohane, 2005).

Another reason for NGO partnership in climate change project is that it is a new idea for the NGOs. The fact is that the NGOs want to create a model partnership project when the climate change is a really unfamiliar, new and cross-cutting issue to be addressed among their local NGO partners and other stakeholders in Cambodia. They want their existing partners in other projects to start learning about climate change concepts and integrate them into the organisation's programmes. Most importantly, those NGOs believe that the benefits will eventually reach the end beneficiaries when climate change is addressed. However, some interviewees provide different views with respect to partnership. They assert that partnership can 
avoid time constraints when setting out new projects in an unfamiliar place. Therefore, the funded NGOs have to find local NGO partners which work in the same place. The reasons are due to the fact that length of time to learn about a new site for project implementation would be long and the process would be uneven to deal with local authorities and other stakeholders. Some other respondents claim that they partner with other NGOs because their organisations have no offices at the local site. In addition, some NGOs have criteria for partnership. They partner with other NGOs if the project's themes share the same vision or goal.

"We partner with other NGOs when we see local people are vulnerable to climate change impacts and we look over the places where the government recognises in high risk of climate change. We have criteria for partnership and we are not required by the donors" (KII, 12).

Last but not least, partnership is viewed as a likely holistic process of learning between NGO partners about climate change in Cambodia. It provides more effective and efficient results and the partners can take this learning process for granted in terms of implementing, monitoring and reflecting. Then LNGOs can build up knowledge of climate change to enhance climate change project implementation in Cambodia.

\section{7 How NGOs implement climate change projects at different levels}

\section{7. 1 National level}

NGO climate change projects in Cambodia are usually implemented in the form of partnership ${ }^{25}$. There are NGOs working on climate change at national level, particularly in policy advocacy and communication. Those NGOs are mostly capable in terms of financing, resources and capacity. But they are usually funded and provided support from external donors such as UNDP, EU and other development agencies. When they receive funds or grant packages from donors, they provide sub grants to the other LNGO partners, particularly those that are working directly with

\footnotetext{
${ }^{25}$ Most NGOs partner with other NGOs while some take partnership or cooperation with the government. But in this study I focus on the partnership between LNGOs that work at grass roots and other large NGOs that provide sub grants only.
} 
local people. Sometimes they act as project implementer if they already have some projects being operated at the grass roots and cooperate with government counterparts at the site. At the national level, they form networks or coalitions to communicate information. Sometimes they even connect the network to regional and international levels. Basically, they collect concerns from the grass roots through their network members and bring those concerns and voices to the consultative meetings or workshops which are attended by the government, donors and development agencies. Then they provide comments and inputs in order to ensure that those concerns are reflected in climate change policy framework and other regulations. Furthermore, some NGOs play an encouraging role toward learning and research for policy establishment. They undertake research and practical learning which is a bridge for policy formulation. For instance, they provide some evidence from case studies of NGO best practices in climate change projects, lessons learnt and other learning documents to policy makers. Besides this, they are also active in preparing workshops or training on climate change issues with their NGO counterparts and other relevant stakeholders at the national level. These extracts illustrate this:

"We work and provide evidence from any case studies and best practices which is a way for the government to develop policies. Our work is to produce insights and inputs to be used by policy makers in policy development with respect to natural resource management, climate change adaptation and biodiversity conservation" (KII, 14).

"Working on the REDD+ project I have provided some pieces of advice for the implementation and we focus on research and learning by writing lessons learnt from the field, thus producing policy brief for REDD+ policy development. The main task of the project is to assess the methodology of REDD+ implementation and support the government institutions in REDD+ roadmap implementation to ensure that REDD+ is ready in Cambodia" (KII, 11). 
"We are like a bridging NGO that bring concerns from the local to policy makers through bilateral meetings, donor consultative meetings and other high level meetings with the government" (KII, 17).

On the other hand, there is some resistance from the government in the acceptance of comments or inputs from CSOs to some extent. Despite the fact that NGO representatives are entitled to have expression and raise concerns in the meetings or workshops with the government, prioritised concerns of the people are usually overlooked. This is due to a lack of political will from the government, coupled with inaction of officials. But NGOs now are actively invovled in the provision of insights for climate change policy formulation by attending multi-stakeholder consultative workshops and meetings with the government and other development partners.

\section{7. 2 Local level}

Whilst some NGOs work on policy advocacy and communication at the national level, there are many NGOs, particularly LNGOs and CBOs that operate their climate change projects at the local level. The projects are basically funded and supported by large $\mathrm{NGOs}^{26}$ with high capacity. Their activities are primarily about climate adaptation, climate resilience and integration in livelihood improvement. When receiving funds or grants from their partners, they cooperate with local authorities and relevant department officials to implement the projects. Beyond climate change awareness, they provide life skill training to local people in the target areas so that they can further enhance livelihood. Those skills are technical knowledge and agricultural technologies that are resistant to climate variabilities. Some NGOs work on water stock construction projects, which aim to provide sufficient water for the local use and promote food security.

\footnotetext{
${ }^{26}$ These NGOs receive funds from large donors and then provide sub grants to their LNGO partners that operate their projects at the grass roots. However, there are also many projects that are funded by donors including UNDP, EU and other development agencies.
} 
In addition, the project's activities are about promoting financial capital at the local level. The people are encouraged to establish community saving groups so that the group members can access community funds for using an emergency. For example, they can use funds to resettle when there is a flood or start micro business activities. Another main activity of the projects is grass roots advocacy support. Most organisations incorporate advocacy in project's objectives and they train local people, particularly youth, women and community representatives to do advocacy. For instance, when there are many people affected by flood or drought, those trained beneficiaries take intervention by reporting to and working with local authorities to solve the problems. Noticeably, the projects usually engage the locals from the beginning until the end of the project cycle to ensure that the local needs are met. An interviewee explained, "prior to developing projects and proposals, an assessment is conducted to identify areas affected by climate change risks and impacts and it is acknowledged and involved by the local" (KII, 11). Sometimes the organisations that work at the ground partner with other LNGOs in the same target area on the condition of joint action plans and shared-direct allowance ${ }^{27}$.

Even though partnerships in climate change projects at the ground are essential for the success of the project, the importance of multi stakeholder cooperation and collaboration is also significant. This can enrich the NGO performance in the projects and produce more impacts on the local. Ngin (2004) argues that no matter how much funded money the NGOs have in projects the organisations should take into account improving good governance and encouraging the local people to be engaged in the projects. Most importantly, information has to be shared among the beneficiaries.

\section{8 Conclusion}

To sum up, I have discusses the research findings which are based on the information from the field. I discussed how NGO accountability is perceived and its importance in project implementation. I shared the perspective of NGO partnership and how it is practised by Cambodian NGOs. Then, I presented some complexities of partnership in climate change projects and discussed how they address climate impacts in Cambodia. I also summarised how climate change projects are implemented and

\footnotetext{
${ }^{27}$ The allowance is for the participants or end beneficiaries who are involved in project activities. The allowance is for the speding of per diem, travel and accommodation.
} 
highlighted that a successful partnership climate change project can be initiated to address climate change issue of Cambodian NGOs. Finally, I gave insight into how Cambodian NGOs implement climate change partnership projects in Cambodia. The following chapter discusses the issues of climate change projects and the impacts on local communities. This chapter has provided some issues of the climate change project that Cambodian NGOs have evidenced through their activities in project implementations. 


\section{Chapter Six: The Impacts of NGO Climate Change Projects}

\section{1 Introduction}

This chapter presents my analysis to answer the question of how Cambodian NGO accountability impact on local communities through climate change work. It highlights the results of climate change projects which Cambodian NGOs have so far accomplished. From the results I discuss challenges and solutions for the implementation of the projects. I also detail the response to the challenges with regard to NGO partnership in climate change project implementation in Cambodia. The role of the government in climate change partnership projects is also discussed in light of the government's awareness, capacity building, technical and financial support towards climate change projects. Since NGO's project activities include policy development to cope with climate change, these matters are also discussed.

\section{2 The Projects' results from the NGO's perspective}

Climate change projects have been increasingly implemented by NGOs since 2010 . Over the period significant results have been achieved from their projects. The concept of climate change is new to Cambodia and is just becoming known, Accordingly, NGOs have made the effort, to complement the government's actions in promoting knowledge and action among stakeholders, particularly local communities, as how to understand and cope with the impacts and risks of climate change. Despite the fact that there are some shortcomings related to funding shortages, time constraints, and other technical problems in the implementation phase, NGOs have established a learning process among partners building on their existing capacity and knowledge, and so continue their actions on climate change. According to the particpants, many of them explained that the impacts caused by NGOs in climate change projects are indirect. This is because the majority of the projects are capacity and knowledge building and so are mainly involved in service delivery and training provision.

Through developing knowledge and skills about climate change the projects have also contributed to the improvement of food security. Since most projects have a broad objective to increase food security in the target areas, they focus on water 
stock construction and rehabilitation ${ }^{28}$ to create a good water supply for agricultural activities and daily use.

\begin{abstract}
“In our organisation's target areas, we constructed water stock to supply water for daily use and agricultural activities. The people there now have sufficient water and they do not need to walk far away from the village to fetch water. Moreover, they can plant rice in dry season and do other farming activities including home gardening, animal raising and fish farming easily” (KII, 3).
\end{abstract}

\title{
6. 2. 1 Climate change knowledge and capacity promotion among NGOs
}

Over the period of project implementation knowledge about, and capacity in relation to, climate change have been improved among Cambodian NGOs and local communities. They are now aware of climate change issue and take action with regard to it. There has been an increase in the number of climate change projects in education. There are now climate change awareness projects at primary schools, being implemented by NGOs that are working in the education sector. Local governments, which work closely with local people and other organisations, have also started having a better understanding of climate change. They integrate the issues into local development plans ${ }^{29}$, especially in food security and risk reduction. However, the capacity of commune councils is limited so they usually seek support from other actors, both from governmental institutions and NGOs. In addition, some NGOs are now able to integrate climate change issues into their strategies and programmes from a longer perspective. They have built on resources and have strengthened the capacity of their staff in order to be able to facilitate climate change adaptation practices at the grass roots.

\section{"We encouraged a cycle of learning which was initiated by our partners. We only facilitated that and the schedules were set by}

\footnotetext{
${ }^{28}$ Water stock construction and rehabilitation can be pond and well digging, irrigation system rehabilitation and stream development.

${ }^{29}$ In Cambodia, local development plans are developed by local governments which are called commune councils. The plans, so called commune development plannings (CDP) are usually in fiveyear period but each year there is a commune investment programmes in which the councils have to analyse issues or problems and then development projects for a yearly implementation. In this occasion, NGOs and private sectors can integrate their projects in this programmes too.
} 
them. They set the gaols, shared experience and lessons learnt and provided feedback to each other to the project" (KII, 9).

According to the interviews, the positive benefits are listed below:

\section{Being able to access funding sources}

Cambodian NGOs have the capacity to access fundings for project support, including their climate change intervention projects. For instance, they now know that the United States Agency for International Development (USAID), EU, UNDP, Global Environment Facility Funds (GEF) etc. are the funding sources for climate change projects. However, NGOs who work on climate change at the grass roots rarely receive huge amounts of funds from large donors. They usually receive only grant packages from donors and other large NGOs. Significantly, the amount of funds they receive is not large and often only short-term. Only large NGOs are able to attract a lot of funds from these overseas donors. They then provide sub grants to their other LNGO partners. This shows the differing capacities of NGOs in funding negotiations, and is evidence of another imbalance in the relation between large and small NGOs (Johnson \& Wilson, 2006).

Those small LNGOs are not funded with large amounts of money from large donors and this is due to the fact that they might lack the capacity in terms of expertise and resources to implement climate change projects, or that they are not being trusted by donors in terms of financial management. Therefore, LNGOs have to build and strengthen their capacity more in order to be able attract funds to support their climate change adaptation at the local level. Some NGOs integrate climate change awareness activities in other projects when there are insufficient funds. An interviewee of an organisation explained that:

"We are not funded any more for climate change projects but what we can do is to continue our activities by including climate change awareness in other existing projects and we work closely with local government. We do not want to stop in the middle and we wait until we can receive more funds" (KII, 15). 


\section{Connecting with other regional and international networks}

By reflecting on what has been found in the field research, Cambodian NGOs are able to connect more actively with other networks in the regional and at international levels. The NGOs have established networks in advocacy efforts and campaigns on climate change, and even retain technical and financial support for project operations from other regional NGO alliances. For example, the NGO Forum on Cambodia, a NGO which works on climate change policy monitoring and advocacy, has a link to the NGOs Environment and Climate Change Alliance (NECA) at the regional level. The NGOs also have connections with international networks, including Adaptation Funds (AFs), the NGO Network of German Watch (GW), Southern Voice Programmes (SV) and Climate Action Network (CAN). Additionally, through the networks they have the chance to attend workshops, conferences and meetings outside the country, and so are able to share lessons learnt and their experience of the grass roots climate change adaptation practices. The voices of the local people affected by the impacts of climate change, are brought by these NGOs, and so these ground level voices are being heard and widely disseminated. This is an important matter revealing that Cambodia's NGOs are being involved, albeit only partly, in global climate change negotiations with regard to policies and other regulatory measures.

\footnotetext{
"We have linked Cambodia climate change action to regional and international levels by bringing local voices and concern to this linking network. People's voices and concern are heard through our project implementation" (KII, 8).
}

NGOs have also become a key player in global environmental governance and actions. They develop projects and make up transnational organisation communities to work directly or indirectly to protect the environment (Ahmed \& Potter, 2006; Martens, 2005; Shigetomi, 2002). There is a substantial literature that proves that NGOs have an important role in climate change policy development, and in advocacy and monitoring, at both interantional and domestic levels (Jancar-Webster, 1993; Arts, 1998; Newell, 2006; Keck \& Sikkink, 1998; Weidner \& Janicke, 2002; and Betsill \& Corell, 2001). In addition, NGOs have been influential in encouraging 
the government to ratify the international climate change negotiations, such as the Kyoto Protocol (Dolsak, 2012).

\section{Climate change and rights-based approach}

According to the interviews, most staff of NGOs have improved their knowledge about climate change in relation to the rights-based approach ${ }^{30}$. The staff of NGOs that I interviewed had attended both internal and external training on climate change. As a result they have received a wider understanding of the implications of natural resource management, local governance and agricultural extenison with regard to the impacts of climate change. By being involved in the projects, staff have also learnt, at the same time, how to integrate climate change perceptions into existing projects. An NGO staff explained:

\section{"The developed capacities and knowledge are oriented towards application to activities related to everyday livelihood improvement in climate change adaptation and this allows project staff to build adaptive capacity among of local people affected by climate change impacts" (KII, 10).}

The staff have also improved their knowledge about gender equality by observing the way that women and men perform different activities in terms of access to, and control of resources, in coping with stresses at the local level created by climate change. In spite of the fact that capacities have been built up among the staff of NGOs, the skills they have acquired are not fully developed. They need more training as the level of skill varies, but those staff who have been trained have the potential to integrate climate change actions into projects.

\footnotetext{
${ }^{30}$ Most interviewed NGOs use this approach in implementing climate change projects. The approach's principles include participation, transparency, accountability and non-discrimination. Participation indicates the involvement of all relevant stakeholders in the project activities whereas transparency is refering to the means of enhancing accountability of local government in climate actions. Accountability indicates the responsibilities of duty bearers to protect rights holders from climate change effects and non-discrimation explains the equal roles of men and women in running local organisations and actions.
} 


\section{Developing curriculum and information, education and communication (IEC) materials}

Through the increased capacity, the staff of the NGOs were able to develop educational videos, curriculum and educational materials, in order to raise climate change awareness at the local level. They used information, education and communication (IEC) materials, to tell people how climate change impacts on the planet, and what adaptive approaches may be used to cope with all the associated risks and impacts. The activities are mainly directed to selected communities which are affected by the impacts of climate change .

"We developed visual aids in climate change training. The materials include IEC, posters, leaflets etc. because local people are mostly not well educated. They might easily understand with visualisations" (KII, 15).

\section{Being more engaged with the government}

What was found in the field interviews was that Cambodian NGOs have the ability to engage with the government actors to discuss climate change actions, policies and financing. The NGOs, through their network, have increased their activities and so are able to influence policies and strategic frameworks including the Cambodia Climate Change Strategic Planning (CCCSP) ${ }^{31}$ 2014- 2023, National Strategic Development Plan (NSDP) ${ }^{32}$ 2014- 2018, REDD+ framework on safeguard and UN climate change negotiations. The capacity of NGOs in relation to climate change work has been recognized by the government. The comments and inputs made by NGOs have been incorporated into policy documents and frameworks. However, if the issues raised were sensitive then to some extent the comments of NGOs were ignored. Taking land and natural resource violations as example, the issue escalates when solutions from the government seem ineffective and the people lose their land. Cambodian people are mostly subsistence-based farmers and land is vital in order to make a living, as well as to cope with climate change stresses. NGO's insights,

\footnotetext{
${ }^{31}$ This is the first ever comprehensive national policy document responding to the climate change in Cambodia. It was recently adopted in 2014 and the process was coordinated by the Ministry of Environment.

${ }^{32}$ In Cambodia NSDP is developed within a four-year period and the establishment process is coordinated by the Ministry of Planning with the involvement of development partners and civil society.
} 
which focused on pro-poor, and which stressed the rights-based perspective, are now beinng considered by the government. Some NGO recommendations were consolidated and incorporated into the CCCSP and NSDP. The members of the NGO Forum on Cambodia and CCCN have been included in the national Green Growth Master Plan so that they could be involved in the follow up of the implementation of this master plan in the coming years.

\begin{abstract}
"We have tried as much as we can to engage with the government and advocate for an acceptance of NGO's work in climate change sector. We have contributed to the government in developing a comprehensive climate change policy as an implementation guide and we want local voices and concerns coming through us reflected in that policy...ultimately the policy has been on place"
\end{abstract} (KII, 15).

The formal inclusion of NGOs in national delegations offers opportunities for these actors to influence government decision making (Weiss \& Gordenker, 1996; Raustiala, 1997; Gulbrandsen \& Andresen, 2004; Steffek \& Nanz 2008; and Bohmelt, 2013a). This could improve political responsiveness, transparency, accountability and ultimately, legitimacy, in the sense of creating international and domestic public support (Clark, Friedman \& Hochstetler, 1998; Grant \& Keohane, 2005; Dombrowski, 2010 and Bernauer \& Betzold, 2012). As a member of a national delegation, NGOs can even influence government policies (Dolsak, 2012 and Bohmelt, 2013b).

The CCCSP basically captures the main strategic objectives and directions, outlining several sustainable development goals for Cambodia to pursue for the next ten years. Cambodian NGOs admire and appreciate the government in establishing CCCSP although it is a government document focusing on the use of public resources. But the use of public resources is expected to catalyse broader actions and responses to climate change impacts by other actors, particularly NGOs (CCNA, 2014). The CCCSP does not provide the specific details of what the partnership with NGOs is going to be, but it does address the commitment of the government to engage with 
other actors in climate change project implementation, and it does identify partnership conditions in the action plans.

According to the interviews, through the activities of NGOs, local governements have been made more aware of climate change and have started cooperating with NGOs on climate change actions. Local governments now have more understanding about both climate change adaptation and the mitigation of its effects. They are also now able to discern problems and to find solutions. Further, local goverments have started taking part with NGOs to share their knowledge and to raise the awareness of people to climate change. The climate change concept has thus been integrated into the local development plans both in CDP and CIP. The local authorities are willing to allocate local funds for climate change actions.

"The local governments including commune councils, village leaders, and other technical officials have changed their attitude in communication and cooperation with NGOs and their actions to support community and address climate change have improved" (KII, 16).

As mentioned above, the level of local government cooperation and participation differs according to geographical factors. The cooperation of local governments in the projects of NGOs is usually limited to the areas where there are sensitive issues with regard to land grabbing, environmental destruction, and the abuse of human rights. However, some local authorities are committed to participate in, and to address climate change issues, irrespective of other geographical factors.

\section{2. 2 Adaptive capacity improved among the local people}

Through the actions of NGOs on climate change the adaptive capacity of the local people has improved as reported by research participants. Adaptive capacity is the "ability to design and implement effective adaptation strategies, or to react to evolving hazards and stresses, so as to reduce the likelihood of the occurrence and/or the magnitude of harmful outcomes resulting from climate-related hazards" (Brooks, Adger and Kelly, 2005, p 14) NGOs often provide training courses which are related 
to the climate change concept, its impacts and solutions. The research found that the training offered aims to promote climate change resilience among the local people who are affected by the impacts of climate change ${ }^{33}$. After training, people know how to cope with climate change risks.

"They can identify available existing resources in their community to contribute to the protection of the environment and to the mitigation and adaptation to the impacts of climate change, especially in the agriculture sector. They have already started now using these techniques to cope with the impacts caused by climate change " (KII, 1)

\section{Adaptation techniques in the agriculture sector}

The target beneficiaries of climate change projects have now improved their knowledge and skills with regard to adaptation techniques and approaches to cope with climate change impacts. They have aquired these skills by attending the training arranged by the NGOs that work at the ground level. Accordingly, they have started planting trees, making compost, using less water when planting vegetables and practising drip irrigation, plus soil improvement methods. Below are some successful adaptation techniques and approaches shared by NGOs with local communities.

- Water saving techniques: to use less water for planting (farmers use drip irrigation systems and planting crops and vegetable in sacks);

- Soil improvement: to make soil more fertile by pooling available resources in the community (making compost, liquid compost, soil moisture, mulching, plastic covered and land arrangement to avoid erosion);

- Drought resilience rice seed (the harvesting period is short - from three months or perhaps a bit longer than that);

- Landless techniques: farmers plant vegetables in bottles and sacks;

- Multi crop growing in the farm;

\footnotetext{
${ }^{33}$ Droughts and floods, which are caused by climate change, are unpredictable due to weather pattern change. The damages caused by these natural destructive events, particularly floods, are economically large.
} 
Even though the findings show that the target beneficiaries of climate change projects have started to use some adaptation techniques, they need more coaching and mentoring from the staff of NGOs who work at the grass roots level. The target beneficiaries lack confidence and trust as to which of the techniques they have learnt will be the most effective. Accordingly, some people still use traditional methods for planting ${ }^{34}$. A respondent pointed out that:

"The farmers still have not believed that the change of crop seeds may yield a better production although they have attended the training already and we will continue to encourage them to try new methods" (KII, 3).

Farmers who are committed to implementing the techniques that they have learnt are further supported by the NGOs. They receive financing and materials in order to cope with the impacts caused by disasters. However, a lack of financial capability is considered a significant barrier in the adaptation process. People need money to manage resettlement and to recover from the impacts caused by climate change. Therefore, every NGO which implements climate change projects inevitably incorperates financial capacity improvement as one of the project's outcomes.

\section{Financial capacity for local adaptation}

Local people affected by the impacts of climate change need to be more financially capable for the purposes of adaptation. As mentioned above, NGOs help in facilitating communities to establish saving groups. These saving groups are managed by local community members. The money saved can be loaned to members who need it. Although these members have to pay interest, it is at a very low rate. For example, members can borrow money to undertake micro economic activities such as vegetable planting, fish farming, animal rearing, and local store operation, etc. This enables the local community to earn more income and so be able to cope better with problems, particularly with climate change impacts. A research participant, who worked in an organisation that improves local economic and

\footnotetext{
${ }^{34}$ Cambodian farmers are subsistence-based and they follow traditional techniques for farming and planting. Therefore, it is difficult and takes longer to change their mind to use the new adaptation techniques.
} 
financial empowerment, explained that the organisation helped in facilitating communities to establish saving groups so that they could mobilise local resources within their communities and build up social networks.

"With regard to the saved money, farmers can borrow it in order to use for creating economic activities to adapt to climate change and their incomes increase then" (KII, 10).

The local people in the target areas of the projects are able to diversify economic activities to improve their living and to become more climate change resilient. These actions however are entirely dependent on the NGO's facilitation, funding ${ }^{35}$ and coordination. The people need to be further trained by the NGOs and to be encouraged by local government to respond to natural disasters caused by climate change.

\section{3. Challenges in climate change partnership projects}

Whilst most interviewees from the field study credit and assess partnership in climate change projects as invaluable for the success of project implementation, some issues are taken into account and there are challenges. The views happen to come from both funding NGOs and grantees. Those problems migh include time constraints, human and financial resources, administrative work, sense of understanding and even a lack of local authority cooperation.

\section{Limited capacity of $\mathrm{NGO}$ partners}

Another challenge viewed by funding NGOs is the limitations of the NGO partner capacity. Donating NGOs not only infuse funds to the partners but aslo provide human resource development and other technical supports in order to make sure that the latter have full capacity to implement the projects. But the main issue is that support is not accomplished due to the level of education of the partner's staffs being relatively low. Therefore, their capacity to gain knowledge from the training is limited and the outputs produced are not so significant. Another cause might be illustrated by the fact that small LNGOs have a limited amount of project funds to

\footnotetext{
${ }^{35}$ However, community people are encouraged to form saving groups. The purpose is to loan money to other group members who need it when they face problems. Some NGOs would provide some funding for this activities.
} 
hire highly-qualified staff to work in the organisations because the expense is likely to be higher ${ }^{36}$.

\begin{abstract}
"Small NGOs have limited amount of grants and money from donors to recruit candidates with capable basic qualifications in project or programme management skills. In addition, the rate of staff salary is determined by internal financial policies which is sometimes underpinned and required by donors in project proposal and agreement" (KII, 04).
\end{abstract}

"Most highly-educated people usually look for a position where high payment and incentives are offered. So the level of achievement might vary due to differing capacity of project staffs", (KII, 01).

\title{
Funding is not long-term
}

Cambodian NGOs have more funding opportunities in climate change projects but the funding is normally in short-term contracts.

\begin{abstract}
"Climate change project funds, as I am aware, are not long-term compared to other projects. We, who work with community, want more funds to help those affected local people" (KII, 03).
\end{abstract}

This is a main constraint for the NGOs because they are entirely dependent on external funding supports. Some NGOs integrate climate change awareness in other project activities. They hope that funding will be available one day. However, among those NGOs, there is still support for capacity building as they are a member of networks.

"We still continue to integrate climate change concepts where we
are working on the other projects. We think that it is a cross-

\footnotetext{
${ }^{36}$ The rate of staff salary of small local NGOs that receive funds from other NGOs is usually largely low compared to the payment for staffs that work in large international NGOs
} 
cutting issue so we have to address it even though there are no funds" (KII, 15).

\section{Time constraint in coordination}

Time constraint is another problem raised by the NGO partners. They provide a reason that coordination with partners might be an exhausting and frustrating task if there are so many partners and it is a waste of time. An NGO official explained:

"When calling them for a meeting or workshop for consultation for urgent occuring issues and problem, this is found to be very difficult to coordinate and to have a concerted schedule and timeframe for the meeting as they are mostly known to stick to their schedules and action plans. Therefore, it takes a long time to reach common agreement and plans. Sometimes, the process to coordinate in a partner meeting take up to more than twenty days if it is in a busy season of project activity implementation" (KII, 09).

Another illustration of time constraint is coordination in proposal approval. When funded NGOs send the proposals for donor NGO's approval, there is a delay because every donor has processes and steps to work on the proposals. They need more time to check, review and comment on the proposals. Then, they bring comments and feedback to a committee meeting which is involved with a management team to discuss and make decision on the proposals. At the same time they also communicate and send feedback to the partners to review and make revision. Ultimately, when the proposals are approved by the committee, funds are disbursed. This process is timeconsuming. Nevertheless, this is usual procedure to which every NGO applies. So funded NGOs have no option since they need funds to operate the organisations.

\section{Workloads in project implementation}

Workloads in arranging documents for budget spending is also another critical challenge in project implementation. There are many complaints about the required documents over spending made by NGO staff, particularly frontline project officers. 
"Some donating NGOs require us to follow all financial policies and conditions over spending so we have to apply but sometimes we find it a complicated work and we think that the times we spend on project results and outputs seem to outweigh the required document preparation" (KII, 15).

On the other hand, this problem is not regularly seen if both parties have similar guidelines so that they can compromise by creating an internal regulation for the partnership project. Very often, if there is no adjustment on spending guidelines it would mean that donors do not trust their grantee's financial policies. It might be the case that donors get aware of corruption and want to inhibit it. So donors stick to their guidelines and policies to prevent corruption.

\section{Lack of Internet access}

There is still gap in information sharing and communication to some extent. This is demonstrated by the fact that there is a lack of internet access at communities as most local-based NGOs have no capacity to afford the internet facilities and computers for all staffs to use. The flow of information goes through senior staff who have computers and internet access. Therefore, most staff of grass root-located NGO partners cannot communicate the information quickly and the process seem very slow. The important information from locals cannot reach the national level on time and vice versas and this can take a long time.

\section{Lack of sense of understanding and local authority cooperation}

According to the interviews, there are other problems happening during partnership project implementation. With respect to partnership agreement, some partners do not respect the common guidelines and immediately stop the agreement. An illustration is when the criteria for partnership is set for the party's agreement to hold responsibility to the shared costs. Later, partnering NGOs find some reasons or whatever to stop the agreement. This make uneasy for the other party to adjust to an immediately-changed situation. The partnership agreement has to stop. Concerning the grant coordination with partners, some INGO partners raise a concern that their partners do not have mutual understanding as they care only about the grant and just need the money. 
"Sometimes our partners want only money from us. They do not understand about us and just force us to give money to them only. We have difficulties too because we have to deal with big donors. If all NGOs have mutual understanding about their partners, partnership is better. However, if there is no mutual udnerstanding, there will be a negative effect" $(K I I, 1)$.

Despite the fact that the afforementioned example comes from experience of the NGOs' staff, in reality all grantees are not likely to force their donors to disburse funds as they need in any circumstance. Finally, limitation of local authority cooperation in the project is also a challenge as NGOs want all key stakeholders to join the activities, especially local government. But this issue is usual and it does not only happen to NGO climate change projects but also takes place across the country where NGOs implement their projects individually.

\section{4. Strategies and solutions in further climate change project implementation} This section outlines various stretegies and solutions that I am putting forward to improve climate change project implementation among Cambodian NGOs.

\subsubsection{Capacity building of new staff}

To enable climate change implementation to continue the problem of NGO staff turnover can be addressed by building up the capacity of new staff. The turn-over of staff in climate change projects is a major problem which results in a lack of human resources to carry out the projects. The fact is that staff,even when they are on a contract and have already been trained and enlightened about climate change knowledge, can change their minds and resign from their organisations. When this happens it takes the organisations a long time to recruit new staff and to build up their capacity and knowlege once again.

"We cannot stop the staff from resignation and this is very challenging for the projects because there are not enough human resources and with this regard, we have only one choice to recruit new staffs and train them again" (KII, 10). 
The differing reasons for staff turn-over are due to some difficulties in the project implementation, and to the low benefits provided by the organisations to their staff. For example, advocacy-related activities are usually frustrating because the staff in project coordinations have to confront the authorities with their demands. Therefore, NGOs, and fund-providing donors, should have support mechanisms in place with regards to advocacy, and should offer a reasonable benefit package for project implementers ${ }^{37}$.

\title{
6.4.2 Developing fundraising strategies
}

Because of a shortage of funding NGOs have to develop fundraising strategies and advocacy for long-term funding to sustain climate change actions. Each partner NGO is trained to be able to create fundraising plans and to write good quality project proposals. Some NGOs are now able to develop proposals without support from their partners. For instance, a participant from an organisation working on youth development explained that:

\begin{abstract}
"Before we asked our partners to help us developing proposals for the projects...but recently we were granted a fund package to implement a climate change project which focused on youth participation in climate change adaptation. We were among other NGOs that competed for this funds and we won. It is unbelievable because our rivals are large NGOs. This can prove that our capacity has grown up eventually thanks to our partner's support in capacity building and training" (KII, 16).
\end{abstract}

\subsubsection{Creating a document library for climate change projects}

According to the interviews, the majority of interviewees suggested that an online database for climate change learning is really important. A respondent explained that:

"There is a need for NGOs in Cambodia to establish an online database or website for literature and materials relating to learning about climate change and its effects. This source should store important documents relating to climate change and

\footnotetext{
${ }^{37}$ As mentioned above a small NGO staff usually has a very low payment compared with those who work in large NGOs.
} 
projects so that the staff of NGOs, researchers, and other interested people, could access the information and learn about climate change in Cambodia" (KII, 11).

This initiative might also partly address the issue of problems caused by staff turnover, because the newly recruited staff could find information about climate change in the library or data base. This initiative should be joined by all NGOs. There should also be one NGO responsible for facilitating the establishment of this library. Some NGOs already have their own information management database relating to climate change projects.

\title{
6.4.4 Strengthening the capacity of commune councils, advocacy initiatives and legal support
}

There is a need to further build up the capacity of local authorities, particularly commune councils, with reference to climate change. Furthermore, the NGOs will have to engage with multi-stakeholders at all stages of the implementation of the projects.

\begin{abstract}
"To encourage the integration of the impact of climate change into local development plans NGOs will need to continue to provide capacity building to commune councils, and to work with them in response to natural disasters and emergencies" (KII, 08).
\end{abstract}

In addition, NGOs should further persist in advocacy work in order to address, at the grass roots level, the issues of ineffective law enforcement. The NGOs will have to motivate local people to initiate local advocacy activities in order to hold the local governments accountable and to encourage them to participate in the project activities. The enforcement of laws and regulations relating to environment and land is widely recognised as ineffective because of conflicts of interest. For instance, deforestation and illegal logging still exist in community protected areas (CPA) or community forestry areas (CF). These regions are meant to be under the control of the communities ${ }^{38}$ This disregard for laws and regulations arises because powerful

\footnotetext{
${ }^{38} \mathrm{CPA}$ and $\mathrm{CF}$ are under legal control and management of community. Basically, CPA is legally recognised by the government under the coordination of the Ministry of Environment whereas CF is under the coordination of the Ministry of Agriculture.
} 
people are involved in the illegal logging, and even government officials are also implicated. .

In response to illegal activities related to forest and land issues, NGOs have created legal support processes to assist local communities. A NGO network member is responsible for faciliating the running of these legal support processes, This network member is also responsible for motivating affected local people to appeal to NGOs who have expertise in law and advocacy.

Ultimately, there are some considerations for NGOs to improve climate change project implementation. Firstly, NGOs need to establish an appropriate strategy to build the capacity of new staff to respond to the staff turn-over. Secondly, the NGOs need to train staff more on fundraising strategies to ensure the longevity of project. They should identify local funding sources, particularly a crowfunding source. Thirdly, the NGOs and government should initiate an online database for literature and documents for learning about climate change. This allow students, project staff and other individuals access to this information and improve awareness on climate change. Furthermore, building capacity of local commune councils and other local government officials is important in climate change projects. They are a partner of NGOs at the grass roots so they need more training about climate change. Last but not least, NGO network members need to work closely to the local people to support advocacy initiatives to ensure that local concerns are heard and brought to policy makers. They need to provide legal support to local communities when they want to complain to authorities or private companies that violate them ${ }^{39}$.

\section{5 The government's role in climate change partnership projects}

The role of the government in the implementation of NGO climate change projects is essential to ensure the success of these projects. The government is the main actor in Cambodian development and it has already co-opted the support of NGOs in development projects. However, the level of participation by the government is manifestly limited. Since the climate change impacts are getting worse, both the government and the NGOs should consistently work together to limit the impacts. According to the inverviews from this research, the NGOs insist that the government

\footnotetext{
${ }^{39}$ There are NGOs working to support legal services to communities. These NGOs usually provide free legal support when affected local people are not able to file complaints or ather legal matter.
} 
has to participate in all the activities operated by NGOs in climate change projects. This means that both the government and the NGOs must support each other, and cooperate together, in response to the same development objectives.

"The government should be responsible for developing common materials $^{40}$ to be used for climate change education and awareness by government officials, NGOs, and the private sector. This would mean that NGOs would have the same guidelines and procedures. It is most important, that NGOs do not, out of necessity, develop their own materials, which would be a waste of time and money" (KII, 11).

Some NGOs, in fact, do have their own EIC materials produced to create climate change awareness, but these materials are not in common use. The development of such materials is supported financially by donors. The ad hoc nature of this production of EIC materials needs to be better co-ordinated.

I would suggest that the local government, particularly commune councils, should be much more involved in project activities facilitated by NGOs. They should, for instance, be responsible in the bidding process, and for the direct implementation in infrastructure development projects ${ }^{41}$ so that they can, at the same, identify and resolve problems. The government should provide technical and financial support to NGOs to implement climate change projects. The government does not yet have full capacity either technically or financially, and so the government climate change projects are all funded by external donors. There are however also a limited number of resource persons working in related ministries, which can support the projects of NGOs. Unfortunately, these technical experts, with access to finance, support only those large NGOs which can offer greater incentives. It seems also that these technical experts have personal connections with the staff of these large NGOs .

\footnotetext{
${ }^{40}$ The materials are education, information and communication.

${ }^{41}$ The projects are about pond and well digging, irrigation system rehabilitation and stream construction.
} 
"It is really good if the government provides technical support to NGOs equally but very often I see that the technical supports from the government are biased. They are willing to support only NGOs that have a lot of funds" (KII, 15).

Lastly, the government should create appropriate policies and regulations which meet the local needs. The policies should be disclosed to all people so that everyone can assess the government's performance. In Cambodia the process of policy development by the government is not widely and fully participated in by the constituency. Public access to development policies, regulations and information is usually restricted. In this regard, NGOs, researchers and members of the public find it difficult to access relevant documents. A research participant explaned that:

"Policy development is based on the message of Prime Minister. Access documents and information from the government has never been easy. If there is no people whom we are acquainted with, we canot have documents and information. To my experience I use personal relationship to get the documents and information [laugh]. Informal communication is important [laugh] an online database or portal through which such climate change documents can be accessed is vital" (KII, 17).

\section{6 Conclusion}

In conclusion, the project resulted in various viewpoints about the situation concerning climate change NGOs in Cambodia. I have discussed the key findings in order to highlight what NGOs have accomplished so far in climate change action when they work in partnership projects in Cambodia. The results, which include knowledge and skill improvement with available funding support and relevant policies, are foundational to Cambodian NGOs encouraging them to pursue their project operations in combating the effects of climate change, as well as awareness and education at local level. The solutions, identified in the framework of climate change project implementations, give NGOs opportunities to explore strategies which address climate change issues effectively and efficiently. Furthermore, this chapter has addressed the possible contributions of the government to the 
implementation of the NGO's projects in regard to capacity building, technical and financial support, and the development of policies.

Last but not least, the results of the study reveal and confirm the important role of Cambodian NGOs in climate change action and policy advocacy. Through partnership projects, NGOs have contributed significantly to climate change awareness and education in Cambodia. Most importantly, local people can gain adaptive capacity to cope with climate change impacts and improve their livelihood. The discussed results illustrate the Cambodian NGO's performance and ability to address climate change issue and engage other stakeholders. The following chapter will conclude the whole thesis by discussing whether the questions which were initially asked have been explored and answered with respect to what has been found in the field research. The chapter also demonstrates some contributions of the research finding to policy and regulation development in regard to Cambodian climate change actions. 


\section{Chapter Seven: Conclusions}

\section{1 Introduction}

In this thesis I have examined NGO accountability through working in partnerships in climate change projects in Cambodia. I have also explored how partnerships practised by Cambodian NGOs in climate change projects are important to produce NGO accountability. This chapter summarises the thesis and concludes with some comments that are a response to the research questions posed ath the beginning. It also concludes with the contributions to the literature, and the NGO's role in adapting to climate change. Last, but not least, the chapter finishes with suggested topics for further research.

\section{2 Summary of findings}

The objective of the study was to explore how the accountability of Cambodian NGOs impact on local communities in climate change partnership projects. A qualititative approach was employed in this study. The secondary data was collected from Cambodian NGOs, government institutions and other development agencies, both on-site and through websites. Semi-structured interviews were conducted to collect primary data from the voluntary participation of research participants. The participants were people who work in climate change projects in Cambodia. The study addressed the main question "how does accountability of Cambodian NGOs impact on local communities, pariticularly with regard to climate change projects"?

There were also some supplementary questions that the research sought to answer.

a). How is partnership between NGOs important to the success of climate change projects?

b). Why are most NGOs in Cambodia interested in climate change projects?

c). What forms of accountability are being put in place by NGOs?

d). How is the accountability of Cambodian NGOs important with regard to the local community impact?

e). Are there any particular challenges to working as partners in climate change projects?

According to the findings, the thesis addressed these questions respectively: 
How is partnership between NGOs important to the success of climate change projects?

Climate change awareness and education is new to Cambodian NGOs. To accomplish the project goals, to do with climate change, the NGOs have to form partnerships in order to enhance effectiveness and efficiency of the project implementations. In this regard, there are two actors: large and small NGOs playing key roles that are important to the success of climate change projects. The financially-large and capable NGOs provide support to the smaller ones in order to implement the projects. The project activities including capacity building, raising awareness, education and policy advocacy were supported by an established network of NGOs. Through these partnerships, NGOs can have mutual benefits and support in terms of financing, technicality and resource use.

\section{Why are most NGOs in Cambodia interested in climate change projects?}

According to the findings, there were some dynamics that make NGOs in Cambodia interested in climate change projects. First of all, climate change is a cross-sectoral issue that affects all sectors in development. So, as a development actor, NGOs need to address this issue in their development activities. At the same time, climate change impacts are seen to be getting worse and funding opportunities are high. Furthermore, the development of strategic planning in the Cambodian government has paid much attention to climate change and has incorporated this issue throughout all other sectors. More importantly, the CCCSP was developed to widely address the issue.

What forms of accountability are being put in place by NGOs? How is the accountability of Cambodian NGOs important with regard to the local community impact?

This question aimed to capture NGO accountability forms in climate change projects. In partnering conditions, large NGOs provide funds to the smaller ones in order to implement projects that address climate change issues. Moreover, they provide other forms of support including capacity building, raising awareness and policy advocacy to make sure that their partners have the capacity to carry out project activities with local stakeholders. On behalf of the donors, they show their accountability to their 
partners. Likewise, the fund-recipient NGOs, as mentioned above, engage other stakeholders, particularly local people, in their project activities by complying with guidelines and policies. They are taking into account the effective and efficient use of resources to produce project results. All of this is similar to Namja's distinctive categories of NGO accountability. NGOs are accountable to their patrons, who provide funds for designated purposes, to their clients, for whom they are working for and to themselves in providing services to society (Namja, 1996).

The study's findings showed that the downward accountability of NGOs in climate change projects in Cambodia is apparent. Funding has made available to local people when donors fund projects through NGO partnerships. This is contrary to what some other researchers found in the past. The processes of NGO accountability generally emphasise on upward and external accountability (Ebrahim, 2003a and Namja, 1996). This is due to donors and NGOs having their own priorities and objectives to be fulfilled (Edwards and Hulme, 1996). However, in Cambodian climate change projects, the objectives of funding NGOs and fund-recipient NGOs seem to be consistent with the local needs. Additionally, through the partnerships, development is grass roots-driven and community ownership is strong so NGOs appear to be able to produce a better impact for local communities.

\section{Are there any particular challenges to working as partners in climate change projects?}

This research found that there were some challenges being faced in the project implementation. The partnering NGOs usually suffered from a high staff turn-over. This leads to a shortage of capable staff needed to run the projects. Another important challenge was that funding is not stable. The funding from donors and large NGOs usually fluctuates and most climate change project grants were not long term. From this finding, I can conclude that funding is crucial to secure Cambodian NGOs operating in climate change because some NGOs, according to the interviews, stopped their climate change actions when there was no continuing external funding support. There were also other challenges with regard to time constraints in partner coordination and a larer workload in project implementation. This study suggests some solutions to address the challenges that climate change projects face, so that they can enhance the effectiveness and efficiency of the results. 
The main question of this research was: "how does the accountability of Cambodian NGOs impact on local communities, pariticularly with regard to climate change projects"?

Cambodian NGOs take a great deal of responsibility in addressing climate change issues and engaging relevant stakeholders to get involved in projects. The definition of NGO accountability, as mentioned in the previous chapter, encapsulates their social roles and performances that promote social responsibility in Cambodian climate change actions. In this regard, this thesis discusses that organisational policies, donor impositions and local participation are significant in improve NGO accountability in social change.

New aid modalities which call for greater local participation have encouraged development NGOs to work closely with the local people who are the end beneficiaries of foreign aid. By doing so, the NGOs are part of transnational organisation networks and partnerships that work in many developing countries to help vulnerable people. In Cambodia, NGOs undertake partnerships with other NGOs to implement climate change projects. NGOs that are large and financially capable provide funds and technical support to other NGOs that work closely with the local people. In the chain of NGO project funding, large donors provide funds to capable transnational organisations and then the latter disburse grants to local organisations that are working closely with the local communities. They support capacity building, budgeting and other forms of support. Through partnerships, it is believed that the required resources are able to reach the local level and therefore NGOs can enhance project results so that they are more effective and efficient. From this partnership perspective, this thesis concludes that the aid chain has been transformed and development funding is moved closer to the poor through NGO activities at a local level.

The study found that partnerships in climate change projects offer significant advantages. Development voices become much stronger and can influence the national policies of the government. This is demonstrated by the current changed roles of NGOs in policy advocacy. NGOs work in partnership to influence development policies and they are encouraged to consult local people in the development policymaking process. Concerning climate change, NGOs work 
together to bring concerns from the local level to the policy makers for them to consider. In addition, partnerships can help protect organisations from risks and threats.

Through partnerships in climate change projects, this study discovered that NGOs accomplish significant results. More importantly, the results reflect NGOs' roles and accountability in social change in Cambodia.

\section{Climate change knowledge and capacity promotion among NGOs}

The knowledge and capacity that NGOs have for climate change projects grow over the period of project implementation. The NGOs then become able to identify and access funding sources for project support. Furthermore, there can now be representation of Cambodian climate change NGOs in regional and international meetings and negotiations. Through continued training and information sharing, NGO staff can have more understanding about rights-based approaches in climate change projects. They have their own IEC materials for climate change awareness and are able to engage with the government and other stakeholders in order to work together to address the climate change issues.

\section{Adaptive capacity improved among local people}

As mentioned in the previous chapter, the adaptive capacity of the local people is improved through targeted projects. They receive training about technological techniques in the agricultural sector, particularly in farming and vegetable planting. Moreover, the local people have an improved financial capacity to cope with climate change risks by establishing community groups for saving money. However, this thesis argues that there are many parts of Cambodia where people are vulnerable to the impact of climate change. NGOs and other stakeholders, particularly the government, should develop concise joint action plans that will allow those in the affected areas to address the issue.

Even though NGO partnerships, with cooperation from other stakeholders in climate change actions, can pull together a lot of resources in order to enhance project results, most Cambodian NGOs need more capacity building. This study specifically found that during partnership project implementation, there were many challenges as 
mentioned in previous chapter. This thesis offers some solutions to address the challenges.

\section{Solutions}

This research has found some solutions to address challenges faced by Cambodian NGOs. Partnering NGOs need to pay more attention to improving the capacity of new staff. This thesis suggests that project budgets allocated to the staff capacity line should be increased and all staff should be fully motivated in capacity development. Also, NGOs need to develop fundraising strategies and not depend entirely on external funding support. Fundraising strategies include identifying and looking for domestic sources and using crowdfunding to secure the projects. Additionally, they could establish a common online database for documents and educational resources for learning about climate change. This idea was raised by most of the research participants. A portal of documents like the database would allow project staff, students and other individuals to learn more about climate change. This thesis concludes that an online portal could significantly contribute to climate change awareness.

There were also other challenges that needed to be addressed. The capacity of commune councils and local government officials needed to be strengthened in regard to climate change. They are key people and partners in project implementation at the ground level so partnering NGOs should provide more capacity building to them. Furthermore, NGOs need to support all advocacy initiatives and legal services to affected people.

While this study found that downward accountability was strenghtened by NGOs that working in climate change projects in Cambodia, this study will also suggest some recommendations. Local governments have to encourage NGO projects by getting involved in activities and policy making in order to respond to the local needs. From the findings this study argues that government partners play a vital role in improving NGO accountability in regard to producing impact for local communities. The government, which is the main actor in development programming and climate change actions, is also encouraged to use social standards in fulfilling the local needs in development objectives. 


\section{3 Contributions of this study and future research}

This study encourages, as mentioned in the objective of this study, key stakeholders to participate in the adaptation to climate change in Cambodia. This study partly contributes to the literature of NGO accountability and partnership in climate change projects. The study also paves the way for policy makers to initiate more complementary measures or regulations in order to cope with climate change in Cambodia. The measures or regulations should have precise guidelines illustrating clear coordination mechanisms of the government, NGOs and the private sector in climate change actions. This thesis concludes that social construction of NGOs in the pursit of social justice and development is factored in climate change actions. The transformed role of NGOs has become a catalyst in influencing policies for a more pro-poor orientation.

As noted in the literature, there is much research conducted into NGOs' role in climate change policy negotiations with regard to political lobbying and policy advocacy at both national and international levels. The research conducted by academics usually focused on how NGOs' roles are played in environmental governmental governance and climate change in both developed and developing countries. More importantly, the affected people are usually those are in poor nations who have a lack of adaptive capacity to climate change. Moreover, climate change impacts are situated at a local level, so government policy coordination and enforcement with regard to climate change actions should be scrutinised by academics at this level. Another key point is that climate fund coordinations between government and inter-agency at national and sector levels are necessary to improve development effectiveness and ensure that climate change project fundings are well spent. Thus academics should also consider undertaking for future research. Last but not least, the best practice of climate adaptation should also be widely studied in order for it to be model for the other parts of the world. 


\section{REFERENCES}

ADB (2011). Overview of Civil Society: Cambodia. ADB: Retrieved date August 27, 2013 www.adb.org/sites/default/files/csb-cam.pdf

Ahmed, S., \& Potter, D. M. (2006). NGOs in International Politics: Kumarian Press, Bloomfield.

Akintola, O. (2011). NGO Accountability and sustainable development in Nigeria. Journal of Modern Accounting and Auditing, 7(1), 67-75.

Alley, P. (2012). Environmental watchdog adds voice to concern over UN seat [2012 October Statement Report to the UN]. Phnom Penh: Global Witness London.

Antlöv, H., Ibrahim, R., \& van Tuijl, P. (2006). NGO governance and accountability in Indonesia: Challenges in a newly democratizing country. $N G O$ Accountability: Politics, Principles and Innovations, London, Earthscan, 147163.

Arts, B. (1998). The Political Influence of Global NGOs: CaseSstudies on the Climate and Biodiversity conventions. Jan van Arkel (International Books).

Baaz, M. E. (2005). The Paternalism of Partnership: A Postcolonial Reading of Identity in Development Aid. Zed Books, London.

Bakker, I. (2002). Fiscal Policy, Accountability and Voice. In J. Bendell (2006), The Example of Gender Responsive Budget Initiatives, United Nations Development Programme (UNDP), New York.

Banks, N., \& Hulme, D. (2012). The role of NGOs and civil society in development and poverty reduction. Brooks World Poverty Institute Working Paper, 171.

Bebbington, A., Hickey, S., \& Mitlin, D. (Eds.). (2008). Can NGOs Make a Difference? The Challenge of Development Alternatives. London: Zed books.

Bendell, J. (2006). Debating NGO accountability. United Nations, New York and Geneva.

Bernauer, T., \& Betzold, C. (2012). Civil society in global environmental governance. The Journal of Environment \& Development, 21(1), 62-66.

Betsill, M. M., \& Corell, E. (2001). NGO influence in international environmental negotiations: a framework for analysis. Global Environmental Politics, 1(4), 65-85.

Böhmelt, T. (2013a). A closer look at the information provision rationale: Civil society participation in states' delegations at the UNFCCC. The Review of International Organizations, 8(1), 55-80. 
Böhmelt, T. (2013b). Civil society lobbying and countries' climate change policies: a matching approach. Climate Policy, 13(6), 698-717.

Böhmelt, T., Koubi, V., \& Bernauer, T. (2014). Civil society participation in global governance: Insights from climate politics. European Journal of Political Research, 53(1), 18-36.

Brett, E. A. (2003). Participation and accountability in development management. The Journal of Development Studies, 40(2), 1-29.

Bryman, A. (2008). Social Research Methods. Oxford and New York: Oxford University Press.

Burger, R., \& Seabe, D. (2014). NGO Accountability in Africa. In E. Obadare (ed.), The Handbook of Civil Society in Africa, Nonprofit and Civil Society Studies, (pp. 77-91). Springer Science and Business Media, New York, 2014.

Chacko, E. (2004). Positionality and praxis: Fieldwork experiences in rural India. Singapore Journal of Tropical Geography, 25(1), 51-63.

Chambers, R., \& Pettit, J. (2004). Shifting power to make a difference In Groves, L., \& Hinton, R. (Eds.). (2013). Inclusive aid: Changing power and relationships in international development. Routledge.

Chum, S. (2010). NGO Coordination and the changing aid environment in Cambodia: Challenges and opportunities (Master Thesis, Victoria University of Wellington, Wellington, New Zealand). Retrieved from http://researcharchive.vuw.ac.nz/handle/10063/1150

Clark, A. M., Friedman, E. J., \& Hochstetler, K. (1998). The sovereign limits of global civil society: A comparison of NGO participation in UN world conferences on the environment, human rights, and women. World Politics, 51(01), 1-35.

Clark, J. (1992). Policy influence, lobbying and advocacy In Hulme, D. (2013). Making a Difference: NGO's and Development in a Changing World. Routledge.

Collier, P., \& Dollar, D. (2001). Can the world cut poverty in half? How policy reform and effective aid can meet international development goals. World Development, 29(11), 1787-1802.

The Committee for Free and Fair Election in Cambodia. (2014). Democracy, Elections and Reform in Cambodia. 2013 Annual Report, Phnom Penh, Cambodia 
Council of Development for Cambodia. (2014). The Cambodia NGO Database.

Retrieved Date June 28, 2014

http://cdc.khmer.biz/ngo/report/listing_by_sector.asp\#none

Creswell, J.W. (2003). Research design: Qualitative, quantitative and mixed methods approaches $\left(2^{\text {nd }} e d\right.$.). London: Sage Publications.

Creswell, J.W. (2013). Research design: Qualitative, quantitative, and mixed methods approaches $\left(4^{\text {th }}\right.$ ed.).London: Sage Publications.

Davison, J. (2007). Photographs and accountability: Cracking the codes of an NGO. Accounting, Auditing \& Accountability Journal, 20(1), 133-158.

DeMars, W., E. (2005). NGOs and Transnational Networks: Wild Cards in World Politics. London: Pluto Press.

Denscombe, M. (2010). The good research guide: For small-scale social research projects: For small-scale social research projects: McGraw-Hill International.

Denzin, N. K., \& Lincoln, Y. S. (2003). Strategies of qualitative inquiry (Vol. 2), London: Sage Publications.

Denzin, N. K., and Lincoln, Y. S (Eds). (2005). The Sage handbook of qualitative research.Thousand Oaks, London \& New Delhi: Sage Publication.

Derman, B., B. (2014). Climate governance, justice, and transnational civil society, Climate Policy, 14: 1, 23-41, DOI: 10.1080/14693062.2014.849492

Dolan, C. (1992). British development NGOs and advocacy in the 1990s. In Groves, L., \& Hinton, R. (Eds.). (2013). Inclusive aid: Changing power and relationships in international development. Routledge.

Dolšak, N. (2009). Climate change policy implementation: A cross-sectional analysis. Review of Policy Research, 26(5), 551-570.

Dolšak, N. (2013). Climate change policies in the transitional Economies of Europe and Eurasia: The role of NGOs. VOLUNTAS: International Journal of Voluntary and Nonprofit Organizations, 24(2), 382-402.

Dombrowski, K. (2010). Filling the gap? An analysis of non-governmental organizations responses to participation and representation deficits in global climate governance. International Environmental Agreements: Politics, Law and Economics, 10(4), 397-416.

Ebrahim, A. (2003a). Accountability in practice: Mechanisms for NGOs. World development, 31(5), 813-829. 
Ebrahim, A. (2003b). Making sense of accountability: Conceptual perspectives for northern and southern nonprofits. Nonprofit Management and Leadership, 14(2), 191-212.

Ebrahim, A. (2005). Accountability myopia: Losing sight of organizational learning. Nonprofit and voluntary sector quarterly, 34(1), 56-87.

Edwards, M., \& Hulme, D. (1996). Too close for comfort? The impact of official aid on nongovernmental organizations. World Development, 24(6), 961-973.

Enrich Institute for Sustainable Development (2013). Climate Change Financing in Cambodia, Phnom Penh, Cambodia.

Fforde, A., \& Seidel, K. (2010). Donor Playground Cambodia? What a look at Aid and Development in Cambodia confirms and what it may imply. Berlin: Heinrich-Böll-Stiftung.

Fitzgerald, G. (2006). Computer-based qualitative data methods. in Becker, H.A., Vanclay, F. (Eds). (2006). The international handbook of social impact assessment: Conceptual and methodological advances. UK and USA: Edward Elgar.

Fowler, A. F. (1998). Authentic NGDO partnerships in the new policy agenda for international aid: dead end or light ahead. Development and Change, 29(1), 137-159.

Fowler, A. (2000). Introduction beyond partnership: Getting real about NGO relationships in the aid system. IDS Bulletin, 31(3), 1-13.

Frewer, T. (2013). Doing NGO Work: The politics of being 'civil society'and promoting 'good governance' in Cambodia. Australian Geographer, 44(1), 97-114.

Godfrey, M., Sophal, C., Kato, T., Vou Piseth, L., Dorina, P., Saravy, T., ... \& Sovannarith, S. (2002). Technical assistance and capacity development in an aid-dependent economy: The experience of Cambodia. World Development, 30(3), 355-373.

Golub, S. (2006). NGO Accountability and The Philippine Council for NGO Certification: Evolving Roles and Issues. Jordan, Lisa et Tuijl (van), Peter (eds.), NGO Accountability: Politics, Principles and Innovations, Earthscan, London.

Grant, R. W., \& Keohane, R. O. (2005). Accountability and abuses of power in world politics. American Political Science Review 99.01 (2005): 29- 43.

Greenhill, R., Prizzon, A., \& Rogerson, A. (2013). The age of choice: Developing countries in the new aid landscape. Synthesis Report. London: Overseas Development Institute. 
Gulbrandsen, L. H., \& Andresen, S. (2004). NGO influence in the implementation of the Kyoto Protocol: Compliance, flexibility mechanisms, and sinks. Global Environmental Politics, 4(4), 54-75.

HAP International. (2010). The 2010 HAP standards in accountability and quality management, HAP International, London.

Hjerpe, M., \& Linnér, B. O. (2010). Functions of COP side-events in climate-change governance. Climate Policy, 10(2), 167-180.

Hodson, R. (1992). Small, medium or large? The Rocky Road to NGO Growth. 1992). Making a Difference. NGOs and Development in A Changing World. London: Earthscan Publications.

Hoksbergen, R. (2005). Building civil society through partnership: Lessons from a case study of the Christian Reformed World Relief Committee.

Development in Practice, 15(1), 16-27.

Hyndman, N. (1991). Contributors to charities - a comparison of their information needs and the perceptions of such by the providers of information. Financial Accountability \& Management, 7(2), 69-82.

Jancar-Webster, B. (Ed.). (1993). Environmental action in Eastern Europe: Responses to crisis. ME Sharpe. New York.

Jegers, M., \& Lapsley, I. (2001). Making sense of non-profit organisations. Financial Accountability \& Management, 17(1), 1-3.

Jepson, P. (2005). Governance and accountability of environmental NGOs. Environmental Science \& Policy, 8(5), 515-524.

Johnson, H., \& Wilson, G. (2006). North-South/South-North partnerships: Closing the 'mutuality gap'. Public Administration and Development, 26(1), 71-80.

Jordan, L. (2005). Mechanisms for NGO accountability. GPPi Research Paper Series(3).

Jordan, L., \& Van Tuijl, P. (2000). Political responsibility in transnational NGO advocacy. World Development, 28(12), 2051-2065.

Johnson, E., \& Prakash, A. (2007). NGO research program: A collective action perspective. Policy Sciences, 40(3), 221-240.

Kamat, S. (2003). NGOs and the new democracy: The false saviors of international development. Harvard International Review, 25(1), 65-69.

Keck, M. E., \& Sikkink, K. (1998). Activists beyond borders: Advocacy Networks in International Politics (Vol. 35). Ithaca, NY: Cornell University Press.

Kilby, P. (2006). Accountability for empowerment: Dilemmas facing nongovernmental organizations. World Development, 34(6), 951-963. 
Lewis, D. (1998). Development NGOs and the challenge of partnership: Changing relations between North and South. Social Policy \& Administration, 32(5), 501-512.

Lister, S. (1999). Power in partnership: An analysis of an NGO's relationships with its partners. London School of Economics and Political Science, LSE Library.

Lister, S. (2003). NGO legitimacy technical issue or social construct? Critique of Anthropology, 23(2), 175-192.

Lloyd, R. (2005). The role of NGO self-regulation in increasing stakeholder accountability. One World Trust, 1-15.

Louis, K. S., \& Barton, A. C. (2002, September). Tales from the science education crypt: A critical reflection of positionality, subjectivity, and reflexivity in research. In Forum Qualitative Sozialforschung/Forum: Qualitative Social Research (Vol. 3, No. 3).

Mango. (2010). Accountability to beneficiaries checklist. How accountable is your organisation to its beneficiaries? Retreived date August 24, 2014 http://researcharchive.vuw.ac.nz/handle/10063/1150

Mansfield, C., \& MacLeod, K. (2002). Advocacy in Cambodia: Increasing democratic space. Pact Cambodia, Phnom Penh, Cambodia.

Martens, K. (2005). NGOs and the United Nations: Institutionalization, professionalization, and adaptation. New York, Palgrave Macmillan.

Mawdsley, E., Townsend, J. G., \& Porter, G. (2005). Trust, accountability, and faceto-face interaction in North-South NGO relations. Development in Practice, 15(1), 77-82.

Maxwell, J. A. (2012). Qualitative research design: An interactive approach: An interactive approach (Vol. 41). Sage: London.

Mayhew, S. H. (2005). Hegemony, politics and ideology: The role of legislation in NGO-government relations in Asia. Journal of Development Studies, 41(5), 727-758.

Minear, L., \& Smith, H. (2007). Humanitarian diplomacy: Practitioners and their craft: United Nations University Press: Tokyo.

Mulgan, R. (2003). Holding power to account: Accountability in modern democracies. Palgrave Macmillan: Basingstoke.

Murtaza, N. (2012). Putting the last first: The case for community-focused and peermanaged NGO accountability mechanisms. VOLUNTAS: International Journal of Voluntary and Nonprofit Organizations, 23(1), 109-125. 
Najam, A. (1996). NGO accountability: A conceptual framework. Development Policy Review, 14(4), 339-354.

Nath, P., K. \& Behera, B. (2011). A critical review of impact of and adaptation to climate change in developed and developing economies, 13: 141-162.

Neuman, W. L. (2006). Social research methods: Qualitative and quantitative approaches. Boston, MA: Pearson.

Newell, P. (2006). Climate for change: Non-state actors and the global politics of the greenhouse. Cambridge University Press.

Ngin, C. (2004). Strengthening NGO Accountability through Beneficiary

Participation: Lessons Learned from Two Cambodian NGOs. Retreived date August 20, 2014http://ir.nul.nagoya-u.ac.jp/jspui/handle/2237/6263

O'Reilly, K. (2009). Key Concepts in Ethnography. Sage Publication: London.

Overton, J., \& Storey, D. (2004). Aid and partnerships: The effectiveness of relationships. Development Bulletin, 65(41-45).

Parks, T. (2008). The rise and fall of donor funding for advocacy NGOs:

Understanding the impact. Development in Practice, 18(2), 213-222.

Pease, K. K. S. (2012). International organizations. Longman: London.

Peterson, M. (1996). Global warming and global politics. London: Routledge.

Postma, W. (1994). NGO partnership and institutional development: Making it real, making it intentional. Canadian Journal of African Studies/La Revue canadienne des études africaines, 28(3), 447-471.

Rauh, K. (2010). NGOs, foreign donors, and organizational processes: Passive NGO recipients or strategic actors. McGill Sociological Review, 1(1), 29-45.

Raustiala, K. (1997). States, NGOs, and international environmental institutions. International Studies Quarterly, 41(4), 719-740.

Schedler, A. (1999). Conceptualizing accountability In Schedler, A., \& Plattner, M. F. (Eds.). (1999). The self-restraining state: power and accountability in new democracies. Lynne Rienner Publishers.

Schepers, D. H. (2006). The impact of NGO network conflict on the corporate social responsibility strategies of multinational corporations. Business \& Society, 45(3), 282-299.

Shigetomi, S. (Ed.). (2002). The State \& NGOs: Perspective from Asia (No. 25). Singapore: Institute of Southeast Asian Studies.

Sida (2013). Final report: Evaluation of the Joint Climate Change Initiative (JCCI) in Cambodia. Phnom Penh, Cambodia. 
Skinner, J. (2012). The Interview: An Ethnographic Approach. London: Berg.

Songco, D. A. (2007). The evolution of NGO accountability practices and their implications on Philippine NGOs. A literature review and options paper for the Philippine Council of NGO Certification. Retrieved date August 20, 2014 http://www.icnl.org/research/library/files/Philippines/philacc.pdf

Star, C. (2012). A tale of two movements? Environmental non-government organisations and community action on climate change. Social Alternatives, 31(1), 10-15.

Steffek, J., \& Nanz, P. (2008). Emergent patterns of civil society participation in global and European governance. Civil society participation in European and global governance: A cure for the democratic deficit. Retrieved date August 20, 2014 http://www.palgrave.com/resources/samplechapters/9780230006393_sample.pdf

Sultana, F. (2007). Reflexivity, positionality and participatory ethics: Negotiating fieldwork dilemmas in international research. ACME: An International EJournal for Critical Geographies, 6(3), 374-385.

Szporluk, M. (2009). A framework for understanding accountability of international NGOs and global good governance. Indiana Journal of Global Legal Studies, 16(1), 339-361.

Thorbecke, E., \& Tarp, F. (2000). The evolution of the development doctrine and the role of foreign aid, 1950-2000 In Tarp, F. (Ed.). (2003). Foreign aid and development: lessons learnt and directions for the future. Routledge.

Unerman, J., \& O'Dwyer, B. (2006a). On James Bond and the importance of NGO accountability. Accounting, Auditing \& Accountability Journal, 19(3), 305318.

Unerman, J., \& O'Dwyer, B. (2006b). Theorising accountability for NGO advocacy. Accounting, Auditing \& Accountability Journal, 19(3), 349-376.

Walker, S., Read, S., \& Priest, H. (2013). Use of reflexivity in a mixed-methods study. Nurse Researcher, 20(3), 38-43.

Wallace, T., Bornstein, L., \& Chapman, J. (2007). The aid chain: Coercion and commitment in development NGOs. Wageningen: Practical Action Pub.

Walsh, E., \& Lenihan, H. (2006). Accountability and effectiveness of NGOs: Adapting business tools successfully. Development in Practice, 16(5), 412424.

Wapner, P. (1995). Politics beyond the state environmental activism and world civic politics. World Politics, 47(03), 311-340. 
Weidner, H., Jänicke, M., \& Jörgens, H. (Eds.). (2002). Capacity building in national environmental policy: A comparative study of 17 countries. Berlin, Germany: Springer Science \& Business Media.

Weiss, E. B. (2010). On being accountable in a kaleidoscopic world. Paper presented at the Proceedings of the 104th Annual Meeting 2010. American Society of International Law. Retrieved date August 28, 2014

http://www.jstor.org/discover/10.5305/procannmeetasil.104.0477

Weiss, T. G., \& Gordenker, L. (1996). NGOs, the UN, and global governance. Boulder: Lynne Rienner

Wenar, L. (2006). Accountability in international development aid. Ethics \& International Affairs, 20(1), 1-23.

Wright, G. W. (2012). NGOs and Western hegemony: Causes for concern and ideas for change. Development in Practice, 22(1), 123-134.

Yukiko, Y. (2000). Partnership for whom? Cambodian NGOs' supporting schemes. IDS Bulletin, 31(3), 35-47.

Zhou, X., \& Mori, H. (2011). National institutional response to climate change and stakeholder participation: a comparative study for Asia. International Environmental Agreements: Politics, Law and Economics, 11(4), 297-319. 


\section{APPENDICES: Ethics Forms}

\section{APPENDIX I}

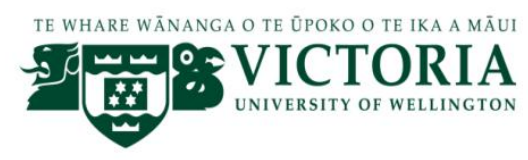

\section{Information Sheet for Key Participants}

\section{Research Title: "The Accountability of Cambodian NGOs in Climate Change Projects: The Impacts on Local Communities"}

Researcher: Sothiary Toch, School of Geography, Environment and Earth Science, Victoria University of Wellington.

My name is Sothiary Toch and I am a Master of Development Studies student at Victoria University of Wellington, New Zealand. As part of my degree I am writing a thesis on the accountability of NGOs in climate change projects and the impacts on local communities.

This study intends to address how NGO partnership works in development practice, particularly in climate change programmes/projects. Therefore, the main objective is in exploring how accountability between INGOs and Cambodian LNGOs having impacts on local communities in these projects. The study also examines some changing policies regard with Cambodian climate change sector and challenges in working as partnership between INGOs and Cambodian LNGOs in climate change programmes/projects.

I am conducting this research through semi-structured interviews by interviewing a number of possible key informants from both international and Cambodian NGOs that are working on climate change programmes/projects.

I would like to invite you to participate in an interview in which you will be able to share your experiences of how NGOs are accountable as partners in climate change programmes/projects with regard to impacts on local communities. The interview is about 45 to 60 minutes long and the place is in your office or anywhere you would favour.

The discussion we have will be structured around questions I have prepared in relation to this topic.

I have been given approval by the ethics committee of Victoria University of Wellington (www.victoria.ac.nz). Therefore, there are several things you need to be aware of before you consent to participate in this research. 
- With your permission I will record the interview. Written notes and electronically recorded material made during the interview will be safely stored and only be seen by my supervisor and myself,

- You can choose whether to have Khmer or English conversation,

- All interview materials will be destroyed upon completion of the thesis,

- It is your decision as to whether you and your organisation will be identified or will remain confidential in the published thesis,

- As a participant you are not required to answer all questions,

- If you agree to take part in the interview, you are free to withdraw at any time without having to give a reason,

- You are free to withdraw any information you have provided before the research is completed on 01 August 2014,

- Following the interview you will have the opportunity to review the information you have provided prior to it being used in the published thesis.

Upon completion of my thesis, a copy will be lodged in the Victoria University Library and a summary of findings will be made available to you if this is of interest. The research may also be published in academic or professional journals.

I hope you will agree to participate in this research and I look forward to speaking with you soon.

Sothiary Toch

Phone: +64-22-302-9535 (NZ)

sothiary@gmail.com
John Overton (Supervisor)

Professor of Development Studies

Victoria University of Wellington

Phone: +64-4-463-5281

john.overton@vuw.ac.nz 


\section{APPENDIX II}

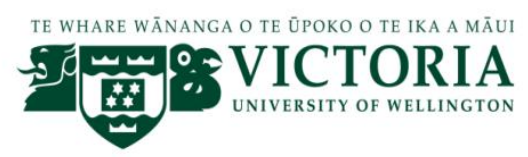

Consent To Participate In Research

\section{Research Title: "The Accountability of Cambodian NGOs in Climate Change Projects: The Impacts on Local Communities}

Researcher: Sothiary Toch, School of Geography, Environment and Earth Science, Victoria University of Wellington.

I have read the participant inforamtion sheet and understand the purpose of the research project.

I understand the interview will be electronically recorded and any notes or recorded material from intervews will be destroyed when the research is completed.

I understand that all information I provided will be safely stored and only accessed by the researcher and supervisor.

I understand I may withdraw myself from this research project without explanation at any time before 01 August 2014.

I understand I will have opportunity to receive a summary of the interview.

I understand the results of this research will be included in a thesis and may be used for publication academic or professional journals.

I agree to take part in this research.

Please tick as appropriate:

I consent to my name being used when my comments or opinions are used in this study. Or

I request that my name be omitted and a pseudonym assigned by the researcher if the comments and opinions are included in the research.

I consent to the name of the organisation I work for being used in this study. Or

I request the name of the organisation I work for being omitted from the study.

Signed:

Name of participant:

Organisation:

(Please print clearly)

Date:............/2014 


\section{APPENDIX III}

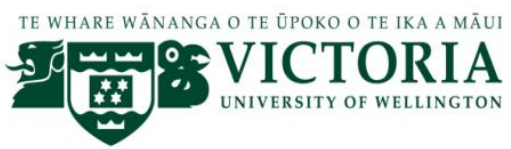

\section{List of Interview Questions for NGO Informants}

1. Could you tell me a little bit about your roles in your organisation?

2. What is the mission of your organisation? And what strategies does your organisation use to achieve the mission?

- How do you think about the impacts your organsiation has achieved so far as working in Cambodia?

- And why it is important?

3. What does NGO accountability mean to you?

- To whom is your organisation accountable for? And why is NGO accountability important in development work?

- Why is the impacts of local communities associated with NGO accountability in development programmes/projects?

4. What do you think about working in partnership with othe NGOs in development programmes/projects?

- Why is the partnership important?

- What conditions in the status of NGO partnership that enumerate the project success?

5. What do you think about climate change issues in Cambodia?

- What kind of climate change programmes/projects is your organisation working for? And which partner organisation is your organisation working with? 
- Why is your organisation working as partnership with other NGOs in climate change programmes/projects?

- How long has your organisation worked on climate change programmes/projects in Cambodia?

- Why is your organisation interested in climate change projects? Are there any policy changes in this sector?

- What/how do you think your organisation will support the national strategies and policies in reducing climate change impacts in Cambodia?

6. What results has your organisation achieved in working with partner NGOs in climate change projects? Could you tell me in any particular programmes or projects your organisation has undertaken?

7. What challenges do you think usually come up and disrupt the process of working in partnership with partner NGOs in climate change projects?

8. What measures, options and principles could be adopted to hold NGO partnership more accountable in climate change projects to the advantages of local communities?

9. What roles do you think the government should play in the aspects of NGO partnership in climate change projects?

10. Is there anything else you would like to say? 


\section{APPENDIX IV}

\section{Ethics application approval}

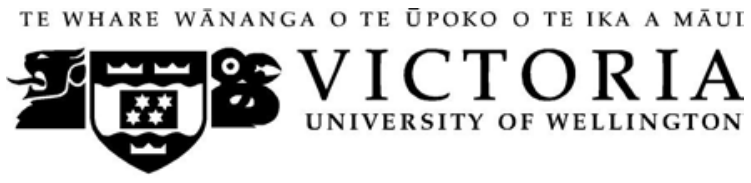

MEMORANDUM

Phone 0-4-463 5676

Fax 0-4-4635209

Email

Allison.kirkman@vuw.a

c.nz

\begin{tabular}{l|l}
\hline TO & Sothiary Toch \\
\hline COPY TO & John Overton \\
\hline FROM & Dr Allison Kirkman, Convener, Human Ethics Committee \\
\hline
\end{tabular}

\begin{tabular}{l|l}
\hline DATE & 28 April 2014 \\
\hline PAGES & 1 \\
\hline
\end{tabular}

\begin{tabular}{l|l} 
SUBJECT & $\begin{array}{l}\text { Ethics Approval: } 20898 \\
\text { The Accountability of Non Government Organisations (NGOs) in } \\
\text { Climate Change Projects in Cambodia: The Impacts on Local } \\
\text { Communities }\end{array}$ \\
\hline
\end{tabular}

Thank you for your application for ethical approval, which has now been considered by the Standing Committee of the Human Ethics Committee.

Your application has been approved from the above date and this approval continues until 1 March 2015. If your data collection is not completed by this date you should apply to the Human Ethics Committee for an extension to this approval.

Best wishes with the research.

Allison Kirkman

Human Ethics Committee

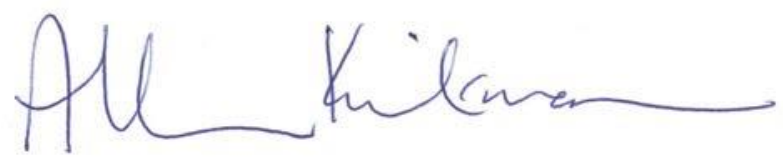

